\title{
POWER SOURCE BUFFERING USING A TRIANGULAR MODULAR MULTILEVEL CONVERTER WITH ENERGY STORAGE
}

\author{
by \\ Alvaro Daniel Cardoza \\ Bachelor of Science in Electrical Engineering, University of Pittsburgh, 2012
}

\author{
Submitted to the Graduate Faculty of \\ Swanson School of Engineering in partial fulfillment \\ of the requirements for the degree of \\ Master of Science
}

University of Pittsburgh 


\section{UNIVERSITY OF PITTSBURGH}

SWANSON SCHOOL OF ENGINEERING

This thesis was presented

by

Alvaro Daniel Cardoza

It was defended on

July 7, 2016

and approved by

Dr. Alexis Kwasinski, PhD, Associate Professor

Department of Electrical and Computer Engineering

Dr. Gregory F. Reed, PhD, Professor

Department of Electrical and Computer Engineering

Dr. Zhi-Hong Mao, PhD, Associate Professor

Department of Electrical and Computer Engineering

Dr. Thomas McDermott, PhD, Associate Professor

Department of Electrical and Computer Engineering

Thesis Co-Advisor: Dr. Alexis Kwasinski, PhD, Associate Professor

Thesis Co-Advisor: Dr. Gregory F. Reed, PhD, Professor

Department of Electrical and Computer Engineering 
Copyright (C) by Alvaro Daniel Cardoza

2016 


\title{
POWER SOURCE BUFFERING USING A TRIANGULAR MODULAR MULTILEVEL CONVERTER WITH ENERGY STORAGE
}

\author{
Alvaro Daniel Cardoza, M.S. \\ University of Pittsburgh, 2016
}

As power systems throughout the world continue to utilize DC infrastructure within distributed generation solutions and microgrid designs, an effective DC-DC interfacing power electronic device must be developed for managing power flow and power quality levels between a system's increasingly diversified array of sources and loads. DC-DC power electronic interfaces are continuing to gain increased attention throughout many distribution applications, including the information and communication technology (ICT), electric vehicle, and renewable generation industries.

The research effort described herein explores the use of a multi-port DC-DC modular multilevel converter interfacing a dual-input connection of a $380 \mathrm{~V}_{\text {DC }}$ system and a $42.9 \mathrm{VDC} / 40.7$ A photovoltaic panel with a $96 \mathrm{~V}_{\mathrm{DC}}$ output resistive load. Ultracapacitors are used to power-buffer the input signal and in this application, the inherently intermittent solar panel output. This technology represents the merits of utilizing a singular interfacing device to consolidate the flows between joint generation and load, while maintaining stable output power using a modular energy storage solution.

This work details the operation and control of the DC-DC converter and its moduleinterfaced power buffering solution, as well as provide design methodologies for the system described. 
TABLE OF CONTENTS

ACKNOWLEDGEMENTS .............................................................................................

1.0 INTRODUCTION - A CHANGING POWER LANDSCAPE ..................................... 1

2.0 BACKGROUND - THE MODERN POWER DISTRIBUTION NETWORK,

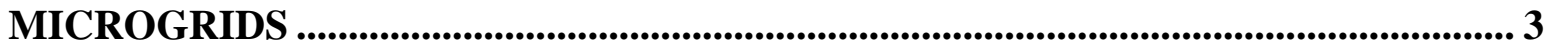

3.0 THE IMPORTANCE OF POWER ELECTRONIC INTERFACES.............................. 5

3.1 MICROGRID APPLICATIONS OF POWER ELECTRONICS.............. 6

TYPE OF INTERFACING CONVERTERS ................................................. 8

3.2.1 Multiple Input, Single Output Converters ........................................................ 8

3.2.2 Single Input, Multiple Output Converters ........................................................ 11

3.2.3 Multiple Input, Multiple Output Converters ................................................. 12

4.0 MOTIVATION - A DC-DC CONVERTER WITH INTEGRATED ENERGY

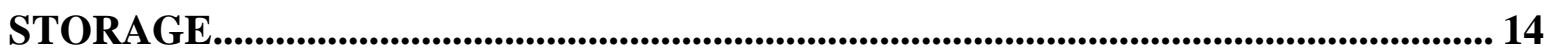

5.0 THE TRIANGULAR MODULAR MULTILEVEL CONVERTER............................... 16

TOPOLOGY OVERVIEW ........................................................................ 16

$5.2 \quad$ APPLICATION OF ENERGY STORAGE .................................................. 18

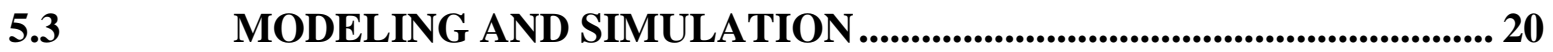

5.3.1 Module Controller Design .................................................................................. 24

5.4 ANALYTICAL MODEL VERIFICATION OF SIMULATION............... 34

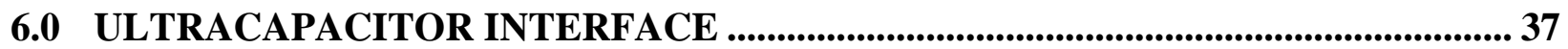


6.2.1 Choosing an Ultracapacitor ................................................................ 42

6.2.2 Choosing a Type-C Chopper Inductor .......................................................... 44

ENERGY STORAGE SYSTEM CONTROL .................................... 45

6.3.1 State Machine Type-C Chopper Control................................................. 46

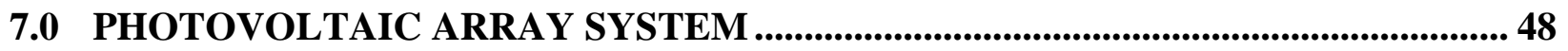

PHOTOVOLTAIC ARRAY DESIGN

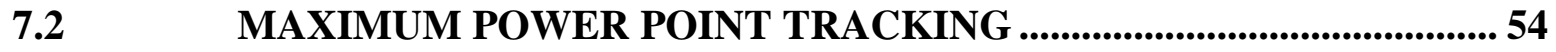

7.2.1 Direct Methods .............................................................................. 54

7.2.1.1 Perturb and Observe ........................................................................ 54

7.2.1.2 Incremental Conductance ............................................................... 55

7.2.1.3 Ripple Correlation Control .................................................................... 57

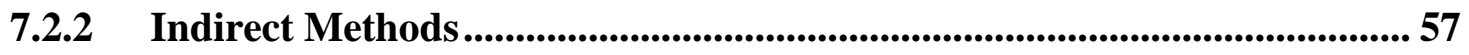

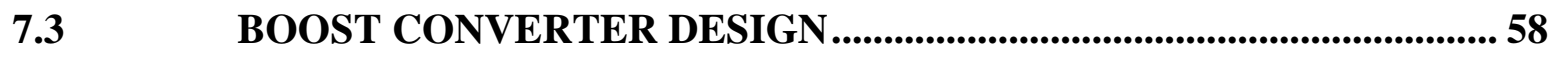

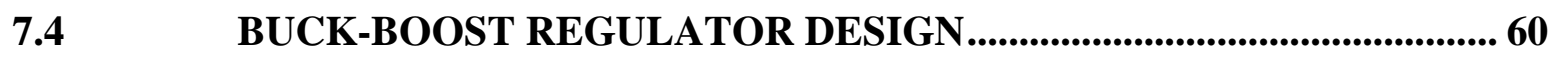

INTEGRATION OF PV ARRAY SYSTEM TO TMMC ........................ 65

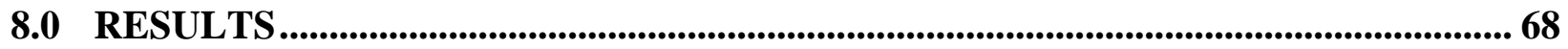

8.1 TEST ONE RESULTS - PV AND LOAD STEP UP............................ 70

8.2 TEST TWO RESULTS - PV AND LOAD STEP DOWN........................ 75

8.3 TEST THREE RESULTS - PV STEP UP AND DOWN ...................... 80

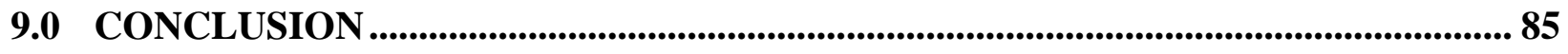

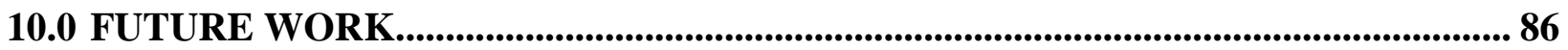




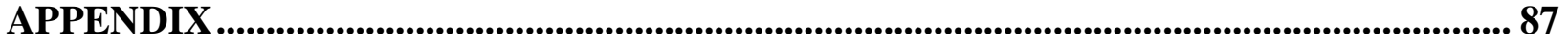

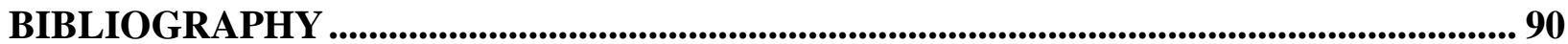




\section{LIST OF TABLES}

Table 1. Charge and Discharge Characteristics of Batteries and Ultracapacitors [33]................ 19

Table 2. Two-Row TMMC Parameters (Step-Up/Step-Down) ............................................ 21

Table 3. Two-Row Step-Up TMMC Design Parameters and Simulation Results ...................... 22

Table 4. Two-Row Step-Down TMMC Design Parameters and Simulation Results................... 23

Table 5. Three-Row Step-Down TMMC Design Parameters and Simulation Results................ 34

Table 6. Two-Row Step-Down TMMC Analytical Verification of Simulation Results .............. 36

Table 7. Energy Comparison of Three Different Ultracapacitor Models ................................. 43

Table 8. PV Array Parameter Specifications ................................................................ 51

Table 9. Boost Converter Parameters …............................................................................ 59

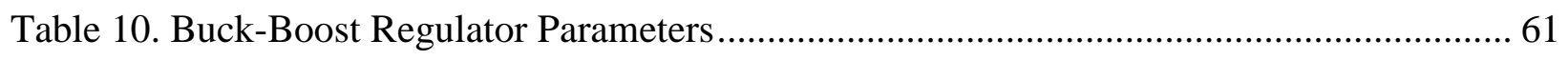

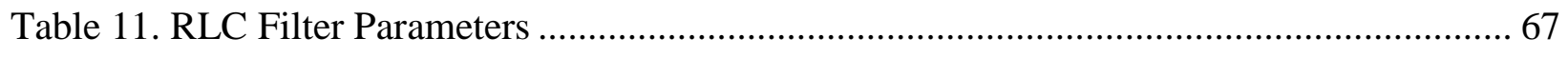

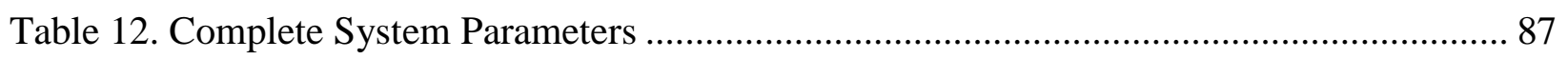




\section{LIST OF FIGURES}

Figure 1. U.S. Energy Information Administration's Projection of World Energy Consumption Growth (Historical Data Up to 2013) ..................................................................... 1

Figure 2. CERTS Microgrid Interfacing Converter Example Incorporating Energy Storage (Surge

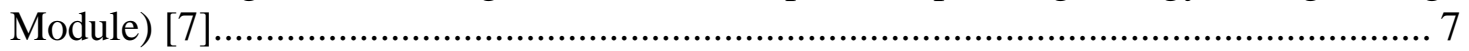

Figure 3. Example Time-Multiplexing MISO Converter [11]............................................... 9

Figure 4. Examples of Non-isolated SIMO Converters with Independent Outputs (left) and Series

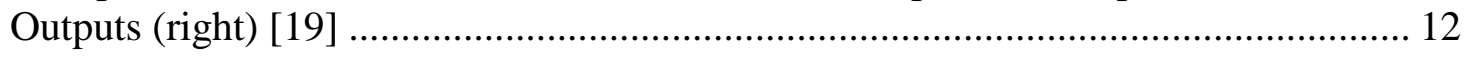

Figure 5. Active Power Distribution Node Example of MIMO Converters[24] ....................... 13

Figure 6. General TMMC Module Row Configuration Pattern ............................................. 17

Figure 7. Two-Row Step-Up TMMC with Output Voltage and Row Voltages ......................... 22

Figure 8. Two-Row Step-Down TMMC with Output Voltage and Row Voltages ..................... 23

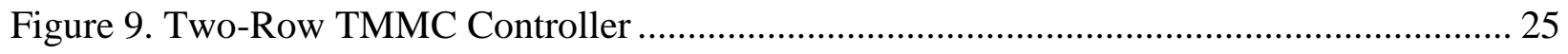

Figure 10. Hysteresis Current Control Logic................................................................... 26

Figure 11. TMMC Closed Loop Control Diagram ............................................................. 27

Figure 12. Two-Row TMMC with PI and Hysteresis Control - Capacitor Row Voltages and Output

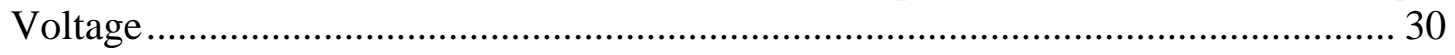

Figure 13. Three-Row Step-Down TMMC with Blown-Up Individual Buck-Boost Module ..... 31

Figure 14. Simplorer Model of TMMC Module Sub-Circuit ................................................. 32

Figure 15. Three-Row TMMC with Hysteresis Controller Module Voltages and Output Voltage 33 
Figure 16. Simplorer Capacitor Voltage Results of Two-Row TMMC

Figure 17. Analytical Results of Two-Row TMMC Showing Capacitor Voltages for Rows One and Two 36

Figure 18. First and Second Quadrant operation of the Type-C Chopper with Depicted Switching

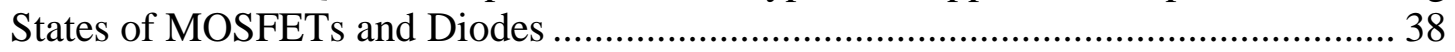

Figure 19. Type-C Chopper Bidirectional DC-DC Converter connected to Ultracapacitor........ 38

Figure 20. Buck or Charging Mode Operation of the Type-C Chopper Red line: Switch $\mathrm{S}_{\mathrm{b}}$ closed; Blue line: Switch $S_{b}$ open 40

Figure 21. Boost or Discharging Mode Operation of the Type-C Chopper Red line: Switch $\mathrm{S}_{\mathrm{a}}$ open; Blue line: Switch $S_{a}$ closed 41

Figure 22. Type-C Chopper State Machine Control Loop (left); Voltage Threshold Transition Requirements 46

Figure 23. Single Diode PV Array Model . 49

Figure 24. Calculation of PV Array Current Source Value using Temperature, Irradiance, and

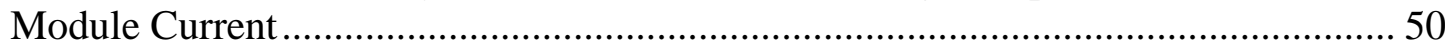

Figure 25. Varied Output Resistive Impedance for Creating IV and PV Curves ....................... 52

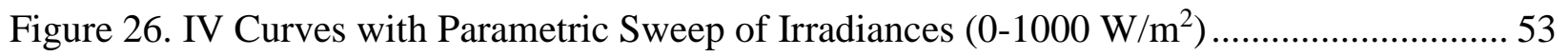

Figure 27. PV Curves with Parametric Sweep of Irradiances $\left(0-1000 \mathrm{~W} / \mathrm{m}^{2}\right)$....................... 53

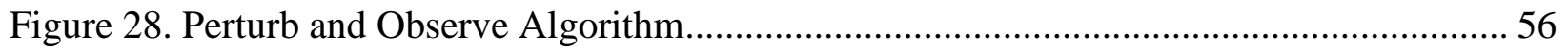

Figure 29. Incremental Conductance Algorithm ........................................................... 56

Figure 30. P\&O Algorithm Function used in Simplorer .................................................... 58

Figure 31. Boost Converter connected to PV Array .......................................................... 58

Figure 32. PV Array and Boost Converter Output Voltage .................................................... 59

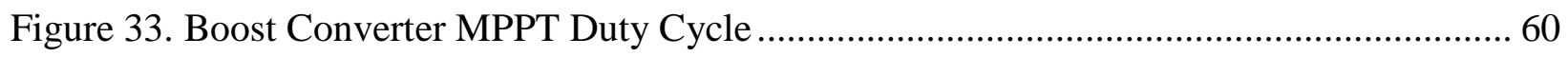

Figure 34. Plot of Irradiance and Maximum Power Points based on PV Curve ........................ 62 
Figure 35. Simplorer PV Array System Includes PV Array, Boost Converter (w/ MPPT), and Buck-Boost Regulator. 63

Figure 36. Demonstration of Stability for PV Array System From Top to Bottom: PV Array Voltage, MPPT Duty Cycle, Regulator Output Power, and Regulator Output Voltage 64

Figure 37. Full PV System with Interconnection Switches and LC filter for Integration into TMMC 65

Figure 38. PV Interconnection Switches and LC Filter............................................................... 67

Figure 39. Test One - TMMC Capacitor Voltages - No ESS …………………………............... 71

Figure 40. Test One - TMMC Capacitor Voltages - with ESS ………………………............... 71

Figure 41. Test One - TMMC Output Voltage and Power, Grid Current, PV Output Power - ... 72

Figure 42. Test One - TMMC Output Voltage and Power, Grid Current, PV Output Power - With

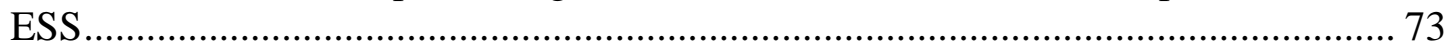

Figure 43. Test One - ESS Row Ultracapacitor Current Injection................................................ 74

Figure 44. Test Two - TMMC Capacitor Voltages - No ESS ........................................................ 76

Figure 45. Test Two - TMMC Capacitor Voltages - With ESS.................................................... 76

Figure 46. Test Two - TMMC Output Voltage and Power, Grid Current, PV Output Power -... 77

Figure 47. Test Two - TMMC Output Voltage and Power, Grid Current, PV Output Power - With ESS. 78

Figure 48. Test Two - ESS Row Ultracapacitor Current Injection .............................................. 79

Figure 49. Test Three - TMMC Capacitor Voltages - No ESS ..................................................... 80

Figure 50. Test Three - TMMC Capacitor Voltages - With ESS..................................................... 81

Figure 51. Test Three - TMMC Output Voltage and Power, Grid Current, PV Output Power - No

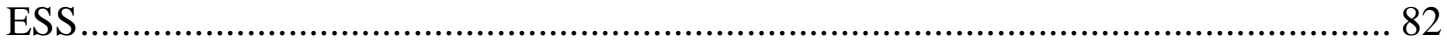

Figure 52. Test Three - TMMC Output Voltage and Power, Grid Current, PV Output Power - With

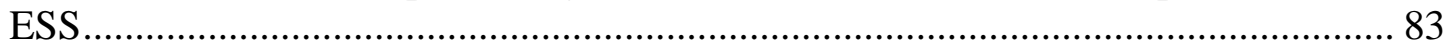

Figure 53. Test Three - ESS Row Ultracapacitor Current Injection ............................................. 84 
Figure 54. Left Side of Model. Includes PV System, PV Filter, TMMC Controller, and Grid

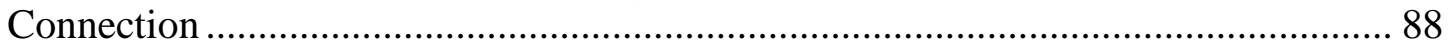

Figure 55. Right Side of Model. Includes TMMC, Ultracapacitor ESS, and ESS Controllers .... 89 


\section{ACKNOWLEDGEMENTS}

I would like to thank my family and countless friends for helping me persevere through the academic journey that has brought me here to defend my master's thesis in electrical engineering. My parents have provided countless hours of support throughout the entirety of my time here at Pitt and helped ignite the flame of an engineering mindset from an early age. My father, having a master's in systems engineering, constantly demonstrated the merits of hard work and effort throughout his career while maintaining an air of humility and promoting lifelong learning. My mother, who served as a stay-at-home mother for most of my childhood, helped to foster my sense of creativity with constant exposure to social and academic activities. Additionally, I would like to thank my amazing girlfriend, Melissa Nuñez, for assisting me through numerous bumps in the road during the past couple years as well as helping to boost me up to new heights in life.

Despite certain bumps in the road concerning health challenges, my family, friends and those in the graduate research group have been there for me and were willing to spend the necessary time with me to help overcome and conquer these obstacles. My time here as part of the electric power research group has provided me with the guidance and support to shape myself as a power engineer, solidifying my resolution to continue onward honing my skills.

My initial advisor, Dr. Gregory Reed, has been a large inspirational figure for me in this program as he was the individual who originally encouraged me to explore the field of power. Having experienced many of the different sectors of power throughout his professional career, he 
is well-versed and connected within the power community. Moreover, his connections have allowed for a unique graduate student experience allowing for us power engineering graduate students to meet Presidents and Vice Presidents within industry. His advocacy of maintaining a balanced lifestyle between engineering and outside life has been a great help to ensuring my success in this program. This is certainly an irreplaceable opportunity placed before me and am very appreciative.

A few years into my program, I was granted the opportunity to transition into being advised by Dr. Alexis Kwasinski. Coming from a position at the University of Texas - Austin, Dr. Kwasinski had well established himself within the academic and IEEE communities as an expert in several realms including power electronics, renewable energy, and resilient grids/microgrids. Leading up to this transition, I had been on a couple different projects that were more power systems focused, but I found myself drifting more towards the power electronics spectrum and this transition was a no brainer. There was a healthy learning curve, but we continued to grow our relationship as advisor and graduate student, and I have become all the stronger of a researcher in the process.

I would also like to thank professors Dr. Zhi-Hong Mao and Dr. Thomas McDermott for providing their guidance both inside and outside of the classroom during my master's work. Their wealth of knowledge in the fields of controls and power systems/transients, respectively, has been a great help for strengthening my foundations in power engineering.

I would be remiss not to mention the wonderful staff and students of the Pitt Excel family. They are a big reason why I am in graduate school to begin with and continue to inspire and motivate me to strive for greatness in my everyday life. A big thank you and hug to Ms. Alaine Allen, Mr. Simeon Saunders, and Ms. Yvette Moore. 
Last, but not least, I would like to thank all of the students in my graduate research group: Dr. Brandon Grainger, Patrick Lewis, Ansel Barchowsky, Hashim Al-Hassan, Dr. Matthew Korytowski, Rusty Scioscia, Dr. Emmanuel Taylor, Dr. Raghav Khanna, Andrew Reiman, Chris Scioscia, Andrew Bulman, and several other students who have been a part of the larger group. We have a unique and diverse group of students working together that helps to promote an unmatched level of critical and creative thought. I have learned a great deal from each of the students in this group and have appreciated the mentorship from the senior students who have since graduated. 


\subsection{INTRODUCTION - A CHANGING POWER LANDSCAPE}

As power systems throughout the world continue to utilize more distributed generation solutions and microgrid systems, an effective interfacing power electronic device must be developed for managing power flow and power quality levels throughout the system and the loads. Global demand for electricity increases annually and is expected to reach over 20 TWy by the end of the decade [1].

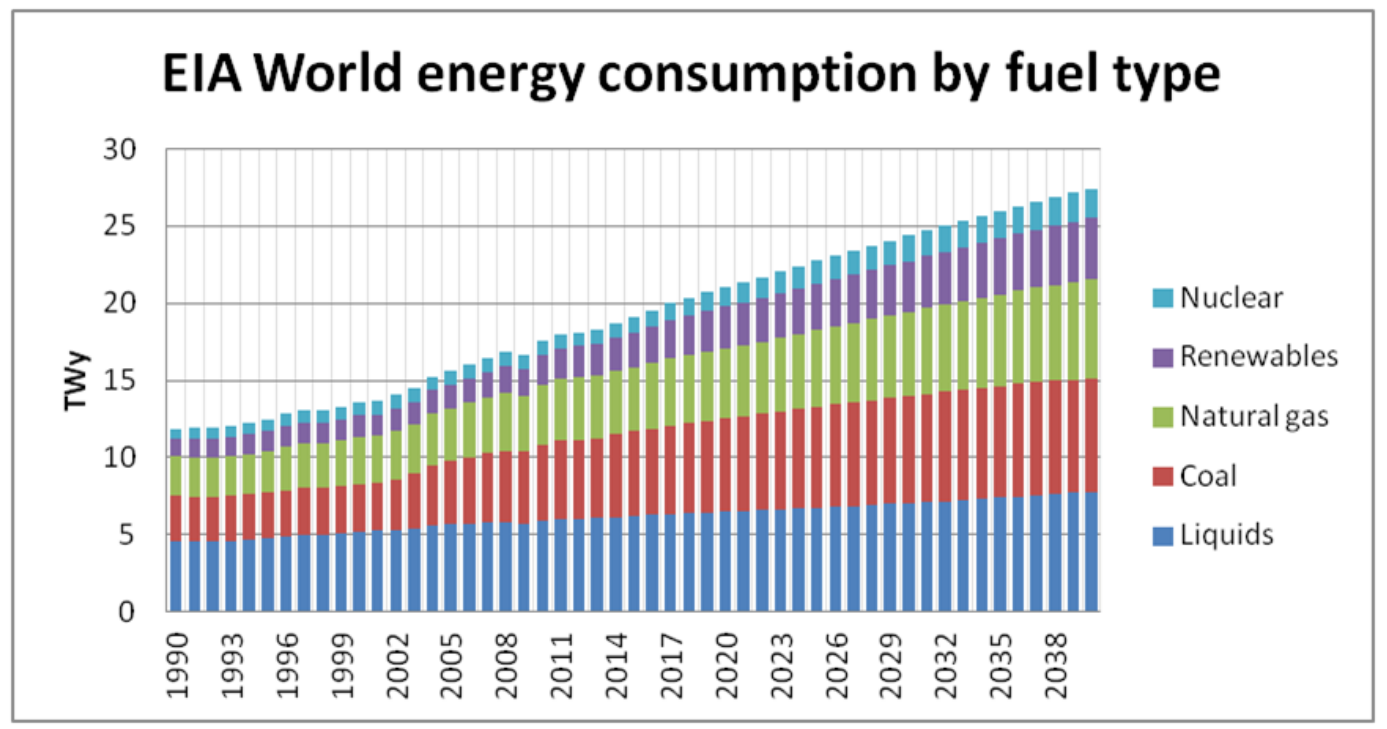

Figure 1. U.S. Energy Information Administration's Projection of World Energy Consumption Growth (Historical Data Up to 2013)

The generation profile is diversifying to meet this growing demand as older power plants are being retired and renewable sources, such as wind and solar, are installed to fill the gap, as well as more efficient conventional plants, such as combined heat and power plants. Conventional 
plants often serve loads by being few in number, spread out over large distances, and by having large generation capacities; renewable sources, on the other hand, are best utilized when placed in distributed networks throughout the load center and are typically many in number and dispersed strategically throughout the area with each unit being relatively small in generation capacity. An emphasis on improving distribution networks has become popular with research and functional examples of microgrids have been established in several regions of the developed world. 


\subsection{BACKGROUND - THE MODERN POWER DISTRIBUTION NETWORK, MICROGRIDS}

Microgrids are localized electric power systems that operate independent of the greater power grid during faulted or emergency events. Local renewable energy, energy storage, as well as more traditional forms of generation are commonly introduced via distributed generation into microgrids, which helps ensure a sustainable, islanded mode of operation. AC microgrids directly connected to a greater utility grid via a point of coupling (POC) are the most commonly

implemented and studied form of microgrid structure; however, DC microgrids have recently gained more attention in the research world as DC generation, storage, and loads have become more prevalent throughout society. A DC system also benefits from a direct connection to energy storage devices such as batteries, ultracapacitors, and flywheels, which allow for active power smoothing and greater resilience to faulted conditions. By no longer operating a grid in AC, control strategies greatly simplify and methods for synchronizing with the AC grid are no longer necessary. Moreover, the lack of both frequency and reactive power components would enhance the system's power quality and power density. DC systems can also easily be developed with parallel branches increasing resiliency through redundant and modular-stacked systems [2]. Additional benefits include: higher levels of efficiency due to fewer conversion steps throughout the system, and a built-in fault-ride-through capability during blackouts and/or voltage sags due to stored energy in DC capacitors and available converter voltage controls [3]. However, there are 
inherent drawbacks to the system being all DC: the large capital costs associated with the installation of new DC distribution lines, undeveloped DC protection measures -- there are no zerocrossings in a DC signal and therefore AC protection is not applicable --, and lastly, loads must be adapted to DC power supplies in order to ensure high efficiency [3]. A third type of microgrid concept exists that hybridizes the functionality of both AC and DC systems to accommodate both the existing AC infrastructure and the growing interest in DC systems. This hybrid microgrid helps to reduce multiple reverse conversions, for instance converting from AC to DC and back to AC, and helps to optimize the connection of various AC and DC renewable sources to AC and DC loads throughout the grid [4]. The operation and control of the hybrid model is significantly more complicated [5], and therefore is not be discussed any further in this thesis. Moving forward, the bulk of the remaining discussion focuses on DC systems, including power electronics, renewable generation, and energy storage - all within the context of integrating distributed forms of generation into an environment such as a microgrid. 


\subsection{THE IMPORTANCE OF POWER ELECTRONIC INTERFACES}

With the increased use of wind and solar generation in recent years, several methods of mitigating their inherent intermittency issues have been developed with power electronic devices being at the forefront of these solutions. Power electronic devices can enable generation-side and grid-side signal decoupling and reduction of total harmonic distortion and voltage flicker injected into the grid. Different combinations of inputs and outputs are necessary in order to adequately serve different types of loads, which call for a specific type of converter. For instance, in a distributed generation network, a home might be powered by a combination of grid-power, solar, wind, and energy storage; while in a hybrid electric vehicle, the vehicle could be powered by a combustion engine, an electric motor, and a battery system. These systems call for a specific family of converters containing multiple ports to coordinate the different generation and load pathways, some of which are unidirectional, while others, like for batteries, are often bidirectional [6]. These converters can adjust sources of different voltage and coordinate their functions to work together in a single system environment. Multi-port converters are classified into three main groups: MultiInput, Single-Output (MISO); Single-Input, Multi-Output (SIMO); and Multi-Input, Multi-Output (MIMO). 


\subsection{MICROGRID APPLICATIONS OF POWER ELECTRONICS}

The CERTS microgrid [7] is a good example of an AC system that can demonstrate the effectiveness of interfacing converter functionality. While some of the DC-DC system merits are lost with the addition of conversion to an AC system, there are still strong, published works demonstrating the proper management of inputs. The CERTS microgrid, according to [7], requires that all of its input sources maintain a plug-and-play functionality with a unified dynamic performance across all inputs regardless of generation type. Each of the sources connect to the grid via an interfacing converter, which adjusts the dynamics of each input. Since no two generators behave identically -- for instance, a photovoltaic (PV) array does not inherently operate like a gas turbine -- it is recommended that energy storage be added to the power electronic interface to help regulate and unify the load-following performance of all input sources at their POC with the microgrid. The addition of energy storage is especially important for converters interfaced with

multiple inputs that respond to power changes according to time constants that are orders of magnitude different. During these time lapses, the energy storage injects instantaneous power until the source is able to adequately accommodate for the load step. This injection of power also helps to ease the strain placed on the source during large load steps. The energy storage module shown in the example is shown in Figure 2 and is represented by the Surge Module block [7]. 


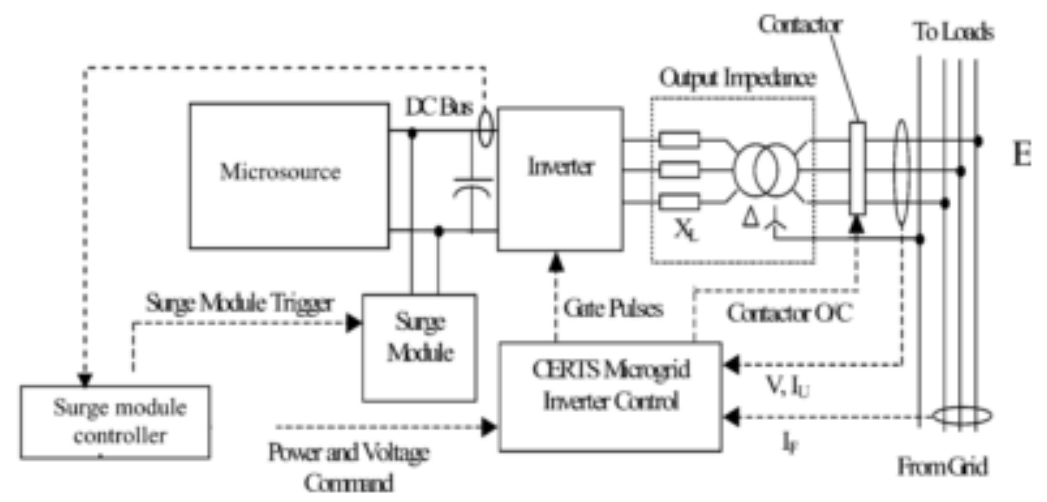

Figure 2. CERTS Microgrid Interfacing Converter Example Incorporating Energy Storage (Surge Module) [7]

While power electronic interfaces are quite effective at minimizing components by connecting together multiple inputs and outputs in one design, this increased complexity could also be a source of power system instability. These interfaces can propagate any unaccounted instabilities such as voltage flicker from intermittent renewable sources or sudden load changes, which can negatively affect all connected systems. Since microgrid-based power electronics devices are tightly regulating several sources of varying voltage and consistently feeding a load with steady power levels, a point of load converter can be viewed as a constant power load (CPL). CPLs function with a negative incremental input impedance that can cause large voltage oscillations or voltage collapse in other system components upstream such as line regulating converters. These issues can be resolved by either altering component sizes -- increasing system capacitances or resistive loads, or by reducing system inductances, which are both typically deemed impractical -- or by implementing properly-tuned boundary and/or linear control schemes [8]. 


\subsection{TYPE OF INTERFACING CONVERTERS}

While multi-port converters can be created by connecting multiple single-input, single-output (SISO) converters together via a shared bus, they often result in an overly complex structure with a high associated cost, and suffer from control and stability issues. SISO converters often consist

of known topologies such as the buck, boost, buck-boost, SEPIC, Cuk, H-bridge, flyback, and forward converters. Due to the aforementioned issues with SISOs, single-stage multi-port systems (MISO, SIMO, and MIMO) are the preferred interfacing topologies.

\subsubsection{Multiple Input, Single Output Converters}

MISO converters, with an example shown in Figure 3, have received a great deal of research attention over the past two decades regarding their applications for microgrids and renewable generation integration. As an interface to microgrids, and grids in general, MISOs can help to reduce cost and simplify the integration of multiple input sources in lieu of using several separate SISO converters. Instead, a single MISO can gather each source in parallel and funnel it into a single output -- the desired grid point or end load -- without negatively affecting the system's availability. Furthermore, MISOs could help to achieve greater levels of system availability since the converters can allow for a fuel-diverse collection of parallel input sources, which has been shown to benefit system availability [9]. Since energy storage and most renewable sources have DC outputs, these inherently DC converters would help streamline these sources' integration into the microgrid. Methods of expanding basic SISO topologies into MISOs are discussed in [10]. 


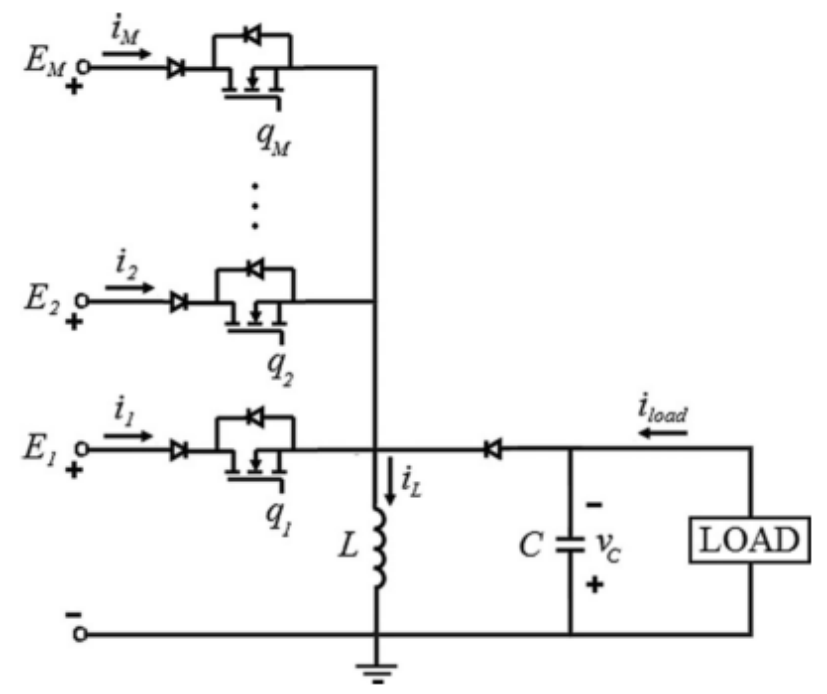

Figure 3. Example Time-Multiplexing MISO Converter [11]

Early MISO converters were constructed by stacking multiple SISO converters with their output capacitors connected in series and both converters sharing a lone output. Such an example was built by the University of Rome in 1996 with two inputs and a shared output [12]. This design, while novel for its time, struggles to regulate its output voltage effectively whenever one of the two input sources falls out of operation, which is due to large input voltage variation [13]. Several of the newer multiple-input converters rely on a time-multiplexing strategy for their source switch operation. These converters contain an active switch in series with the input sources that only allows one source to transfer energy to the load at any one time. These active switches utilize forward-conducting-bidirectional-blocking (FCBB) topologies comprised of a MOSFET in series with a diode, which tend to increase power losses in a time-multiplexing-based MISO [14]. All switching operations share one fixed time period; therefore, as the number of input legs increases, it becomes increasingly more difficult to generate and control switching signals to accurately represent each fraction of the period [11]. Concerning modeling and simulation, inputs of MISO 
converters are systemically coupled through their topologies and their switching function control operations. For instance, a state variable from one input leg is dependent upon the state variables from the other input legs and their respective switching functions. This coupling of states can bring about moderate averaged-model simulation error as the number of input legs increases [15]. An alternative method of simulating time-multiplexing-based MISO converters is proposed in [15] using a multi-frequency approach derived from system-switched dynamic equations. A different MISO topology was proposed back in 2004 designed to overcome some of the switching and regulation issues related to the previous two designs. The topology was designed with input sources of an AC grid and a PV array -- ideally with both of these sources delivering constant power to the load. The design incorporates a 3-winding coupled transformer, additional full bridge DC-AC converters with reverse blocking diodes, and coupled inductors to reduce ripple on the input sources. Operation of this device allows energy sources to deliver power either individually or simultaneously, eliminating issues associated with voltage regulation from a faulty input or switching complexity associated with time-multiplexing MISOs. Instead of combining inputs electrically and sending them directly to the output, the converter combines input source magnetic flux terms and induces the magnetic core to provide a cleaner output. There are numerous benefits to this design including very high efficiency and reduced total harmonic distortion, however, these benefits come at the cost of using a large amount of components to assemble the design [13]. Inductors and/or transformers are typically the largest off-chip components and require additional integrated circuitry, ultimately increasing the cost. An updated summary of the latter two methods of synthesizing MISO operation can be found in [16]. 


\subsubsection{Single Input, Multiple Output Converters}

SIMO converters are useful for applications requiring multiple regulated supply voltages. Many of these applications are relevant for small-scale devices such as microprocessors and wireless transceivers [17]; however, some different grid-based applications are also being explored [18], [19]. These converters are grouped into two categories: isolated and non-isolated designs. Isolated topologies either utilize a transformer or coupled inductor with multiple secondary windings to interface the input and outputs. One method of operating this design actively regulates only the output port with the heaviest load, while the remainder of the ports rely on the turn ratios of the secondary windings to maintain regulation. Although this method simplifies basic controls, it complicates the ability to independently control each output without incurring large current ripple and peak inductor current levels with the system under heavy loading. Methods have been explored to overcome this limitation by modifying the operating continuous conduction mode (CCM) slightly into what is described as a pseudo CCM [17]. Non-isolated configurations come in two variations: independent output and series output. Independent output topologies have outputs sharing the same ground (Figure 4) and can help reduce cross regulation issues with both CCM and discontinuous conduction modes (DCM) from the previous design by implementing a digital control structure. This methodology uses control variables of common and differential modes as decoupling algorithms and is easily extended to an arbitrary number of outputs [20]. The one downside of implementing such a solution comes with the increased sophistication of implementing a nonlinear controller. 

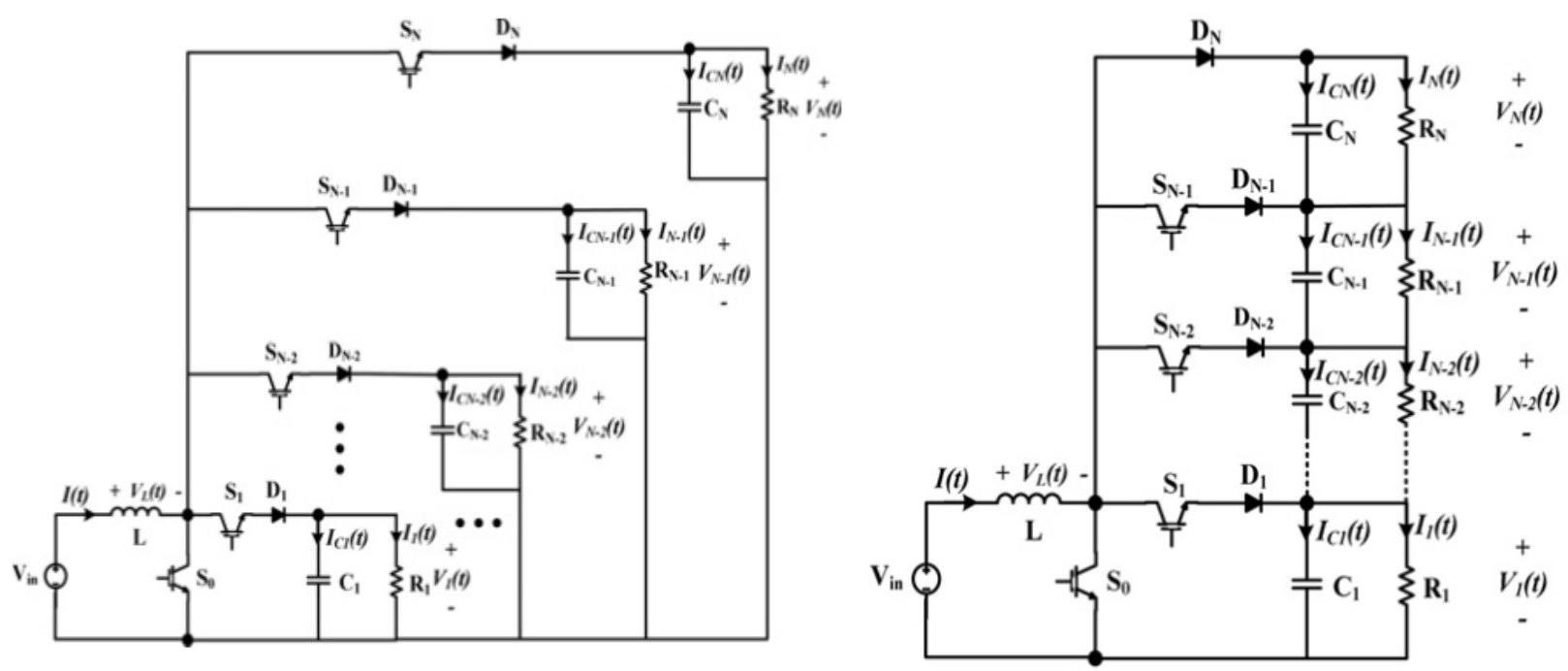

Figure 4. Examples of Non-isolated SIMO Converters with Independent Outputs (left) and Series Outputs (right) [19]

On the other hand, series output configurations stack their outputs on top of each other in series with a path to ground as shown in Figure 4. This proposed topology could serve as an interfacing DC link between renewable sources and a microgrid when cascaded into a multi-level inverter [19]. This combination of systems allows for a lower harmonic distortion and lower switching frequency, which leads to lower losses as well. An ancillary applied benefit of this design is seen by placing this series output SIMO converter at the DC link terminal of a DiodeClamped inverter. This combination provides a solution for balancing DC link voltages and correcting potential capacitor voltage imbalance, which creates a simpler control scheme for implementation [19].

\subsubsection{Multiple Input, Multiple Output Converters}

The last general family of interfacing topologies to discuss is the MIMO converter. A MIMO converter should be able to take advantage of the benefits of both MISO and SIMO converters, 
producing a more efficient and cost effective solution for interfacing microgrids with their generation and loads. A few studies exist that demonstrate both low and high power applications [21] of the converter. In [22], a 0.1 W MIMO energy harvesting device is proposed offering maximum power point tracking (MPPT), multi-load regulation, and power management through the use of energy storage systems. This designed converter operates in DCM, which is beneficial in limiting the inductor current, but also limits any high power operation of the system. For a higher power example, [23], [24] discuss MIMOs that are designed with energy storage at their core and rebranded as active power distribution nodes (APDN). These nodes operate as a power buffer by utilizing a dynamic operation of energy storage to correct any power mismatch that may occur between connected sources and loads. Inspired by the need for a reconfigurable and modular MIMO device to interface an increasingly more complex generation and load landscape, the focus of this thesis work centers around a specific MIMO known as the Triangular Modular Multilevel Converter (TMMC) [25]. This architecture is expanded from its original design by directly implementing energy storage into its modular structure.

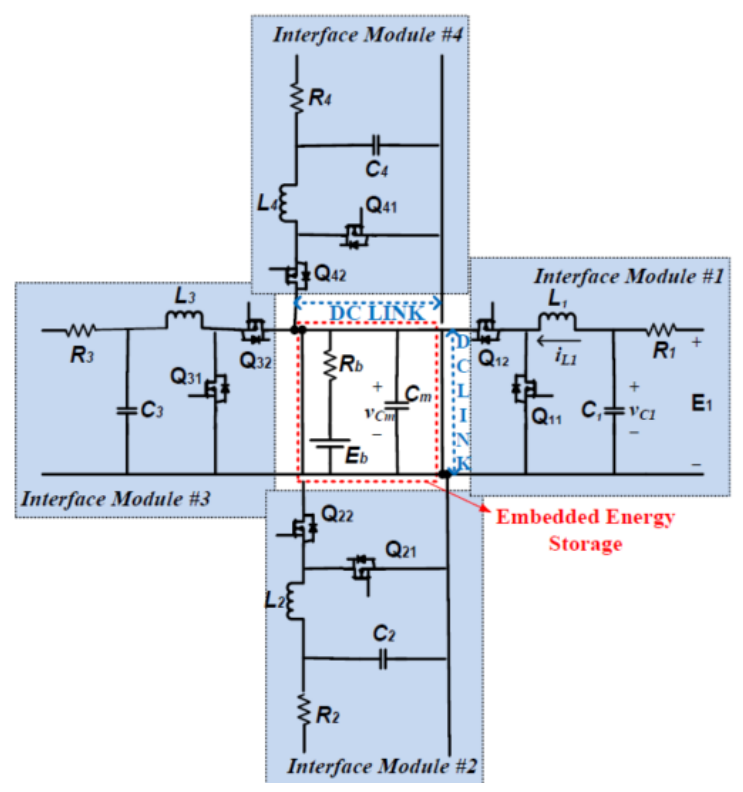

Figure 5. Active Power Distribution Node Example of MIMO Converters[24] 


\subsection{MOTIVATION - A DC-DC CONVERTER WITH INTEGRATED ENERGY STORAGE}

As power systems throughout the world may continue to utilize DC infrastructure within distributed generation solutions and microgrid designs, an effective DC-DC interfacing power electronic device must be developed for managing power flow and power quality levels between a system's increasingly diversified array of sources and loads [7]. DC-DC power electronic interfaces are continuing to gain increased attention throughout many distribution applications, including the information and communication technology (ICT) [26], electric vehicle [27], and renewable generation [28] industries.

The research effort described herein explores the use of a multi-port DC-DC converter interfacing a dual-input connection of a $380 \mathrm{~V}_{\mathrm{DC}}$ idealized "grid" and a $42.9 \mathrm{~V}_{\mathrm{DC}} / 40.7 \mathrm{~A}$ photovoltaic panel with a $96 \mathrm{~V}_{\mathrm{DC}}$ output resistive load (which can be divided in half to tap into the commonly used $48 \mathrm{~V}$ ). Ultracapacitors, $83 \mathrm{~F}$, are used to power-buffer the input signal and in this

application, the inherently intermittent solar panel output. This technology represents the merits of utilizing a singular interfacing device to consolidate the flows between joint generation and load, while maintaining stable output power using a modular energy storage solution.

The multi-port topology used in this work is called a triangular modular multilevel converter (TMMC), which utilizes stacked capacitor voltages from buck-boost derived modules in order to effectively step-up or step-down the voltage depending upon the direction of current 
flow [25]. Input and output ports can be placed between any of the modules to meet source and/or load system requirements. This variant of the modular multilevel (MMC) family of converter topologies benefits from having a natural power sharing capability across modules for single-input, single-output applications due to its triangular structure.

With the addition of a robust control system (a PI voltage controller fed into a current hysteresis controller, for each module) and an ultracapacitor-based power buffering solution, this power-sharing attribute can be maintained for multiple inputs and/or outputs. Applications that incorporate energy storage within MMC topologies for high power applications have already been explored [29], [30] in order to help meet a growing need for load leveling and power buffering. Within the proposed circuit design, power buffering is achieved by attaching an array of ultracapacitors to each of the TMMC's modules via an interfacing dual-quadrant Type-C Chopper circuit. With the intermittency of renewable generation sources like solar, it would be preferred to utilize an energy storage solution that provides quick discharges of power while subsequently recharging quickly. Ultracapacitors are a good fit for such an application with a high power density profile to meet dips in power output, quick charge and discharge cycling, and a long lifespan. 


\subsection{THE TRIANGULAR MODULAR MULTILEVEL CONVERTER}

\subsection{TOPOLOGY OVERVIEW}

Proposed out of the University of Toronto in [25], the TMMC utilizes stacked capacitor voltages from buck-boost converter derived modules with a unity designed conversion ratio in order to effectively step-up or step-down the voltage depending upon the direction of current flow. Voltage taps can be made on any of the modules' input or output terminals, allowing for the possibility of creating multiple inputs and outputs based on source or load requirements of a system. This is very desirable for interfaces between building loads and the grid for instance, which may require multiple voltage level taps as well as multiple sources such as the grid and perhaps some local rooftop PV generation for example. With its modular structure and bidirectional functionality, the TMMC can be modified to operate as a reconfigurable APDN and can be modified to act as a SISO, MISO, SIMO, or MIMO converter. Modules are stacked in a triangular fashion with the top most row containing a single module and subsequent rows beneath it containing a module directly underneath and one to the right. This pattern continues as shown in Figure 6. Furthermore, its modular design can be expanded for a wide range of conversion ratios with power sharing achieved across all modules and localized module-based control for increased dynamic performance. This power sharing capability indicates that each module handles roughly the same amount of voltage across its capacitor and similarly, roughly the same amount of current flowing through its inductor. 
With respect to the shared ground on the low voltage side of the converter, the triangular configuration of the converter has its lowest row of modules processing the highest amount of current and the lowest amount of voltage. Working upwards through the rows towards the top most row’s singular module, each row collectively processes less current and more voltage (with respect to ground) the higher you climb up the architecture, further demonstrating the TMMC's power sharing capability.

It is worth pointing out however that since the TMMC is a transformer-less DC-DC converter design, it is not suitable for applications requiring isolation. Additionally, while the topology is inherently capable of handling both multiple inputs and multiple outputs, the control design would need to be overhauled beyond the basic SISO design for optimal performance. This thesis research effort focuses just on the simplified controller design, which is suitable for the dynamics introduced evenly across modules with the energy storage and a robustly designed PV secondary source design. Further description of this topology is discussed in the Modeling and Simulation section.

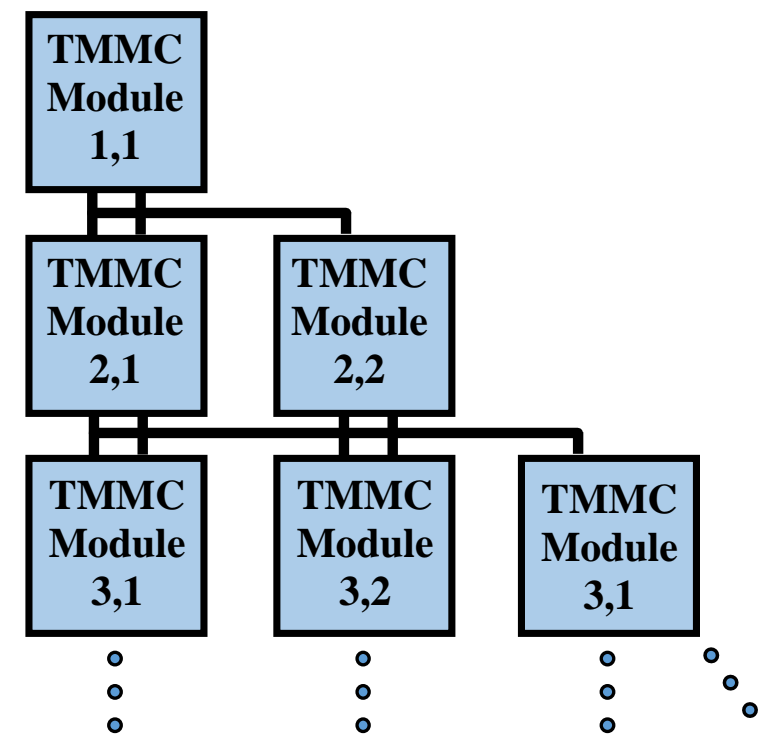

Figure 6. General TMMC Module Row Configuration Pattern 


\subsection{APPLICATION OF ENERGY STORAGE}

Renewable generation sources such as PV and wind naturally exhibit an intermittent supply of generated power. The impact of this intermittency upon the grid is typically reduced by grouping collections of PV or wind units together in large farms and utilizing some form of MPPT to ensure maximum production of electricity despite changing environmental conditions. Large collections of PV or wind help to aggregate the technologies' intermittencies by summing together their generation; however, overall generation profiles of large plants can still be negatively impacted by meteorological effects creating large steps in generation that can have potentially damaging effects to the stability of the connected grid as well as its loads and equipment. As renewable generation installations are becoming increasingly distributed at localized portions of the grid closer to the load base, the potential impact for creating a large number of instabilities throughout the grid similarly grows. This greater potential for system instability is a problem that must be dealt with before penetration of these generation sources grows too large. Some methods of mitigating these instabilities have been explored as a means of implementing a more constant power generation out of these renewable sources. Examples of this include: integrating energy storage into the renewable system, implementing a defined power management controller to regulate active power on the secondary control level of a renewable system, and modifying the MPPT algorithm to increase controllability of active power [31].

This work focuses on the application of energy storage in order to resolve these issues regardless of the nature of the connected power source. Using an energy storage system to decouple renewable generation from its load helps to alleviate some of the intermittent stress placed grid equipment. Typical energy storage solutions include batteries, flywheels, and ultracapacitors. 
Batteries are energy dense solutions offering hours of consistently discharged energy, but similarly require a long time to recharge. Therefore, with a low power density, they are not good for quick, deep discharge scenarios. Flywheels utilize the kinetic energy and inertia of large rotating masses to support power systems, and are best implemented for high-power, high energy demanding use cases $(>100 \mathrm{~kW})$. Ultracapacitors are power dense solutions that are best utilized for quick charge and discharge scenarios, but have a relatively low energy density [32] Table 1, compiled by Tecate Group, details some performance characteristics of both batteries and ultracapacitors, demonstrating their capabilities for charge/discharge cycling as well as their energy/power density levels. Energy storage decoupling can be accomplished either by connecting large installations of energy storage that is directly charged by the renewable sources and then discharge into the grid when desired, or by directly affixing some kind of energy storage to the converter that is re-routing power to the grid for power buffering.

Table 1. Charge and Discharge Characteristics of Batteries and Ultracapacitors [33]

\begin{tabular}{|l|c|c|c|}
\hline $\begin{array}{c}\text { Available } \\
\text { Performance }\end{array}$ & $\begin{array}{c}\text { Lead Acid } \\
\text { Battery }\end{array}$ & Ultracapacitor & $\begin{array}{c}\text { Conventional } \\
\text { Capacitor }\end{array}$ \\
\hline Charge Time & 1 to $5 \mathrm{hrs}$ & 0.3 to $30 \mathrm{~s}$ & $10^{-3}$ to $10^{-6} \mathrm{~s}$ \\
\hline Discharge Time & 0.3 to $3 \mathrm{hrs}$ & 0.3 to $30 \mathrm{~s}$ & $10^{-3}$ to $10^{-6} \mathrm{~s}$ \\
\hline Energy $(\mathrm{Wh} / \mathrm{kg})$ & 10 to 100 & 1 to 10 & $<0.1$ \\
\hline Cycle Life & 1,000 & $>500,000$ & $>500,000$ \\
\hline Specific Power $(\mathrm{W} / \mathrm{kg})$ & $<1000$ & $<10,000$ & $<100,000$ \\
\hline $\begin{array}{l}\text { Charge/discharge } \\
\text { efficiency }\end{array}$ & 0.7 to 0.85 & 0.85 to 0.98 & $>0.95$ \\
\hline Operating Temperature & -20 to $100 \mathrm{C}$ & -40 to $65 \mathrm{C}$ & -20 to $65 \mathrm{C}$ \\
\hline
\end{tabular}

With the rapid fluctuations of PV generation, it would be preferable to utilize an energy storage solution that provides quick injections of discharged power while subsequently recharging quickly. Therefore, ultracapacitors would be the best fit for such an application with their power density, cycling capabilities, and long life span. 
With the addition of energy storage shunt-connected to each module of a TMMC, the converter would gain the ability to power buffer any input signals from generation sources. This power buffering should improve the overall power profile of a renewable generation source like PV by smoothing out voltage and current irregularities. By having the ESS distributed across each individual module versus a lumped solution connected to an individual module port, a steadier injection of current supports the stability of the entire converter [29]. ESS redundancy is also achieved, by having a split accumulation of the ESS cascaded across each module. By interfacing the storage with the module via a non-isolated DC-DC converter, an additional degree of freedom is added to the system in terms of ensuring voltage stability for each module's capacitor [29].

\subsection{MODELING AND SIMULATION}

Preliminary simulation efforts began by modeling a simple two-row SISO TMMC converter design without any control system as seen in Figure 7 and Figure 8. Ansys Simplorer was used as the simulation testbed for the research. The TMMC buck-boost modules utilize two active switches to promote the bidirectional flow of power with each switch operating complementary of one another (when one is on, the other is off). These switches were triggered directly with PWM blocks with a switching frequency of $20 \mathrm{kHz}$ and a constant duty cycle of 50\%, in order to achieve a buckboost module unity conversion ratio. The output load for the converter was represented as a resistor. The TMMC conversion ratio is determined as an $n+1$ function, with $n$ being equal to the number of rows. Therefore, a two-row system should step up or down the voltage by a factor of three. The converter component values were selected to recreate the results from the source work 
and verify the operation of the topology. The simulated two-row SISO $1.7 \mathrm{~kW}$ TMMC has an input of $70 \mathrm{~V}$ with an expected output of $210 \mathrm{~V}$. Output resistor values for both the step-up and stepdown configurations were calculated using the power formula (1).

$$
P=\frac{V^{2}}{R} .
$$

Additionally, parallel filter capacitors are placed in between the lower most modules and their shared ground. A summary of system parameters is shown in Table 2.

Table 2. Two-Row TMMC Parameters (Step-Up/Step-Down)

\begin{tabular}{cc}
\hline System Parameter & Value \\
\hline $\mathbf{f}_{\mathbf{s}}$ & $20 \mathrm{kHz}$ \\
$\mathbf{C}$ & $60 \mu \mathrm{F}$ \\
$\mathbf{L}$ & $560 \mu \mathrm{H}$ \\
$\mathbf{R}_{\mathbf{0}}$ & $25.9 \Omega$ (step-up) \\
Vin $_{\text {Switches }}$ & $70.88 \Omega$ (step-down) \\
& MOSFETs and \\
& Diodes \\
\hline
\end{tabular}

The two-row system was first tested in the unidirectional step-up and step-down configurations by modulating one of the two active switches with a constant ON trigger depending upon the desired converter stepping direction as shown in Figure 7 and Figure 8 in order to meet the design criteria specified in Table 3 and Table 4, respectively. 

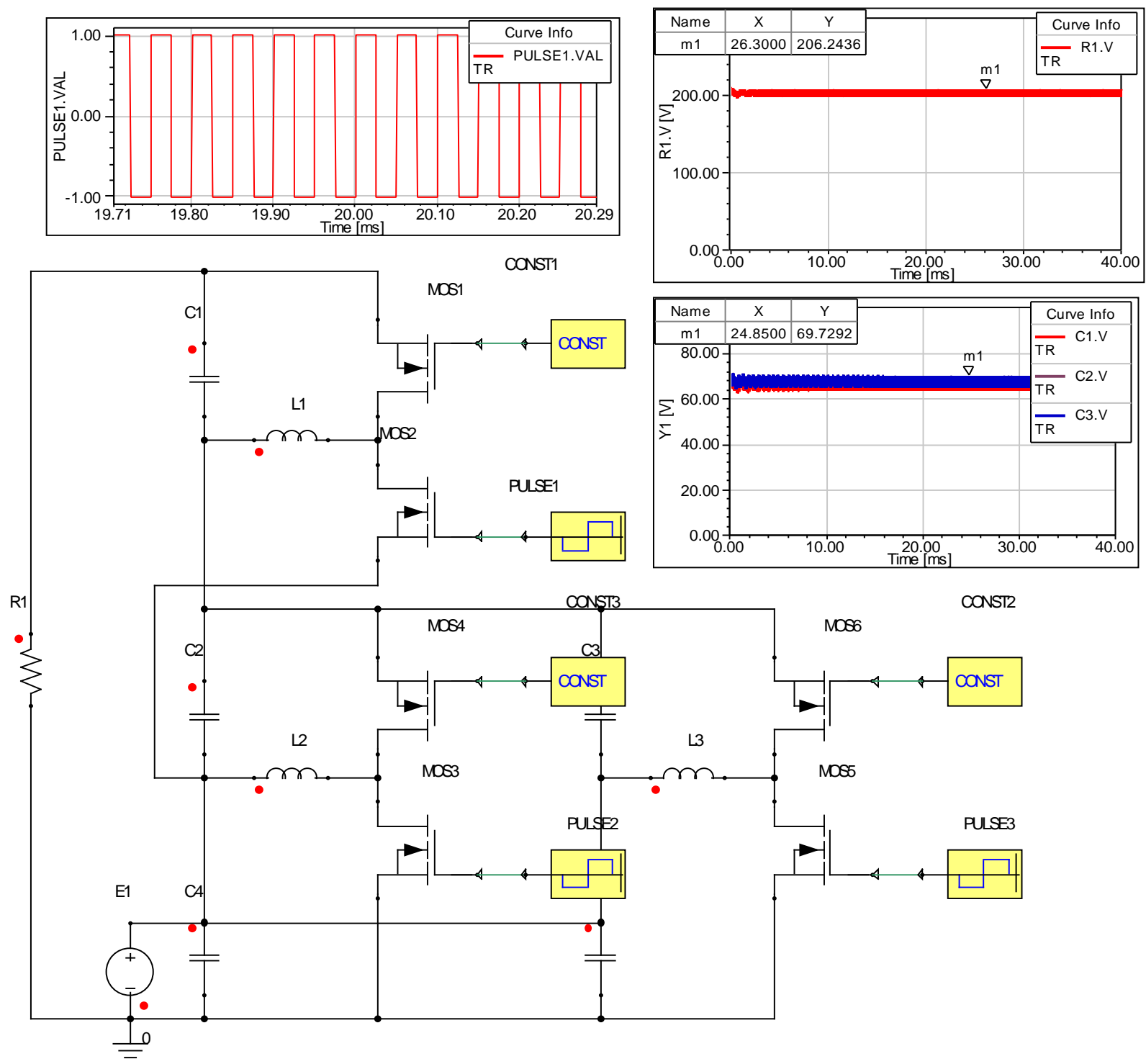

Figure 7. Two-Row Step-Up TMMC with Output Voltage and Row Voltages

Table 3. Two-Row Step-Up TMMC Design Parameters and Simulation Results

\begin{tabular}{|cc}
\hline Parameter & Value \\
\hline Number of Rows & 2 \\
\hline Desired Input Voltage & $70 \mathrm{~V}$ \\
Desired Output Voltage & $210 \mathrm{~V}$ \\
\hline Simulated Output Voltage & $206.24 \mathrm{~V}$ \\
\hline Simulated Capacitor Voltage & $69.73 \mathrm{~V}$ \\
\hline System Power & $1.7 \mathrm{~kW}$ \\
\hline
\end{tabular}



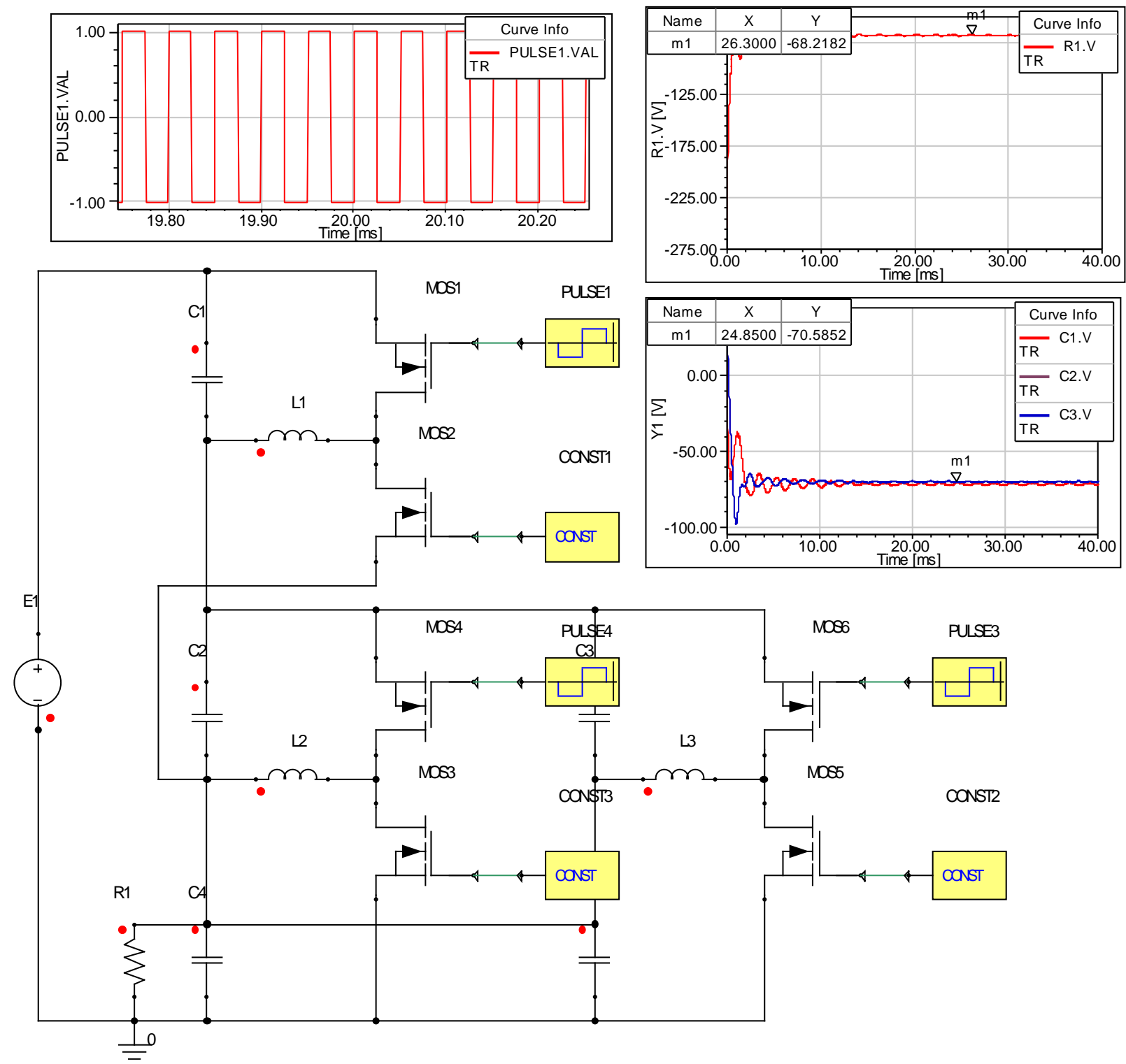

Figure 8. Two-Row Step-Down TMMC with Output Voltage and Row Voltages

Table 4. Two-Row Step-Down TMMC Design Parameters and Simulation Results

\begin{tabular}{cc}
\hline Parameter & Value \\
\hline Number of Rows & 2 \\
\hline Desired Input Voltage & $210 \mathrm{~V}$ \\
Desired Output Voltage & $70 \mathrm{~V}$ \\
\hline Simulated Output Voltage & $68.22 \mathrm{~V}$ \\
Simulated Capacitor Voltage & $70.58 \mathrm{~V}$ \\
\hline System Power & $1.7 \mathrm{~kW}$ \\
\hline
\end{tabular}




\subsubsection{Module Controller Design}

After completing the previous simulations, a PI-based control system is derived based on the above system parameters. The designed PI controller can function for both step-up and step-down operations. The overall control system consists of a cascaded voltage controller fed into a current controller. For each row of the TMMC, only one voltage controller is necessary for all row modules to promote current sharing; however, an individual current controller must be created for each module of the converter. This one-to-one ratio of modules to current controllers is to ensure sufficient stability of each module in the face of transient events. During normal steady state operation, each current controller within a row should ideally operate identically. For rows containing multiple parallel modules, the $\mathrm{P}$ and I gain terms for that row must be multiplied by the number of parallel module capacitors to account for added capacitor dynamics. The voltage PI controller is fed by two voltages subtracted from one another: the first being a reference voltage that is set when designing the converter controller, and the second being a summation of voltages between a selected capacitor voltage from current row as well as a capacitor voltage from the previous row. It is important that the set reference voltages for each row be the same to ensure equal voltage and current sharing. The summed voltage between the current row and the previous

row helps to establish an interdependency of voltage controllers helping to enhance the dynamic performance of the converter. The output of this PI block provides a reference inductor current value, which is then similarly subtracted by the actual inductor current of the module of interest. Based on the proposed TMMC paper, a second PI block would then process this current difference and provide an output switching signal for its respective module switches, with the design consideration that it must operate much faster ( $>10$ times) than the voltage controller, so that inductor current dynamics are much faster than capacitor voltage dynamics. It is much more 
desirable for the capacitor voltage to change more slowly than the current flowing across in the inductors to promote greater converter stability. For ease of implementation and to ensure fast current compensation performance, a hysteresis controller was chosen over a second PI block as shown below in Figure 9.

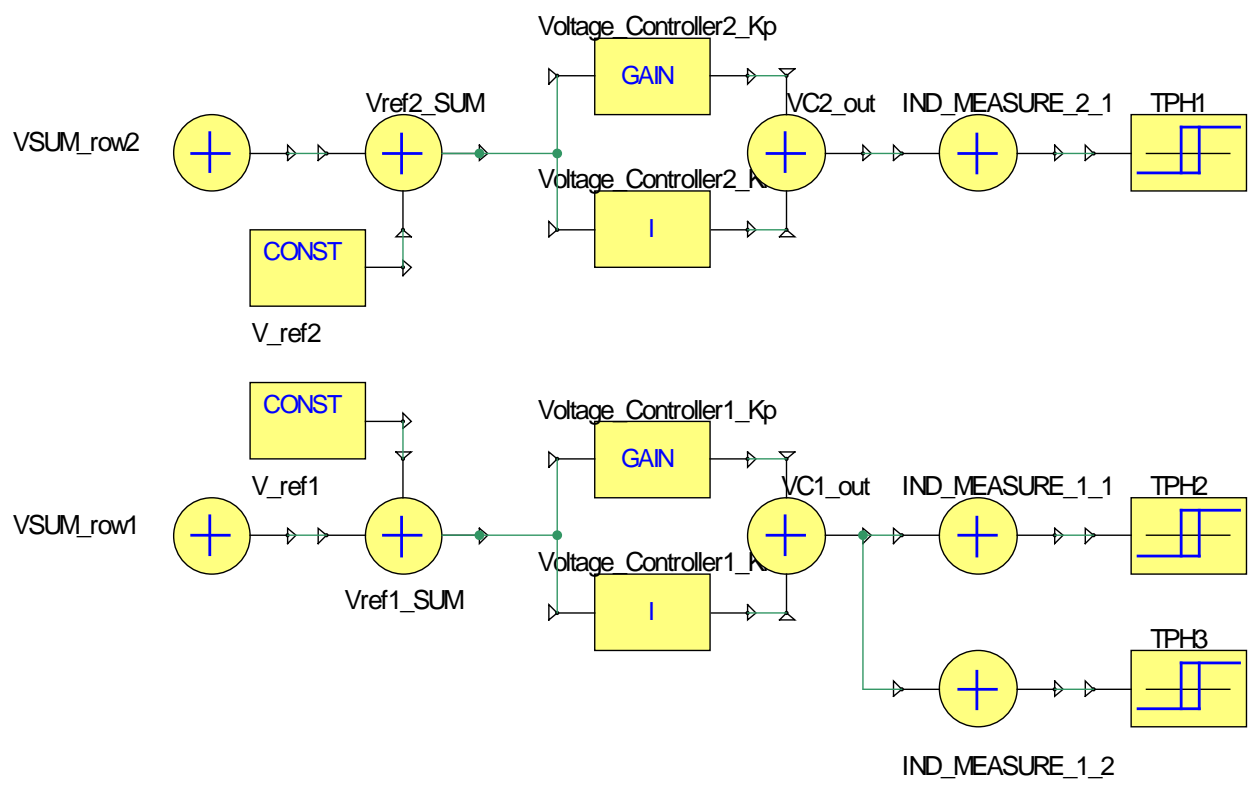

Figure 9. Two-Row TMMC Controller

(PI Voltage Controller fed into a Hysteresis Current Controller)

Hysteresis current controllers are known for their robust stability, fast performance, and good accuracy; however, it is worth noting that they also can lend themselves to uneven switching frequencies that can potentially lead to acoustic harmonic noise [34]. By tuning the hysteresis threshold bandwidth experimentally, any negative effects from the switching frequency and noise can be mitigated. The basic functionality of the hysteresis loop-based controller is depicted in (2) and Figure 10. 


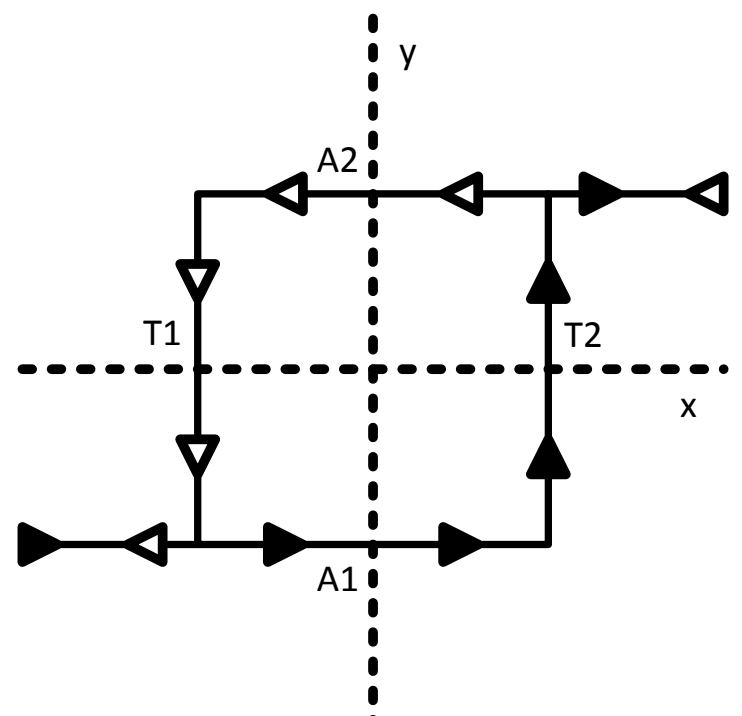

Figure 10. Hysteresis Current Control Logic

$$
\begin{array}{ll}
y(n)=A 1, & \text { if } x(n)<T 1 \\
y(n)=A 1, & \text { if } x(n)<T 2 \text { and } A(n-1)=A 1 \\
y(n)=A 2, & \text { if } x(n)>T 2 \\
y(n)=A 2, & \text { if } x(n)>T 1 \text { and } A(n-1)=A 2
\end{array}
$$

where $y(n)$ is the output and $x(n)$ is the input at simulation time step $n$ $T 1$ and $T 2$ are the threshold values

$A 1$ and $A 2$ are the specified output values

To begin determining both proportional and integral gain parameters, a mathematical representation of the system plant must be specified. With each of the modules being identical and each module maintaining equal power sharing, a single buck-boost converter is the focus of the plant design. The plant is designed so that it encompasses the operation of the current controller, meaning that the plant's input is the reference inductor current coming out of the PI voltage controller, and the output is the new capacitor voltage after the hysteresis controller feeds the module's switches with a new duty cycle value. With the plant input and output determined, a mathematical representation for the module plant can be calculated per (3), (4), (5), (6), and (7). 


$$
\begin{gathered}
\text { Input }=u=I_{L, \text { ref }} \\
\text { Output }=y=V_{C} \\
I_{L}=\frac{I_{O}}{1-D} \\
\text { where } I_{O}=\frac{V_{O}}{Z_{O}}=\frac{V_{C}}{\frac{1}{s C}}=V_{C} s C \\
\therefore \frac{y}{u}=\frac{V_{C}}{I_{L, \text { ref }}}=\frac{V_{C}}{\frac{I_{O}}{1-D}}=\frac{V_{C}}{\frac{V_{C} S C}{1-D}}=\frac{1-D}{s C}
\end{gathered}
$$

The simplified closed loop controller operation, as shown in Figure 11, consists of the PI voltage controller described above, the plant calculated above, and a feedback loop to update the voltage reference minus the capacitor voltage calculation feeding voltage controller. With this information, the closed loop transfer function can be determined providing us with a second order characteristic equation to derive proportional and integral gain parameters for the voltage controller per (8), (9), (10), (11), and (12).

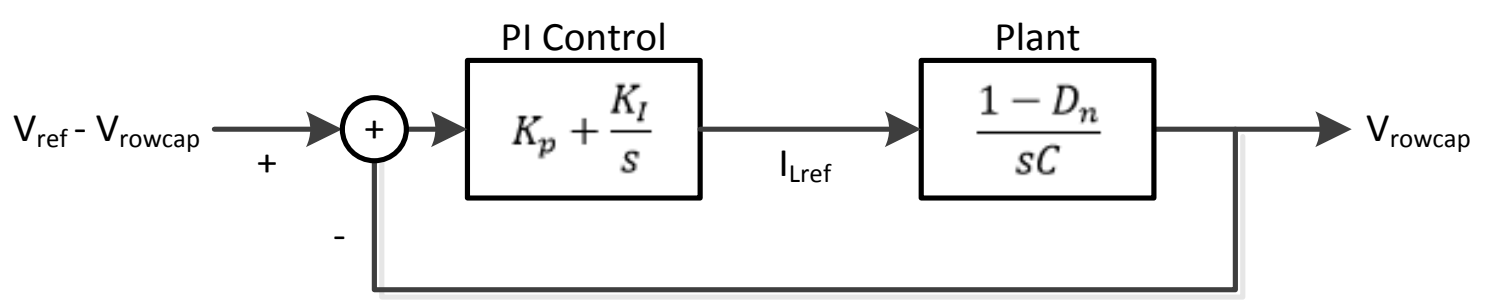

Figure 11. TMMC Closed Loop Control Diagram

$$
\text { Simplified } P I=K_{p}+\frac{K_{I}}{S}
$$




$$
\begin{gathered}
\text { Simplified Plant }=\frac{1-D}{s C}=\frac{D^{\prime}}{s C} \\
\text { ClosedLoopTransferFxn }=\frac{\left(K_{p}+\frac{K_{I}}{s}\right)\left(\frac{D^{\prime}}{s C}\right)}{1+\left(K_{p}+\frac{K_{I}}{s}\right)\left(\frac{D^{\prime}}{s C}\right)}=\frac{\left(\frac{K_{p} s+K_{I}}{s}\right)\left(\frac{D^{\prime}}{s C}\right)}{1+\left(\frac{K_{p} s+K_{I}}{s}\right)\left(\frac{D^{\prime}}{s C}\right)} \\
=\frac{\frac{K_{p} s D^{\prime}+K_{I} D^{\prime}}{s^{2} C}}{1+\left(\frac{K_{p} s D^{\prime}+K_{I} D^{\prime}}{s^{2} C}\right)}=\frac{\frac{K_{p} s D^{\prime}+K_{I} D^{\prime}}{s^{2} C}}{\frac{s^{2} C}{s^{2} C}+\left(\frac{K_{p} s D^{\prime}+K_{I} D^{\prime}}{s^{2} C}\right)}=\frac{\frac{K_{p} s D^{\prime}+K_{I} D^{\prime}}{s^{2} C}}{\frac{K_{p} s D^{\prime}+K_{I} D^{\prime}+s^{2} C}{s^{2} C}} \\
=\frac{K_{p} s D^{\prime}+K_{I} D^{\prime}}{s^{2} C+K_{p} s D^{\prime}+K_{I} D^{\prime}}=\frac{K_{p} s D^{\prime}+K_{I} D^{\prime}}{s^{2}+\frac{K_{p} s D^{\prime}}{C}+\frac{K_{I} D^{\prime}}{C}}
\end{gathered}
$$

Since we are working with a second order system, we know that the denominator of the closed loop transfer function (characteristic equation) can be equated to (13).

$$
s^{2}+2 \zeta \Omega_{0} S+\Omega_{0}^{2}=0
$$

By equating the denominator of the closed loop function to the second order system equation, we are able to find the terms for the proportional and integral gain terms for the system. A settling time for the system is selected to be 25 ms based off of the TMMC's origin paper [25] and the system is designed to be critically damped $(\zeta=0.707)$, with a settling time tolerance fraction of 2\%. With that information, the natural frequency was found using (14) and (15).

$$
T_{s}=0.025=\frac{\ln (\text { tolerance fraction })}{\zeta \omega_{n}}=\frac{\ln (0.02)}{\zeta \omega_{n}} \approx \frac{4}{(0.707) \omega_{n}}
$$




$$
\omega_{n}=\frac{4}{(0.025)(0.707)}=226.31 \frac{\mathrm{rad}}{\mathrm{s}}
$$

With the natural frequency of the plant determined, the $\mathrm{P}$ and I gain terms for the top row are calculated in (16), (17), (18), (19), (20), (21), and (22).

$$
\begin{gathered}
s^{2} C+\frac{K_{p} s D^{\prime}}{C}+\frac{K_{I} D^{\prime}}{C}=s^{2}+2 \zeta \omega_{0} s+\omega_{0}^{2} \\
\omega_{0}^{2}=\frac{K_{I} D^{\prime}}{C} \\
K_{I}=\frac{\omega_{0}^{2} C}{D^{\prime}}=\frac{(226.31)^{2}\left(60 * 10^{-6}\right)}{0.50}=6.146 \\
K_{p}=\frac{2(0.707)(226.31)\left(60 * 10^{-6}\right)}{D^{\prime}}=\frac{K_{p} s D^{\prime}}{C} \\
2(0.707)(226.31)=\frac{K_{p} D^{\prime}}{C}
\end{gathered}
$$

Assuming an ideal unity conversion duty cycle where $D=D^{\prime}=0.50$

$$
K_{p}=\frac{2(0.707)(226.31)\left(60 * 10^{-6}\right)}{0.50}=0.0384
$$

As mentioned earlier, these $\mathrm{K}_{\mathrm{P}}$ and $\mathrm{K}_{\mathrm{I}}$ terms must be multiplied by the number of parallel modules in the row that they are controlling (i.e. times 1 for the top row, times 2 for the second row, etc.). Figure 12 shows the stable steady state voltage levels of each module row and the output resister of the two-row step-down TMMC. The achieved output of $68.147 \mathrm{~V}$ is satisfactorily close to the desired $70 \mathrm{~V}$ as are the row module voltages. 


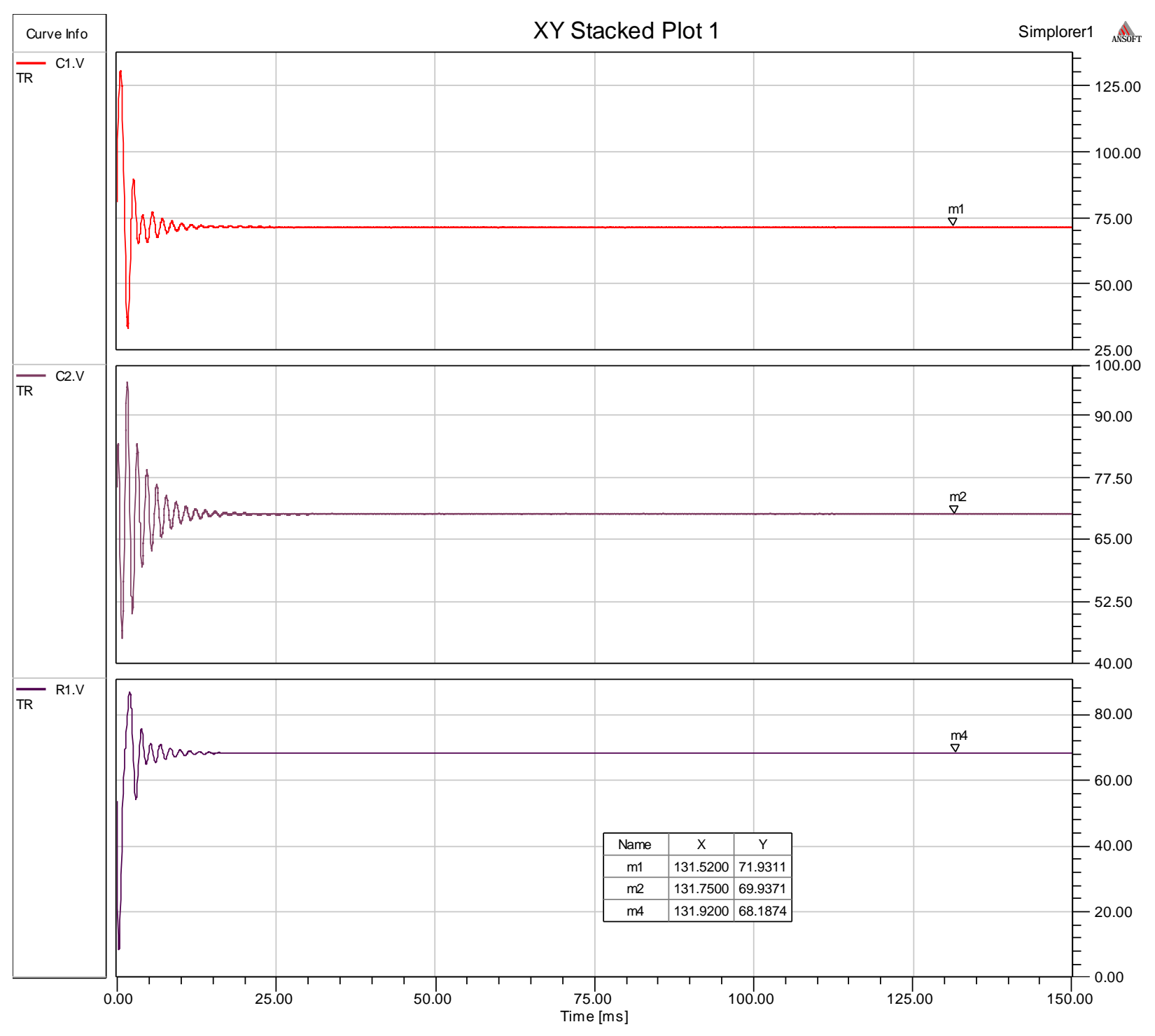

Figure 12. Two-Row TMMC with PI and Hysteresis Control - Capacitor Row Voltages and Output Voltage

Now that the TMMC controller is operating properly and desired voltage levels are achieved at each level of the converter, steps must be taken in order to smoothly transition the design of the converter to reach a step down configuration with an input of $380 \mathrm{Vdc}$ and an output of $95 \mathrm{Vdc}$-- half of which closely reaches the desired $48 \mathrm{Vdc}$ level. This lower voltage level is useful for potential DC building applications such as homes and IT equipment within data centers. 
The TMMC can be expanded infinitely in terms of number of rows, and could theoretically be extended to include seven rows, providing a conversion ratio of $n+1$ (or 8), allowing for a direct step down of voltages from a $380 \mathrm{Vdc}$ input connection down to $47.5 \mathrm{Vdc}$ at the lowest level. For ease of simulation, however, the converter is only extended to three rows, with the lowest row's voltage able to be divided in half for the use of a 48 Vdc tap.

To make the process of extending the number of rows easier, a sub-circuit of each buckboost module, Figure 14, was created with available taps to trigger both of its switches as well as with available ports for its capacitor voltage and inductor current levels. Input and output ports also extend out of the sub-circuit to attach the modules to one another. In addition to adding a third row of modules, a third level of controllers must be added to the system for this new row. The new converter design was also increased to process $4 \mathrm{~kW}$ of power, closer to that of a small building load. A simplified version of the three level TMMC incorporating sub-circuits is shown in Figure 13.

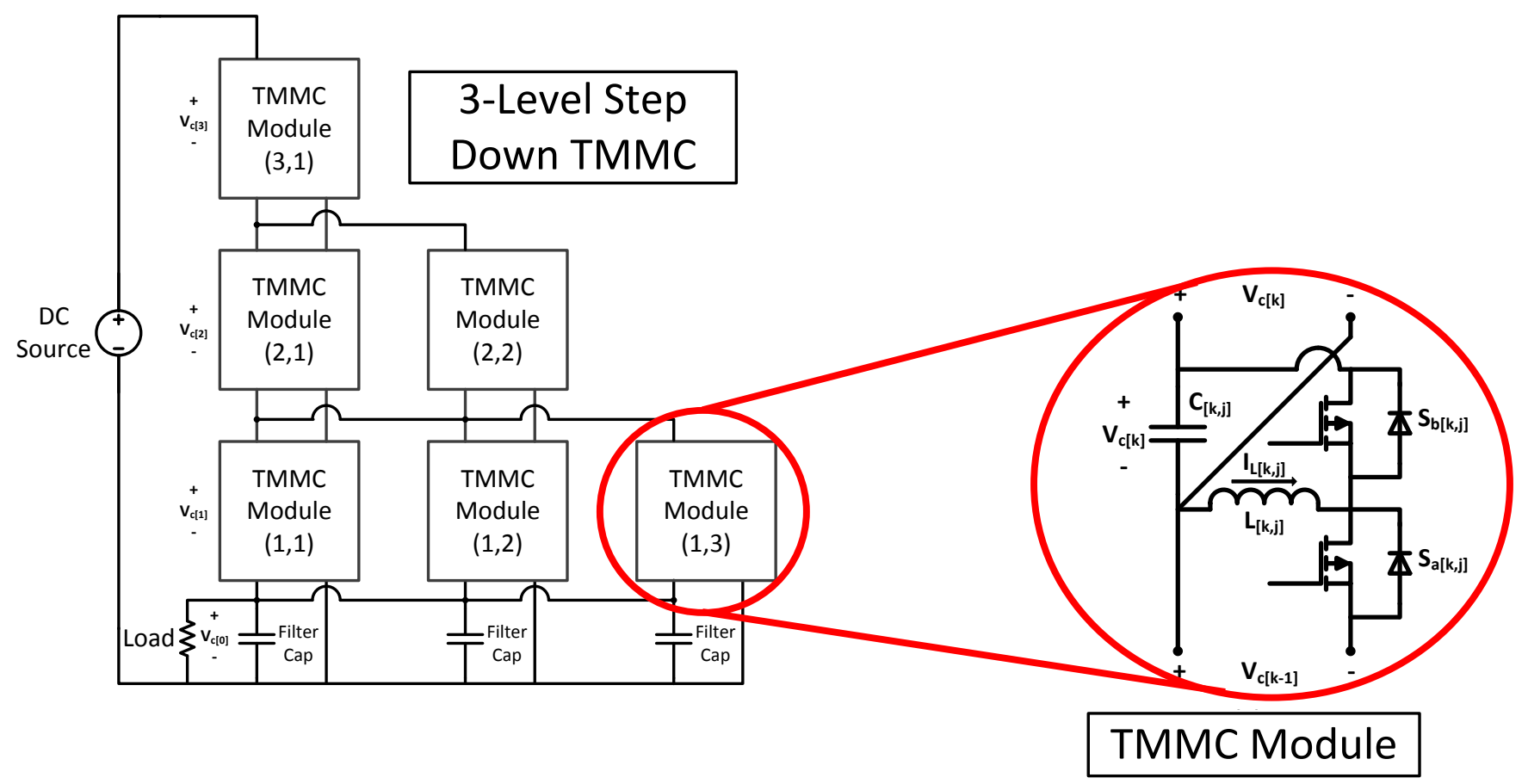

Figure 13. Three-Row Step-Down TMMC with Blown-Up Individual Buck-Boost Module 


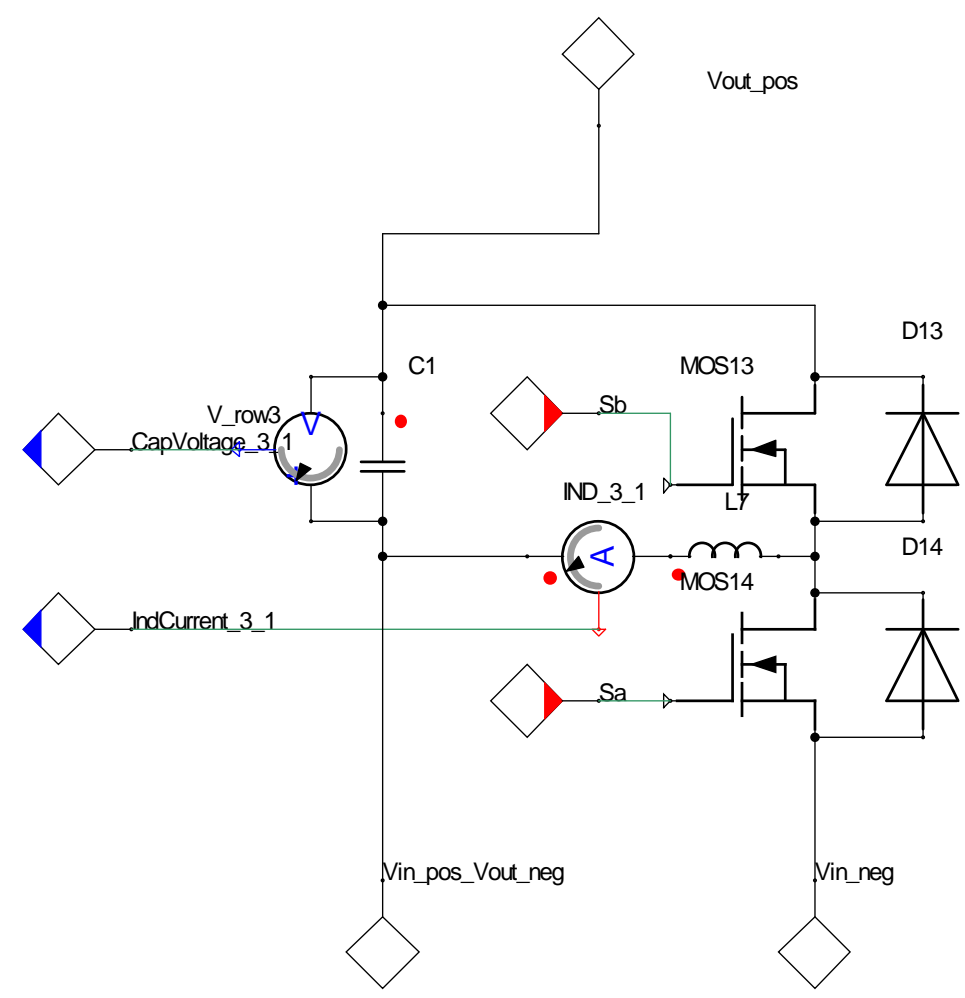

Figure 14. Simplorer Model of TMMC Module Sub-Circuit

The three-row step-down TMMC was simulated once more to evaluate for proper steady state performance. These results, shown in Figure 15 and summarized in Table 5, demonstrate the stability of the converter's output and capacitor row voltages. It should be noted, that as the number of rows and the power level of the converter increases, a slight degradation of the voltage sharing between rows is visible. The degradation of the row voltage sharing is something that could be corrected with an overhauled control system, but is out of the scope of this work. 


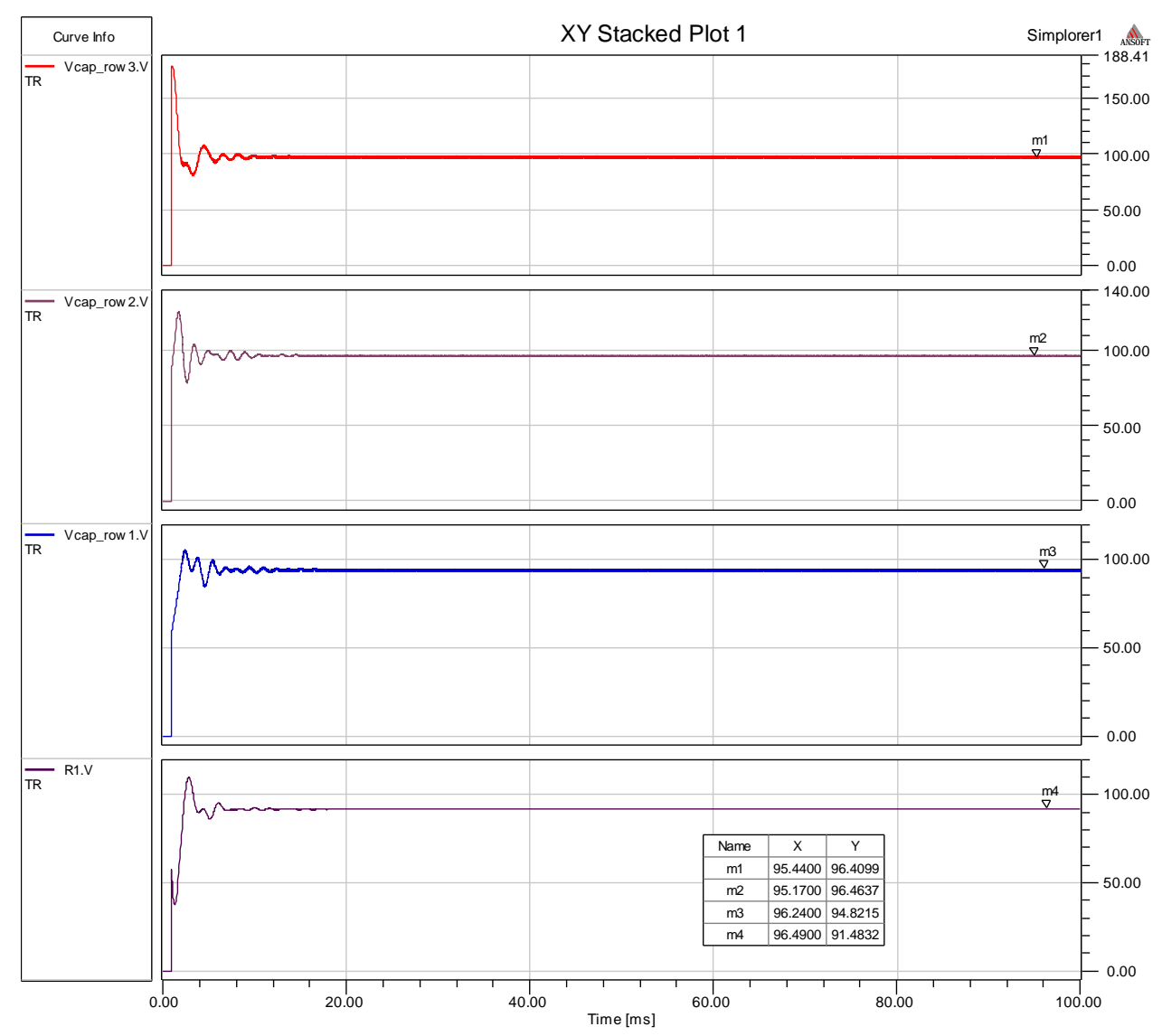

Figure 15. Three-Row TMMC with Hysteresis Controller Module Voltages and Output Voltage

In order to achieve the increase in converter power, the output resistor of the converter needs to shrink and requires a redesign (23). With the steady state output voltage of the converter around $92 \mathrm{~V}$, the resistor value for $4 \mathrm{~kW}$ is $2.12 \Omega$.

$$
R=\frac{V^{2}}{P}=\frac{92^{2}}{4000}=2.12 \Omega
$$


Table 5. Three-Row Step-Down TMMC Design Parameters and Simulation Results

\begin{tabular}{|cc}
\hline Parameter & Value \\
\hline Number of Rows & 3 \\
\hline Desired Input Voltage & $380 \mathrm{~V}$ \\
\hline Desired Output Voltage & $95 \mathrm{~V}$ \\
\hline Simulated Output Voltage & $91.48 \mathrm{~V}$ \\
\hline Simulated Capacitor Voltages & $96.41,96.46,94.82 \mathrm{~V}$ \\
\hline System Power & $4 \mathrm{~kW}$ \\
\hline Output Resistor & $2.12 \Omega$ \\
\hline
\end{tabular}

\subsection{ANALYTICAL MODEL VERIFICATION OF SIMULATION}

With the simulation model results achieving stability with their steady state values, it is important to verify that those values mathematically make sense considering potential dynamics from each of the module converters. The following capacitor (24) and inductor (25) differential equations were evaluated in MATLAB Simulink for a two-row system for simplicity’s sake. Mathematically representing additional rows should not provide sufficient added dynamics since a heavy emphasis on interdependency between rows and power sharing is emphasized throughout the TMMC. Furthermore, only a single module per row is represented in the analytical model since parallel module all share identical dynamics.

$$
\begin{gathered}
C \frac{d V_{C[k]}}{d t}= \\
\left\{\begin{array}{c}
-i_{L[k+1]}+i_{L[k+2]} d_{[k+2]}+C \dot{V}_{C[k+1]}-i_{[k]}, \quad k=0 \\
i_{L[k]}\left(1-d_{[k]}\right)-i_{L[k+1]}+i_{L[k+2]} d_{[k+2]}+C \dot{V}_{C[k+1]}-i_{[k]}, \quad k=1, \ldots, n-2 \\
i_{L[k]}\left(1-d_{[k]}\right)-i_{L[k+1]}+C \dot{V}_{C[k+1]}-i_{[k]}, \quad k=n-1
\end{array}\right. \\
L \frac{d i_{L[k]}}{d t}=V_{C[k-1]} d_{[k]}-V_{C[k]}\left(1-d_{[k]}\right)-i_{L[k]} R_{L}, \text { where } k=1, \ldots, n
\end{gathered}
$$




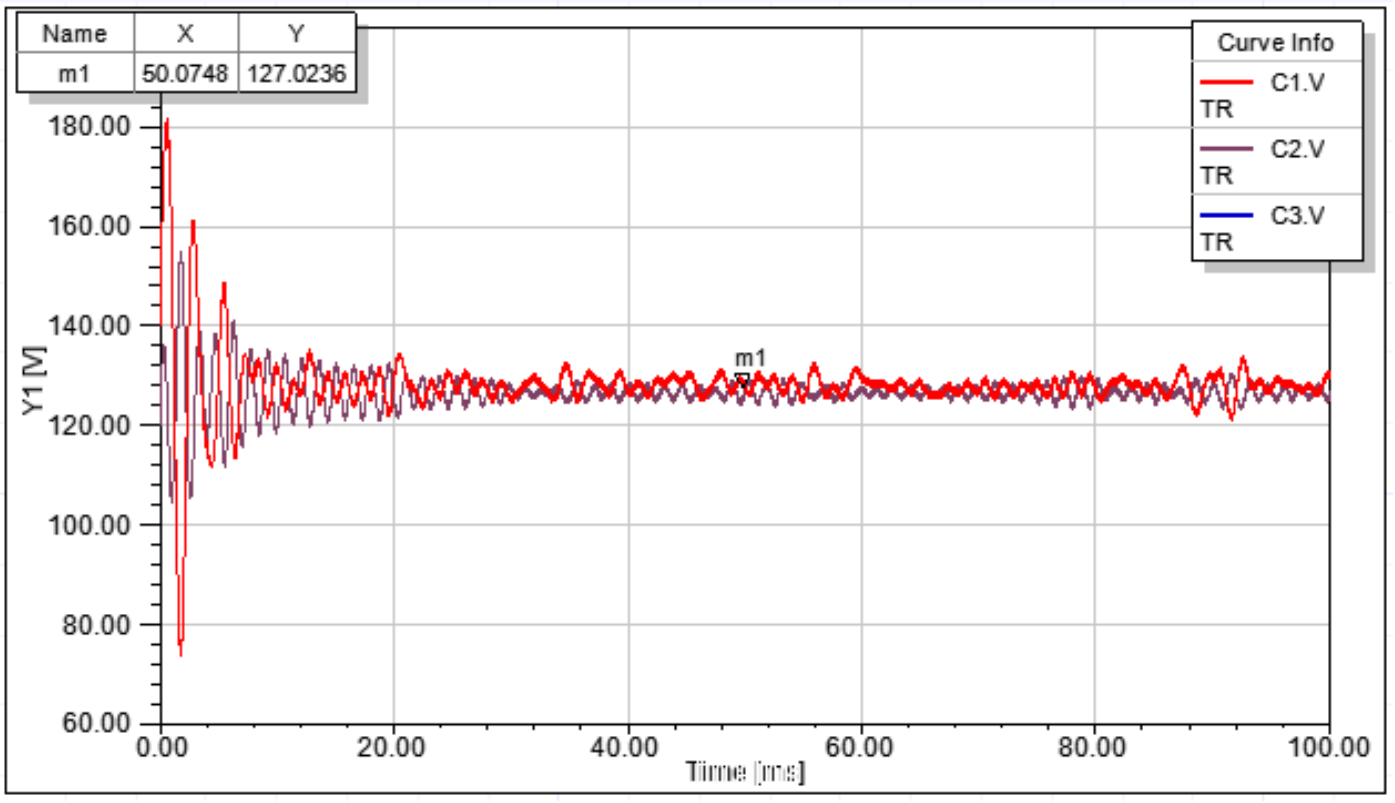

Figure 16. Simplorer Capacitor Voltage Results of Two-Row TMMC

Figure 16 highlights the three module capacitor voltages of a two-row step-down TMMC. Since both of the modules of the bottom-most row share dynamics, there are only two unique overlapped signals present in this diagram. These results are compared to the analytical results of Figure 17, with a goal for both of these simulations to achieve values present in summarized in Table 6. The simulation results of $127.02 \mathrm{~V}$ very closely match up to the desired $126.67 \mathrm{~V}$ as well as the analytical results of $130.50 \mathrm{~V}$ and $129.1 \mathrm{~V}$. Furthermore, the settling times of both simulations achieve steady state roughly around $30 \mathrm{~ms}$, demonstrating validation of the control functionality of the simulation. The Simulink Analytical model can be found in Appendix A. 
Table 6. Two-Row Step-Down TMMC Analytical Verification of Simulation Results

\begin{tabular}{cc}
\hline Parameter & Value \\
\hline Number of Rows & 2 \\
Desired Input Voltage & $380 \mathrm{~V}$ \\
Desired Output Voltage & $126.67 \mathrm{~V}$ \\
\hline Simulated Capacitor Voltage & $127.02,127.02 \mathrm{~V}$ \\
\hline Analytical Capacitor Voltages & $130.50,129.1 \mathrm{~V}$ \\
\hline System Power & $4 \mathrm{~kW}$ \\
\hline
\end{tabular}
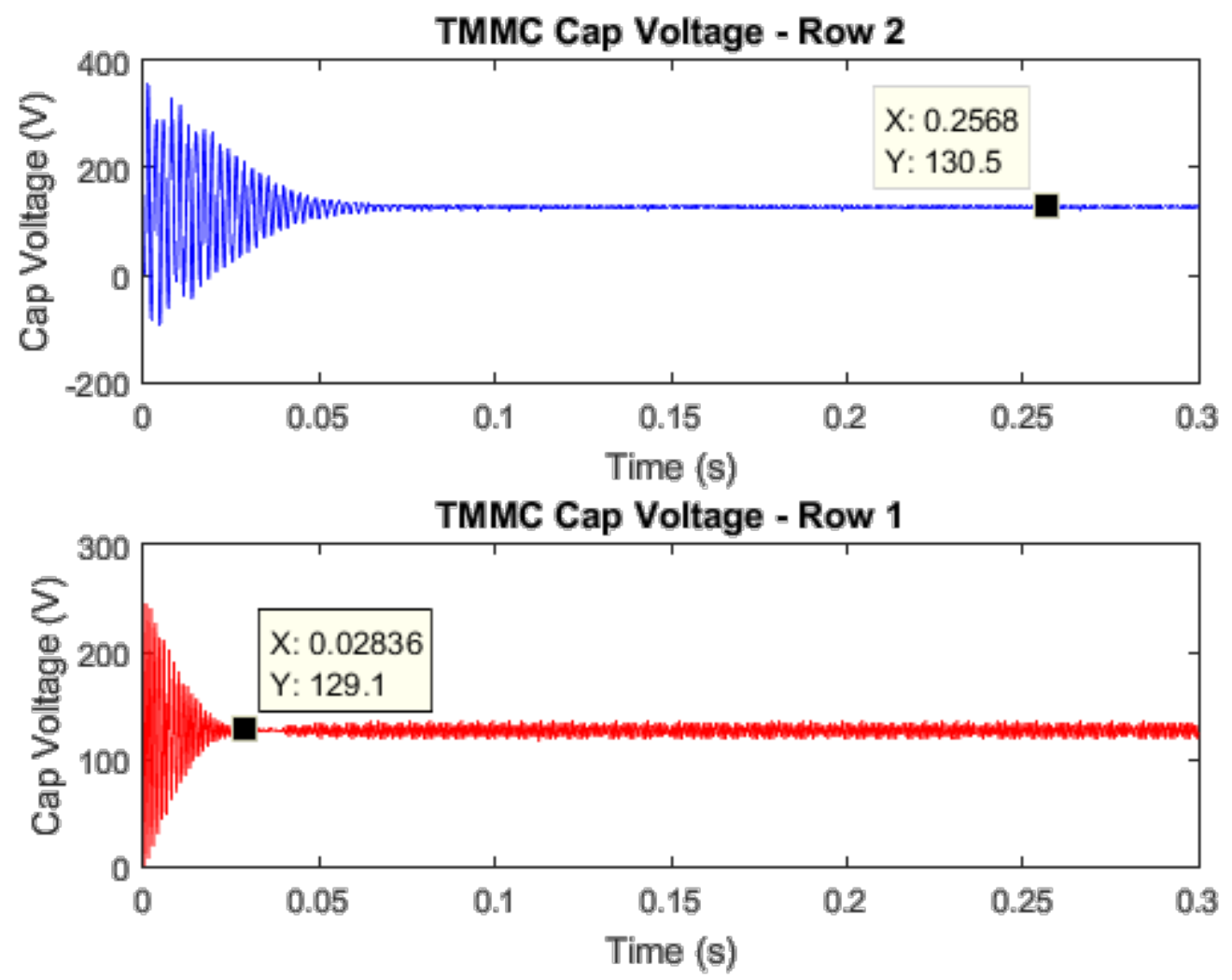

Figure 17. Analytical Results of Two-Row TMMC Showing Capacitor Voltages for Rows One and Two

With an extra degree of confidence in the performance of the two-row TMMC Simplorer simulation, work efforts could then be applied towards the integration of energy storage along each module of the converter. 


\subsection{ULTRACAPACITOR INTERFACE}

With the core of the converter modeling effort completed, research efforts were then refocused on implementing elements of energy storage throughout the TMMC topology. With the high power density ultracapacitor selected as the energy storage solution, an adequate non-isolated DC-DC interface between the ultracapacitors and the TMMC modules needed to be selected. This converter needs to be both a two-quadrant device with bi-directional current flow in order to both charge and discharge the ultracapacitor, as well as be easily controllable to allow for the simple selection between charging and discharging operations. A Type-C chopper DC-DC Converter, also referred to as a Buck and Boost converter, is able to achieve both of these functionalities and was selected as the interfacing topology between the ultracapacitor and the TMMC modules. Chopper circuits interface sources and loads and are static power electronic devices used to convert fixed DC power to variable DC power by means of high speed switches connecting and disconnecting from a specified load. Their operation allows for connected sources and loads to operate in both single-quadrant or multi-quadrant regions based on the configuration of switches and their impact on the flow of power. The four quadrants are denoted by voltage (y-axis), current (x-axis), and their respective polarities as shown in Figure 18, which ultimately dictate the directional flow of power. There are five types of choppers, labeled A through E, but the main focus of this research focuses on the Type-C chopper, which combines the functionality of both the Type-A chopper (unidirectional, first quadrant) and the Type-B chopper (unidirectional, second quadrant), in order 
to achieve bi-directional, dual quadrant power flow (first and second quadrant). The Type-C chopper topology connected to an ultracapacitor is shown below in Figure 19.

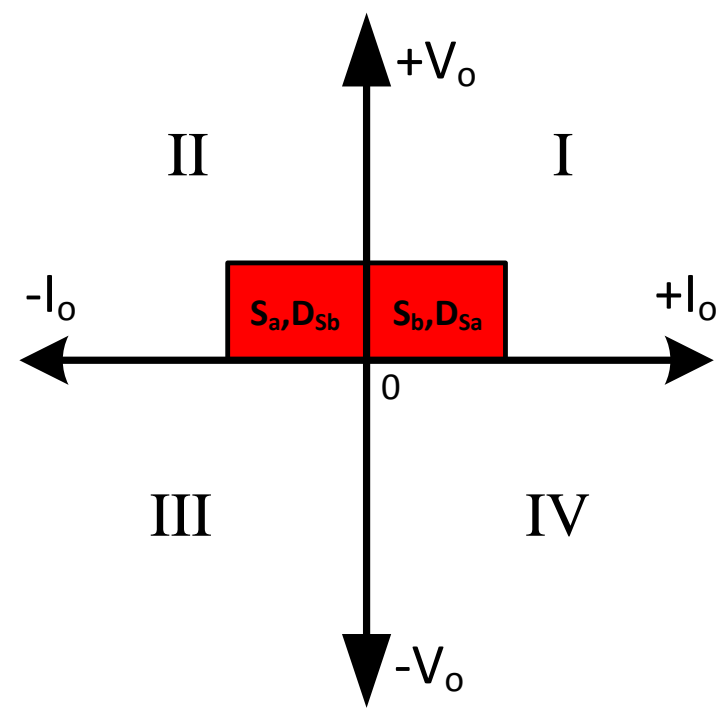

Figure 18. First and Second Quadrant operation of the Type-C Chopper with Depicted Switching States of MOSFETs and Diodes

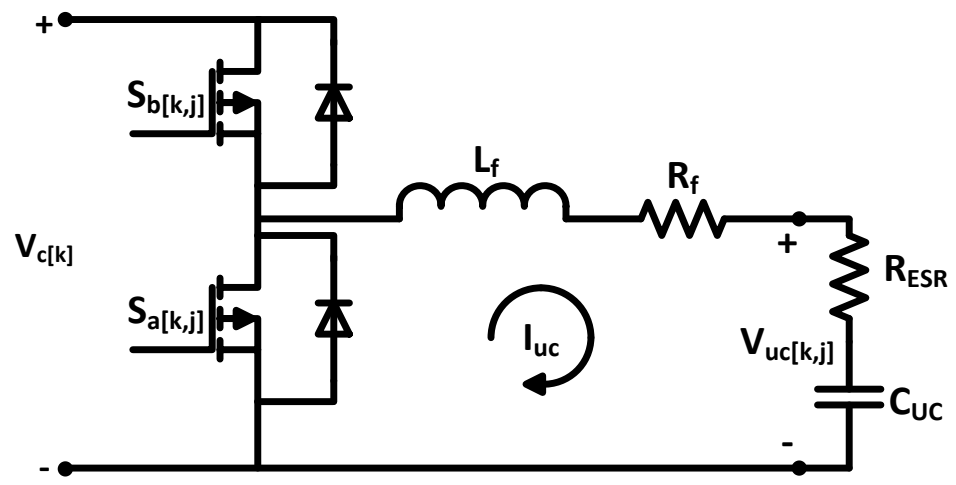

Figure 19. Type-C Chopper Bidirectional DC-DC Converter connected to Ultracapacitor 


\subsection{MODES OF OPERATION}

For the Type-C chopper's proper interfacing of the module and the ultracapacitor, the module capacitor voltage, $\mathrm{V}_{\mathrm{C}}$, must always be greater than the voltage across the ultracapacitor, $\mathrm{V}_{\mathrm{UC}}$. This voltage bias ensures the proper flow of current from high side to low side, and vice versa. As such, with an average module capacitor voltage of $95 \mathrm{~V}$, the ultracapacitor voltage was designed for 48 $\mathrm{V}$ - a roughly 2:1 ratio of voltages. The Type-C chopper can effectively operate as both a buck converter and a boost converter based on proper switching modulation. Each switch utilizes a freewheeling diode for when it is not actively in operation. By modulating the top switch, $\mathrm{S}_{\mathrm{b}}$, and keeping the bottom switch, $\mathrm{S}_{\mathrm{a}}$, open, the converter is in "buck" or "charging" mode with power flowing from the module to the ultracapacitor; conversely, by modulating the bottom switch, $\mathrm{S}_{\mathrm{a}}$, and keeping the top switch, $\mathrm{S}_{\mathrm{b}}$, open, the converter is in "boost" or "discharging” mode with power

flowing from the ultracapacitor to the module. Both of these operating modes are depicted in Figure 20 and Figure 21. 


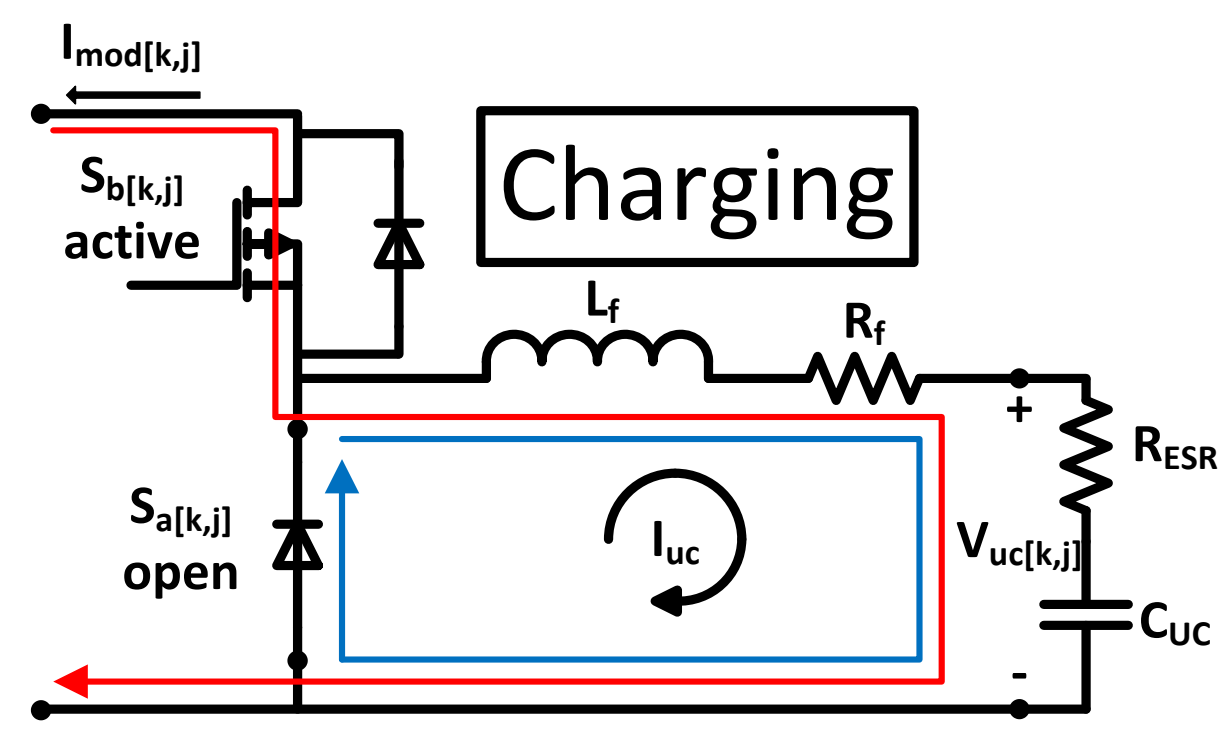

Figure 20. Buck or Charging Mode Operation of the Type-C Chopper Red line: Switch $S_{b}$ closed; Blue line: Switch $S_{b}$ open

When switch, $\mathrm{S}_{\mathrm{b}}$, is switched on, current flows from the positive terminal of the module capacitor, through the ultracapacitor loop of IUc, charging the inductor, $\mathrm{L}_{\mathrm{f}}$, and then flows out of the negative module terminal back into the TMMC. At this point, the ultracapacitor voltage $\mathrm{V}_{\mathrm{UC}}$ and current $\mathrm{I}_{\mathrm{UC}}$ are positive. When $\mathrm{S}_{\mathrm{b}}$ is switched off, the inductor discharges with its current freewheeling through the ultracapacitor loop and $\mathrm{S}_{a}$ 's diode; current IUC flows in the same direction and zero voltage is held across the ultracapacitor. This buck mode operation, operating in the first quadrant with positive voltage and current, charges the ultracapacitor from the module and helps lower the voltage across the module capacitor. 


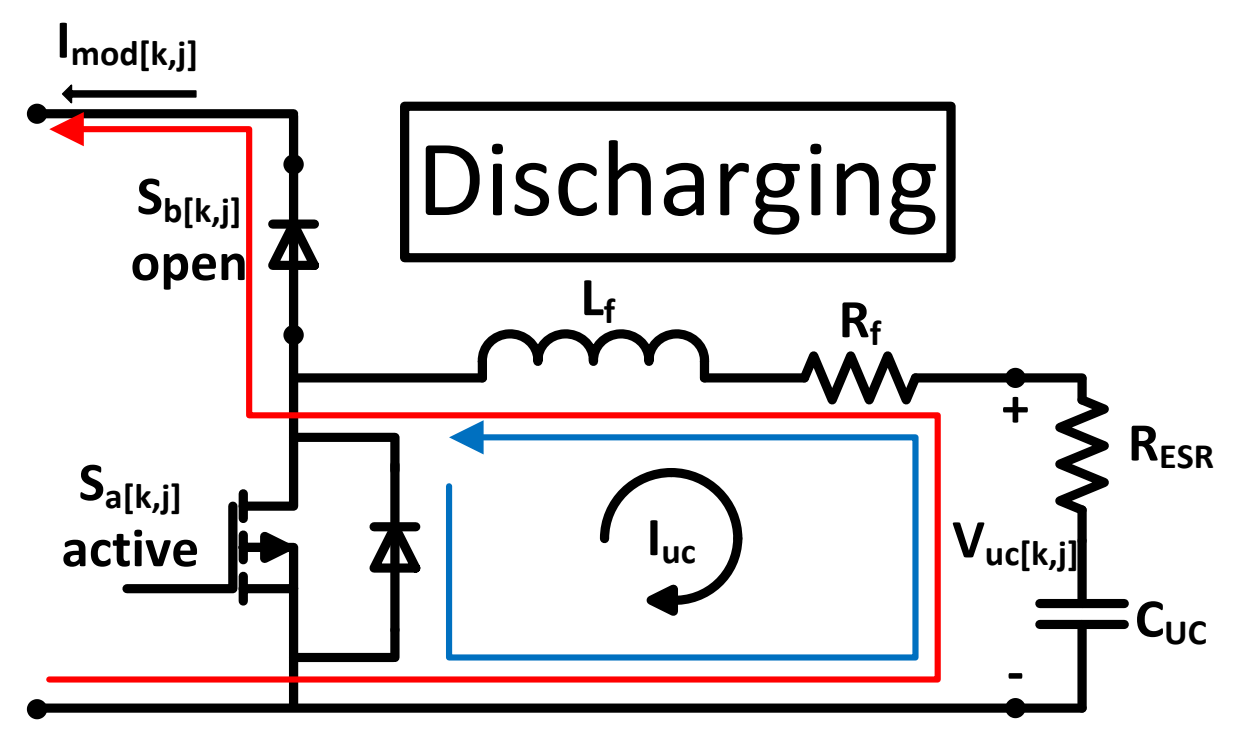

Figure 21. Boost or Discharging Mode Operation of the Type-C Chopper Red line: Switch $S_{a}$ open; Blue line: Switch $S_{a}$ closed

When switch, $S_{a}$, is on, current flows from the negative terminal of the module capacitor and into freewheeling loop of the ultracapacitor and the switch. The current is now forced to flow in the opposite direction and charges the inductor in the negative direction (-IUC). The voltage across the ultracapacitor is zero. When $S_{a}$ is switched off, the current still flows from the negative terminal of the module and through the ultracapacitor loop in the negative Iuc direction (via the negatively charged inductor), but now flows through switch $\mathrm{S}_{\mathrm{b}}$ 's diode back into the positive module terminal. The ultracapacitor voltage is once again positive. This boost mode operation, operating in the second quadrant with positive voltage and negative current, discharges the ultracapacitor back into the module and helps raise the voltage across the module capacitor.

During the transition between the buck and boost modes of operation, the current IUC flows around the ultracapacitor loop via switch $S_{a}$ 's diode until the polarity of charged current across the inductor flips directions and the respective switch in the new mode of operation can conduct current. 


\subsection{ENERGY STORAGE COMPONENT SIZING}

Several component values need to be selected in order to fully realize each module's energy storage stack. An ultracapacitor value must be selected, which must adhere to the Type-C chopper design choice of having a $48 \mathrm{~V}$ ultracapacitor; and an inductor and resistor value for the actual chopper circuit must be chosen, which minimizes current ripple and coordinate with the switching frequencies of the switches.

\subsubsection{Choosing an Ultracapacitor}

Two methods for selecting an ultracapacitor were available: 1) choose a bulk single unit ultracapacitor for each energy storage array that meets the voltage requirement or 2) chain multiple smaller rated ultracapacitors in series to achieve the adequate voltage rating. Both options have their downfalls. The first choice is the most straightforward; however, it is a much larger and more expensive unit to realistically implement in prototypical hardware. The second choice, suffers from

a much smaller total capacitive rating due to the series connection of ultracapacitors. While the voltages are added in series to equal $48 \mathrm{~V}$, the inverse of the capacitances are added together with this sum inverted once more to produce the new total capacitance. The following product comparisons were made of ultracapacitors from the manufacturer Maxwell in order to determine the most energy dense solution. Total energy stored within a capacitor is calculated via (25).

$$
E=\frac{1}{2} C V^{2}
$$


Preliminary calculations (27) and (28) were made for the bulk capacitor and then the procedure was repeated for two smaller ultracapacitor models with the compiled results presented in Table 7.

$$
\begin{gathered}
\frac{1}{2} * 83 * 48^{2}=95,616 \mathrm{~J} \\
95,616 \mathrm{~J} * \frac{1 \mathrm{~J}}{0.000277778 \mathrm{Wh}}=26.56 \mathrm{Wh}
\end{gathered}
$$

Table 7. Energy Comparison of Three Different Ultracapacitor Models

\begin{tabular}{ccccc}
\hline $\begin{array}{c}\text { Ultracapacitor } \\
\text { Model Name }\end{array}$ & $\begin{array}{c}\text { Capacitance of } \\
\text { Individual } \\
\text { Ultracapacitors }\end{array}$ & $\begin{array}{c}\text { Voltage per } \\
\text { Ultracapacitor }\end{array}$ & $\begin{array}{c}\text { Total } \\
\text { Capacitance } \\
\text { per } \sim 48 ~ V \\
\text { string }\end{array}$ & $\begin{array}{c}\text { Total Energy } \\
\text { Rating }\end{array}$ \\
\hline $\begin{array}{c}\text { BMOD0083 } \\
\text { P048 B01 }\end{array}$ & $83 \mathrm{~F}$ & $48 \mathrm{~V}$ & $83 \mathrm{~F}$ & $\begin{array}{c}95,616 \mathrm{~J} \\
(26.56 \mathrm{Wh})\end{array}$ \\
BMOD0058 & $58 \mathrm{~F}$ & $16 \mathrm{~V}$ & $19.333 \mathrm{~F}$ & $\begin{array}{c}22,272 \mathrm{~J} \\
(6.187 \mathrm{Wh})\end{array}$ \\
E016 B02 & $350 \mathrm{~F}$ & $2.7 \mathrm{~V}$ & $19.444 \mathrm{~F}$ & $22,399 \mathrm{~J}$ \\
BCAP0350 & & & $(48.6 \mathrm{~V})$ & $(6.222 \mathrm{Wh})$ \\
\hline
\end{tabular}

The TMMC requires its energy storage to compensate for swings in connected intermittent generation sources with transient compensation lasting anywhere from the milliseconds to seconds range. The connected PV array ideally is able to inject as much as $1747 \mathrm{~W}$, so it is necessary that the ultracapacitor array be able to compensate for a transient of such magnitude in the case of unexpected step changes up or down. All three ultracapacitors could potentially supply the amount of energy necessary to support the operation of the TMMC; however, the most energy dense ESS solution is the $83 \mathrm{~F}$ ultracapacitor, with more than four times the energy than both the $58 \mathrm{~F}$ and the 350 F ultracapacitors. The unit of a Joule is equivalent to a Watt-second and therefore, the $83 \mathrm{~F}$ 
ultracapacitor, with an energy store of 95,616 $\mathrm{J}$ is the most attractive choice for providing the desired module regulation. For future iterations of this work, a comprehensive comparison of the different ultracapacitors could be performed in order to find the most optimal ultracapacitor size for the application.

\subsubsection{Choosing a Type-C Chopper Inductor}

The selection of an appropriately sized inductor for the Type-C chopper is closely involved with the switching operation of the circuit and is a compromise between size, current ripple, and control performance. As seen in equation (29), current ripple in the chopper is proportional to the module voltage and can be reduced by increasing either the switching frequency or the inductor size. Current ripple is directly related to losses in the device, so it should ideally be kept as low as possible.

$$
\Delta I=\frac{V_{\bmod }}{f_{s} L} D(1-D)
$$

It is also important to relate the size of the inductor and its time constant for charged current to the switching frequency of the MOSFET devices within the chopper. The time constant for the inductor can be found using (30) and (31). $R_{L}$ refers to the inductor resistance and $R_{E S R}$ is the ultracapacitor equivalent series resistance.

$$
\begin{gathered}
\tau=\frac{L}{R_{L}+R_{E S R}} \\
\tau=\frac{0.001}{2.990+0.010}=0.000333 \mathrm{~s}
\end{gathered}
$$


The inductor time constant, $\tau$, relates directly to the switching frequency via the following relationship (32), (33), and (34) in order to achieve stable current regulation. A summary of this design process can be found in [35].

$$
\begin{gathered}
\tau>\frac{1}{2} T_{s} \\
\therefore T_{S}<2 \tau=2 * 3.33 * 10^{-4} \mathrm{~s}=6.66 * 10^{-4} \mathrm{~s} \\
\therefore \text { Minimum Switching Frequency }=\frac{1}{6.66 * 10^{-4} \mathrm{~s}}=1500 \mathrm{~Hz}
\end{gathered}
$$

\subsection{ENERGY STORAGE SYSTEM CONTROL}

There are several methodologies for designing a controller for the ESS including PI control and state machine control. It is very important to actively regulate the ultracapacitor current in order to protect the Type-C Chopper semiconductors from over-current and over-temperature damage, as well as to provide adequate energy storage support for the connected TMMC modules. Modulating the ultracapacitor current is also a suitable way to module the ultracapacitor voltage. While PI control would work sufficiently well, it is not necessary because the time constant of the ultracapacitors (35) is very large relative to the rest of the components within the overall system.

$$
\text { Ultracapacitor Time Constant }=\tau=R C=0.010 \Omega * 83 F=0.83 \mathrm{~s}
$$

For comparison, the TMMC is designed to achieve steady state within $0.025 \mathrm{~s}$. This large ultracapacitor time constant demonstrates that its voltage does not require dynamic regulation. Moreover, with the connected TMMC module's own separate dedicated controller, the Type-C 
chopper does not require its own dedicated PI regulator and a simpler control method can be explored.

\subsubsection{State Machine Type-C Chopper Control}

Since the voltage level of the ultracapacitor does not require any dedicated regulation, a simplified method of operating the Type-C chopper is used, which monitors the voltage level of its connected TMMC module capacitor. An upper and a lower voltage threshold is established that functions as the triggering points for a transition from an idle state to either a charging (buck) state or a discharging (boost) state. For reference, Figure 22, details the three different operating states of the controller with the blue dot representing the current state of operation.

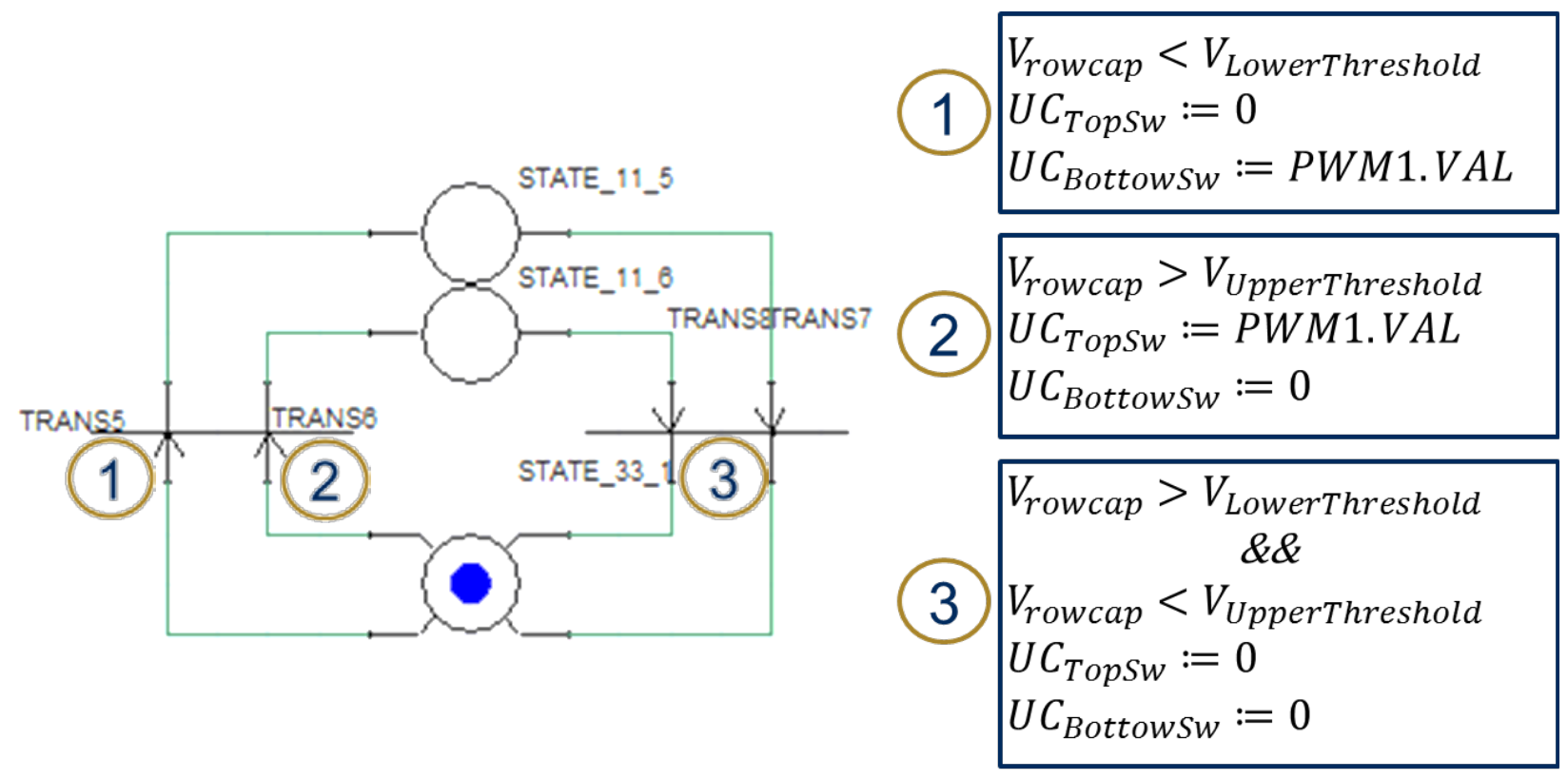

Figure 22. Type-C Chopper State Machine Control Loop (left); Voltage Threshold Transition Requirements 
Per the state machine diagram in Figure 22, the chopper circuit begins in an idle mode of operation with the voltage of the module capacitor falling in between the two defined thresholds of $91 \mathrm{~V}$ and $99 \mathrm{~V}$, denoted by circle 3. Neither of the two switches in the chopper circuit are triggered in this state. In the event of a system perturbation leading to the module voltage crossing either threshold, the state machine shifts modes from the idle state to either the buck state or the boost state in order to regulate the voltage and bring it back between the thresholds more quickly. If the module voltage drops below the lower threshold, the chopper enters its discharging (boost) state, denoted by circle 1, effectively raising the voltage of the module capacitor. As mentioned before, the bottom switch of the chopper is triggered for this state. Similarly, if the voltage exceeds the upper threshold, the chopper enters its charging (buck) state, denoted by circle 2, effectively lowering the voltage of the module capacitor. The upper switch of the chopper is triggered for this state. The switching frequency for the chopper devices was determined earlier with the chopper inductor sizing and is $20,000 \mathrm{~Hz}$. 


\subsection{PHOTOVOLTAIC ARRAY SYSTEM}

A photovoltaic array is used as the main vehicle for evaluating the transient resiliency of the TMMC enhanced with energy storage. The PV array, with its natural intermittencies throughout the course of a day, injects power into the power electronic interface with scheduled step changes in its output. This intermittency serves as a natural test bed for the energy storage to engage and counteract the transient spikes present throughout the TMMC rows. This PV system needs to be able to handle large steps in the solar irradiance $\left(\mathrm{W} / \mathrm{m}^{2}\right)$ to simulate the varying irradiance of a PV array mid-day. The output load is designed to receive around $4 \mathrm{~kW}$ of power, and the PV array, connected directly to positive and negative terminals of one of the TMMC modules, was designed to be just under half of that total power capacity at $1747 \mathrm{~W}$. The general design of the array includes a single diode PV model, a boost converter implementing MPPT, and a buck-boost regulator to achieve an output voltage as close to the connected module capacitor voltage, $95 \mathrm{~V}$, as possible.

\subsection{PHOTOVOLTAIC ARRAY DESIGN}

In order to model the photovoltaic array component of the system, it is important to choose a simplified model that accurately recreates the dynamics of a PV array while minimizing simulation-processing demands. While the PV model is helpful for validating the operation of the ESS, it is not the focus of the research study and a high fidelity detailed model is not required. The 
output power of a PV array is determined via inputs of temperature and irradiance, but for simplification, temperature is maintained at an ideal $25^{\circ} \mathrm{C}$ and only the irradiance levels are varied. Increased temperature can degrade the performance of the PV, limiting its potential output, but an additional layer of output variability does not improve the efficacy of this study. Irradiance levels directly affect the output power of the modules and/or arrays. Two different models were preliminarily chosen for investigation: a detailed single diode Matlab model and an approximated 4-level piecewise linear model published by Sandia National Labs. Both models adequately allow for the variation of irradiance, however, the Matlab model utilizes an exhaustive database of actual manufacturer module/cell performance data, which helps to strengthen the validity of the model's performance relative to a real installation. Therefore, the Matlab PV array model was chosen for this research. The general structure of the PV module uses the single diode model, which utilizes a controllable current source, a diode, a shunt resistor, and a series resistor as shown in Figure 23.

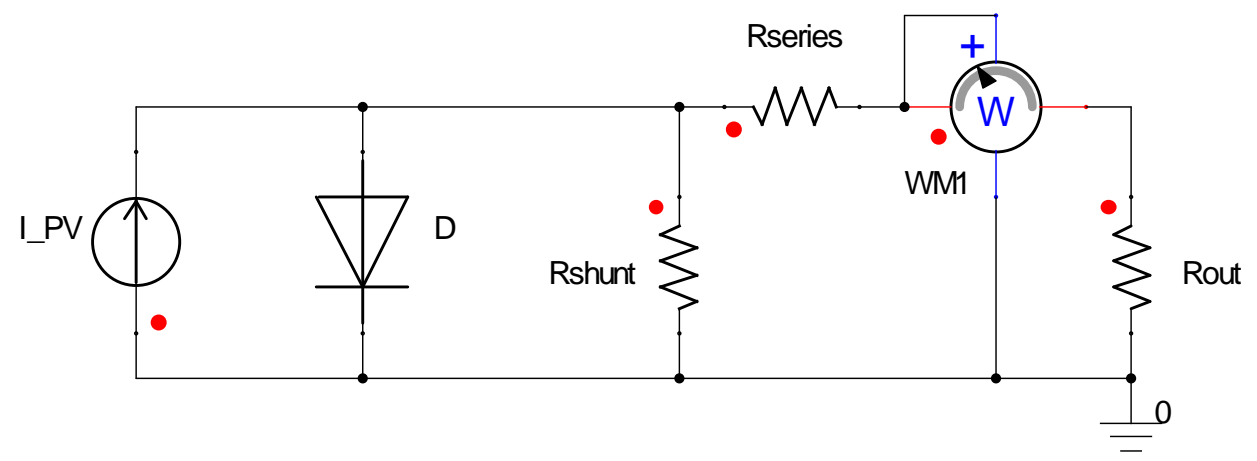

Figure 23. Single Diode PV Array Model

The current source shown in the single diode model is controlled by a mathematical relationship dependent upon irradiance and temperature (36), shown in Figure 24 in block form. 


$$
I_{L}=\frac{S}{S_{\text {ref }}}\left(I_{\text {Lref }}+\alpha_{i s c}\left(T_{\text {cellK }}-T_{\text {refK }}\right)\right)
$$

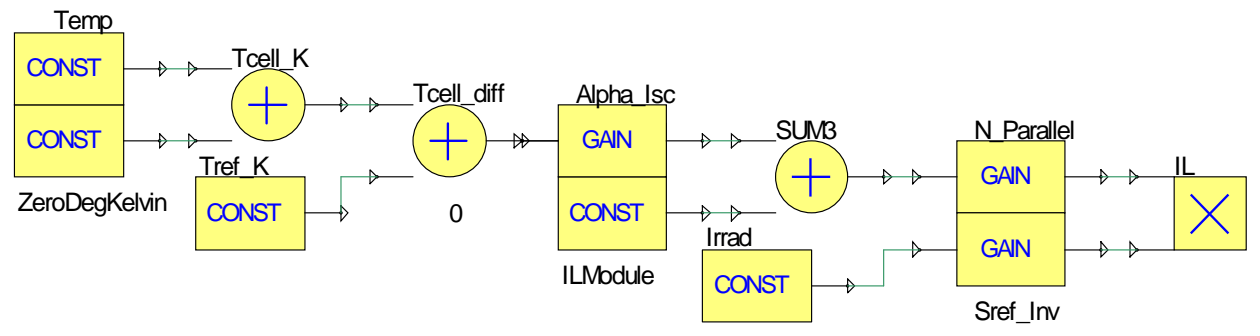

Figure 24. Calculation of PV Array Current Source Value using Temperature, Irradiance, and Module Current

The Matlab single model was recreated in Simplorer in order to integrate directly into the TMMC model. Once the proper current, voltage, and power ratings were established for the PV array, the current-voltage (IV) and power-voltage (PV) curves for the array were compared between Matlab and Simplorer in order to verify proper operation of the recreated model. The single diode in the model was set to operate in exponential mode, with the saturation current component taken from the Matlab data and the thermal voltage parameter calculated using the data along the allotted number of series cells of the array. In order to more closely match output data between the two simulation software, the diode ideality factor was adjusted until satisfactory results were achieved in Simplorer. The diode within the PV array model uses equation (37) in order to determine the current that it passes through it. To solve this equation, the thermal voltage must be calculated using (38) several of the parameters that comprise the PV array, summarized in Table 8.

$$
I_{d}=I_{O}\left[e^{\frac{V_{d}}{V_{T}}}-1\right]
$$




$$
V_{T}=\frac{k T}{q} * n I * N \text { cell }=\frac{\left(1.3806 * 10^{-23}\right)(298.15)}{1.6022 * 10^{-19}} * 0.97 * 80=1.9936 \mathrm{~V}
$$

where $I_{d}=$ diode current $(A)$

$V_{d}=$ diode voltage $(V)$

$I_{O}=$ diode saturation current $(A)$

$n I=$ diode ideality factor, ideally 1, but ranges from $1-2$

$k=$ Boltzman constant $=1.3806 * 10^{-23} \mathrm{~J} * K^{-1}$

$q=$ electron charge $=1.6022 * 10^{-19} \mathrm{C}$

$T=$ cell temperature $(K)$

Ncells $=$ number of cells connected in series in a module

Table 8. PV Array Parameter Specifications

\begin{tabular}{|c|c|}
\hline Parameter & Value \\
\hline Number of Parallel Strings & 5 \\
\hline Number of Series Modules per String & 1 \\
\hline Number of Cells per Module & 80 \\
\hline Open Circuit Voltage (Voc) & $51.5 \mathrm{~V}$ \\
\hline Short Circuit Current (Isc) & $47 \mathrm{~A}$ \\
\hline Light-Generated Current (IL) & $9.4447 \mathrm{~A}$ \\
\hline Diode Saturation Current (Io) & $3.2328 \mathrm{e}-10 \mathrm{~A}$ \\
\hline Diode Ideality Factor (nl) & 0.97 \\
\hline Shunt Resistance $\left(\mathbf{R}_{\mathrm{sh}}\right)$ & $47.9694 \Omega$ \\
\hline Series Resistance $\left(R_{s}\right)$ & $0.22828 \Omega$ \\
\hline Irradiance & $0-1000 \mathrm{~W} / \mathrm{m}^{2}$ \\
\hline Temperature & $25^{\circ} \mathrm{C}(298.15 \mathrm{~K})$ \\
\hline
\end{tabular}

For the proper recreation of the IV and power curves for the array, the module was evaluated with an ideal load resistor of varying resistance from 0 ohms to a maximum value set by an IV value near open circuit voltage (39). The impedance swing shown in Figure 25 causes the PV array to generate the full IV and PV performance curves. 


$$
R_{\text {loadmax }}=\frac{\sim V_{O C}}{\sim I_{O C}}=\frac{50.92}{0.9655}=52.74 \Omega
$$

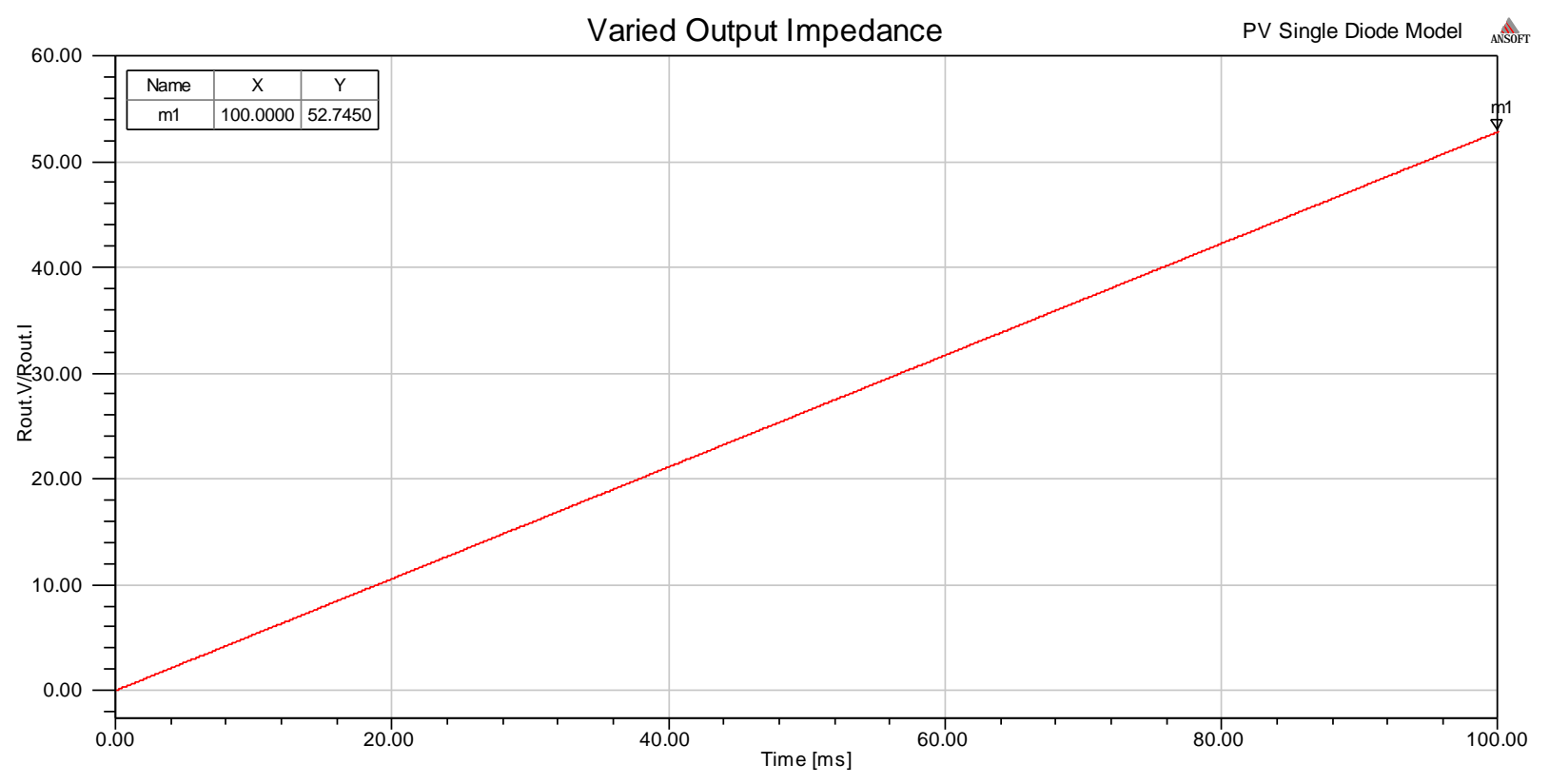

Figure 25. Varied Output Resistive Impedance for Creating IV and PV Curves

Next, a sweep of irradiance values from $100 \mathrm{~W} / \mathrm{m}^{2}$ to $1000 \mathrm{~W} / \mathrm{m}^{2}$ is performed in order to gain a better understanding of how it affects the performance of the PV Array as shown by the IV and PV curves in Figure 26 and Figure 27. The top most curves represent the $1000 \mathrm{~W} / \mathrm{m}^{2}$ input and as the irradiance is decreased, a steady drop in power and short circuit current is evident with a lesser impact in terms of a dropping open circuit voltage. The PV curve is a very useful reference for PV simulation testing; the maximum power points marked on this graph for each irradiance curve are used to fact check PV generation outputs in simulation efforts. Additionally, the series and shunt resistances of the PV array can be directly related to the slopes of the IV curve. The 
series resistor relates to the pseudo horizontal component of the curve, and the shunt resistor relates to the pseudo vertical component of the curve.

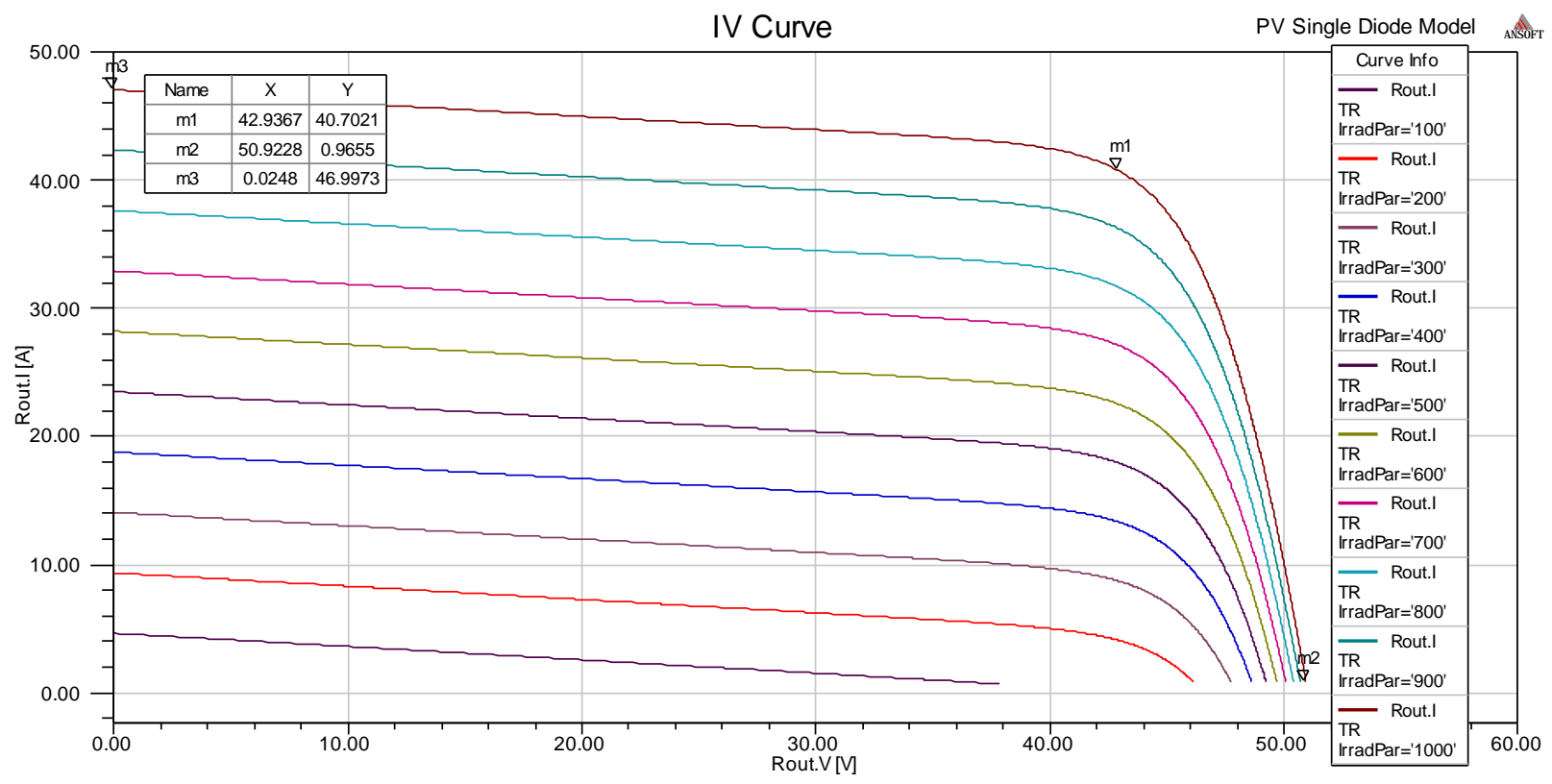

Figure 26. IV Curves with Parametric Sweep of Irradiances $\left(0-1000 \mathrm{~W} / \mathrm{m}^{2}\right)$

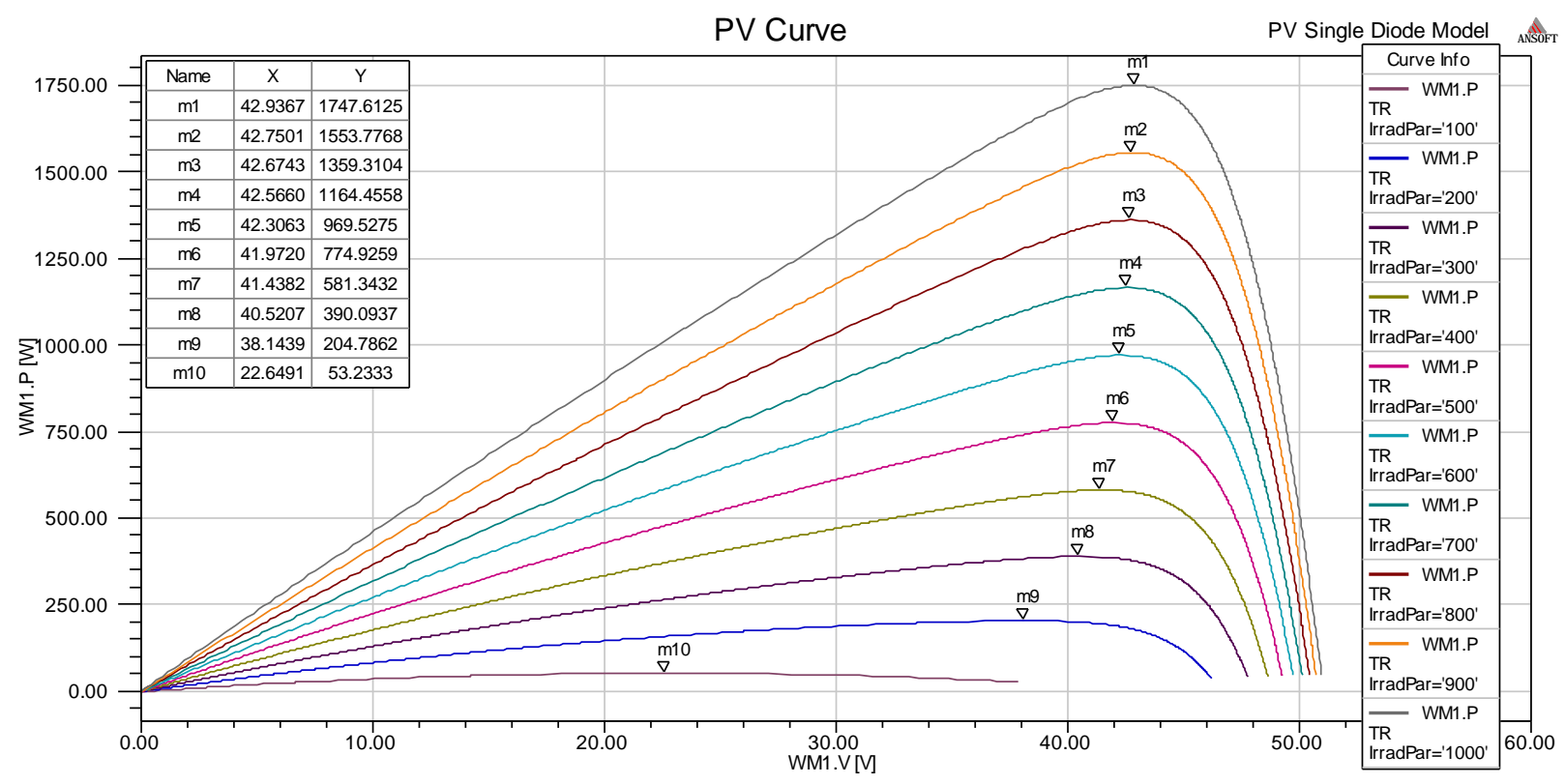

Figure 27. PV Curves with Parametric Sweep of Irradiances (0-1000 W/m²) 


\subsection{MAXIMUM POWER POINT TRACKING}

To ensure that the maximum power was extracted from the PV array, an MPPT algorithm needs to be selected and implemented using an additional interfacing converter. MPPT algorithms utilize these converters to adjust the output impedance seen by the PV array, and in turn, adjust the array’s operating point along the IV and PV curves. There are several types of MPPT algorithms, primarily broken into two different categories: direct and indirect methods.

\subsubsection{Direct Methods}

Direct methods dynamically adjust the operating point of the PV array by comparing a specific measurement of voltage, current, and/or power with its previous measurement, and then adjusting the attached converter's duty cycle accordingly. With a dynamic approach to MPPT, direct methods are able to adequately adapt for changing conditions of irradiance and temperature and still acquire the desired operating region with a high degree of accuracy. Three types of direct methods were explored: Perturb and Observe (P\&O), Incremental Conductance (IC), and Ripple Correlation Control (RCC).

\subsubsection{Perturb and Observe}

Perturb and observe is one of the simplest and most commonly used MPPT algorithms for its ease of implementation. This method looks at the measurements of power and voltage to determine the operating point on the PV curve. First, a power reading is taken and compared to the previous value. Based on these results, the operating point could still be to the left or to the right of the maximum power point, so a voltage reading is also taken and compared to its previous value. So 
for instance, if the power difference is negative, the operating point could be moving left when left of the maximum power point, or moving right to the right of the maximum power point. The voltage difference then clarifies whether we are looking at the right or left slopes of the PV curve. If operating to the left of the maximum power point, the duty cycle is increased to raise the voltage and subsequently the operating point towards the maximum power point. Conversely, if operating to the right of the maximum power point, the duty cycle is decreased to lower the voltage and subsequently the operating point towards the maximum power point. One downside to this method relates to its need to determine where it is on the PV curve each iteration. With rapid fluctuations in irradiation levels on the PV array, it may struggle to converge quickly due to comparing a present value on a new PV curve with a previous value from the old curve [36]. This algorithm is visually reinforced with the flow chart in Figure 28.

\subsubsection{Incremental Conductance}

Incremental conductance is also widely adopted by industry and similarly uses collected data of current and previous power and voltage measurements. This method determines the slope on which the operating point lies. If the slope is positive, the duty cycle is increased to raise the voltage and output power; and conversely, if the slope is negative, the duty cycle is decreased to lower the voltage and raise the output power. Ideally, the algorithm strives to achieve a slope of zero, which indicates that the maximum power point has been reached. Some of the same issues from $\mathrm{P} \& \mathrm{O}$ are shared with IC, although to a lesser extent, in the presence of a fast changing solar irradiance [36]. A flow chart of this algorithm can be found in Figure 29. 


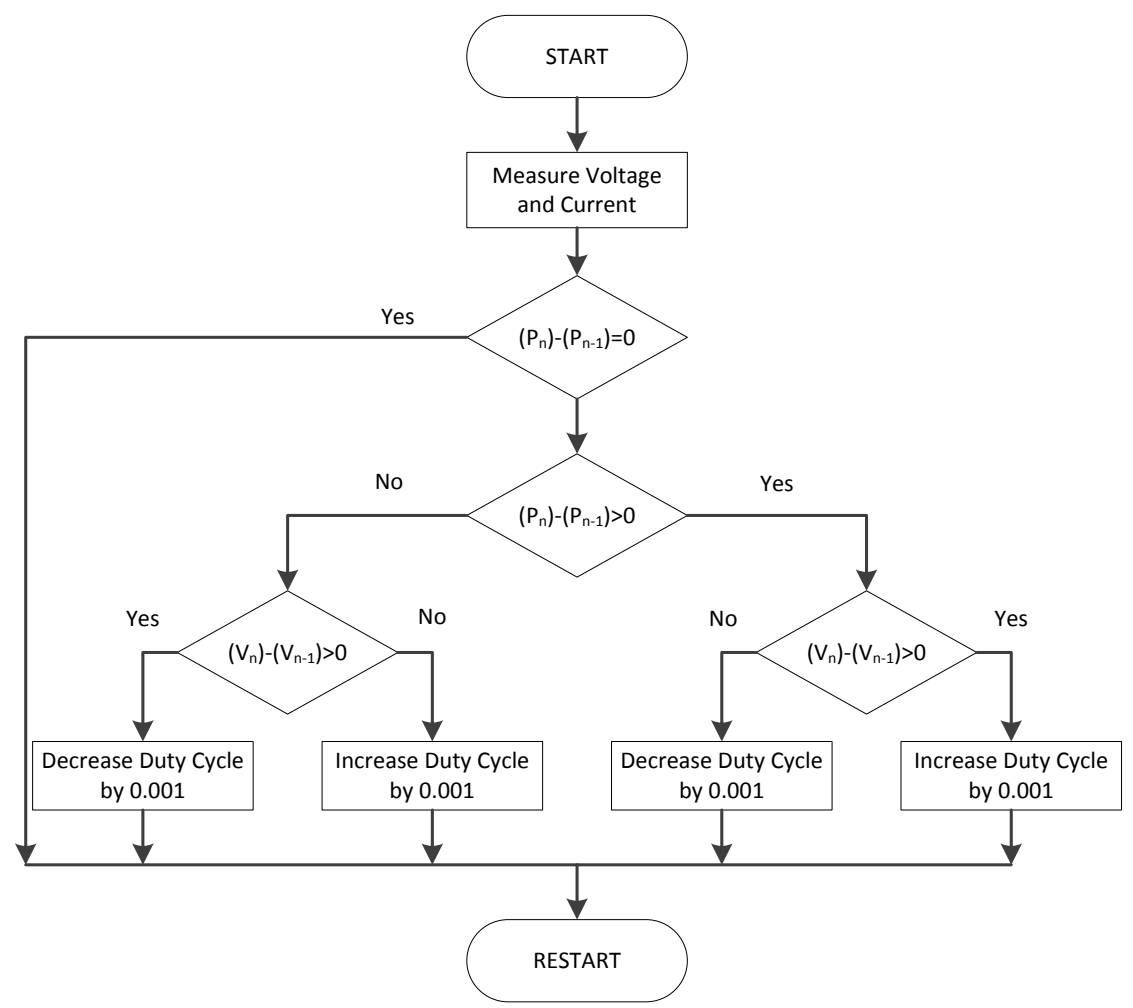

Figure 28. Perturb and Observe Algorithm

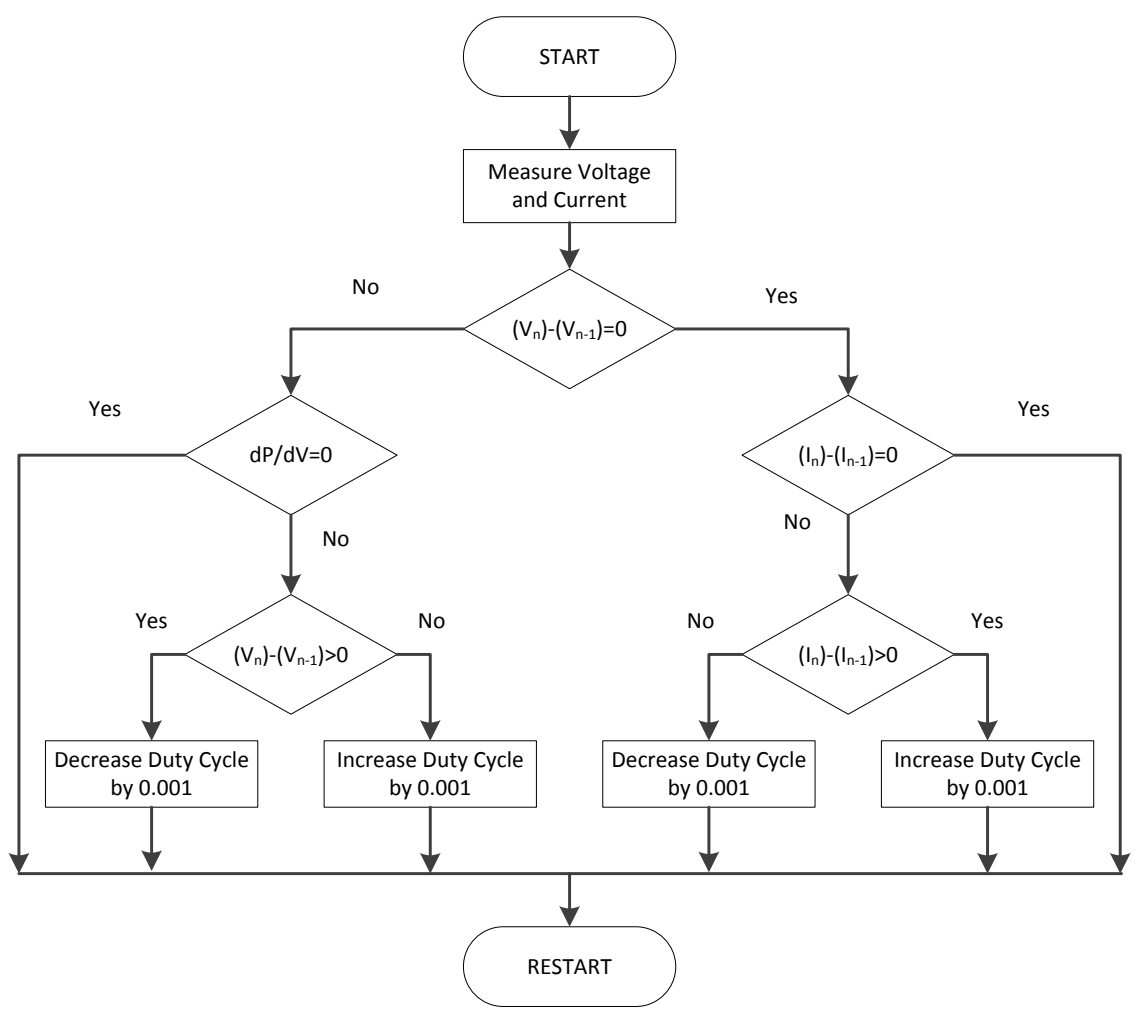

Figure 29. Incremental Conductance Algorithm 


\subsubsection{Ripple Correlation Control}

Ripple correlation control is a slightly more complicated and less adopted method of MPPT; however, it is the most robust of the three methods discussed so far. This method dynamically calculates the duty cycle necessary to achieve the maximum power point by analyzing the inherent switching ripple induced by the boost converter. By evaluating the derivative of power and voltage with respect to time, the algorithm is able to determine where the operating point sits on the PV curve. These derivate values are then plugged into a dedicated control loop in order to calculate a new duty cycle that converges at the maximum power point. The complex nature of the algorithm is what prevents this method from being widely adopted. While it accounts and mitigates some of the issues present with $\mathrm{P} \& \mathrm{O}$ and IC, these benefits do not outweigh the added complexity, and RCC is not considered for this research’s implementation of MPPT [36].

\subsubsection{Indirect Methods}

Indirect methods establish set conditions for achieving maximum output power and do not dynamically chase after the maximum power point in the presence of changing system conditions, such as temperature and irradiance. However, for simple testing of PV near a design operating irradiance and temperature point, they work sufficiently well. Two types of indirect methods are the fractional open circuit voltage and fractional short circuit current methods. They establish a certain ratio relating either the open circuit voltage or the short circuit current to the maximum power point. For instance, if the established fractional setting were 95\%, the maximum power point for the fractional short circuit current method, would be at 95\% of the PV array’s short circuit current. These methods were not considered since the research conditions utilizes a changing irradiance term, effectively breaking the usefulness of these fractional settings [36]. 


\subsection{BOOST CONVERTER DESIGN}

While both the P\&O and IC algorithms are promising, for the simplicity of implementation, the P\&O algorithm was chosen. A boost converter was affixed to the PV's output ports having its duty cycle regulated by the $\mathrm{P} \& \mathrm{O}$ algorithm to accommodate for the optimal operating point of the PV array. The algorithm implemented in Simplorer can be seen in Figure 30. For each adjustment of the P\&O, the duty cycle is adjusted by 0.001 .

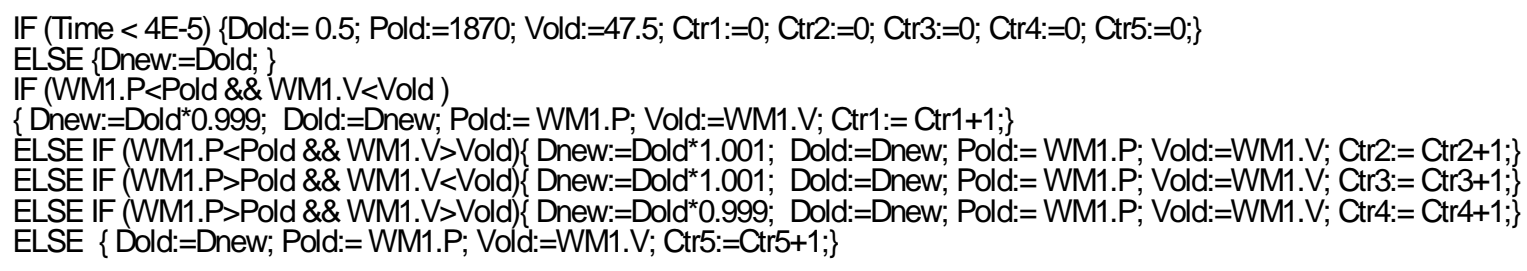

Figure 30. P\&O Algorithm Function used in Simplorer

Shown below in Figure 31, the single diode PV array attaches to the boost converter, which implements the MPPT. The boost converter was designed to operate in continuous conduction mode (CCM) with the parameters shown in Table 9.

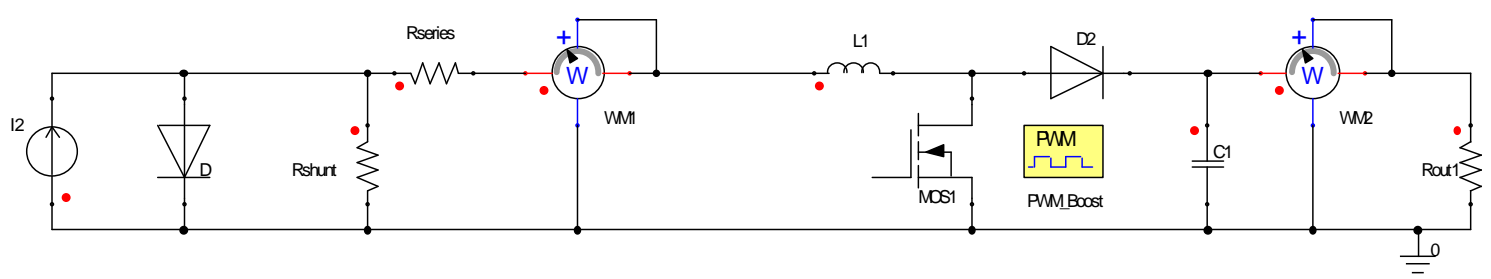

Figure 31. Boost Converter connected to PV Array 
Table 9. Boost Converter Parameters

\begin{tabular}{cc}
\hline Parameter & Value \\
\hline $\mathbf{L}$ & $0.001 \mathrm{H}$ \\
$\mathbf{C}$ & $0.002 \mathrm{~F}$ \\
$\mathbf{f}_{\mathbf{s}}$ & $70 \mathrm{kHz}$ \\
$\mathbf{R}$ & $10 \Omega$ \\
\hline
\end{tabular}

Figure 32 displays the stable voltage output of the PV array - boost converter combined circuit with $1000 \mathrm{~W} / \mathrm{m}^{2}$ irradiance, demonstrating a functional maximum power point tracking algorithm. The duty cycle in Figure 33 achieves steady state around 0.67 providing a very clean output waveform with minimal ripple. The output voltage of the PV array, $42.54 \mathrm{~V}$, matches up closely with that of the PV curve for $1000 \mathrm{~W} / \mathrm{m}^{2}$ 's maximum power point voltage, $42.94 \mathrm{~V}$.

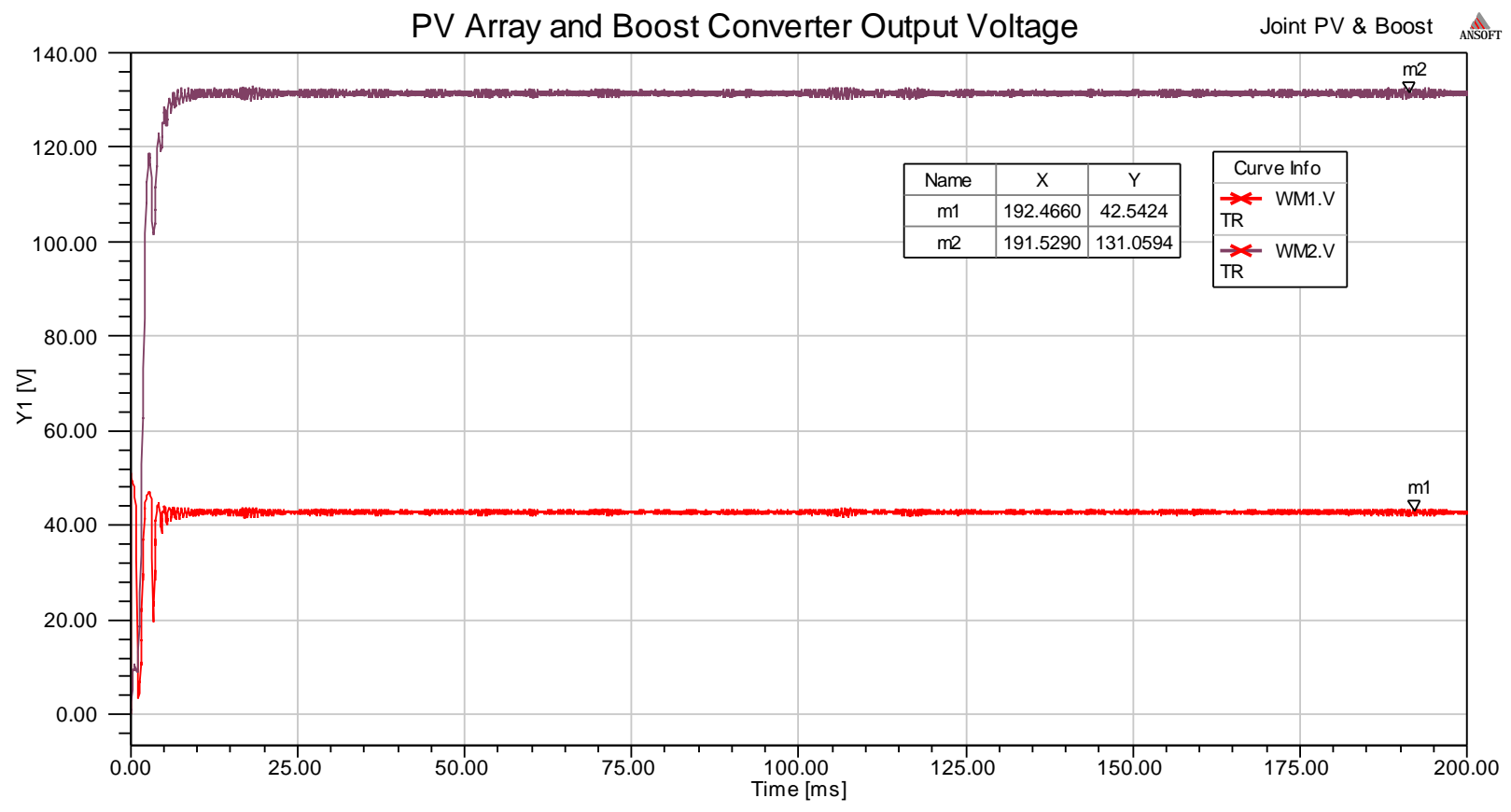

Figure 32. PV Array and Boost Converter Output Voltage 


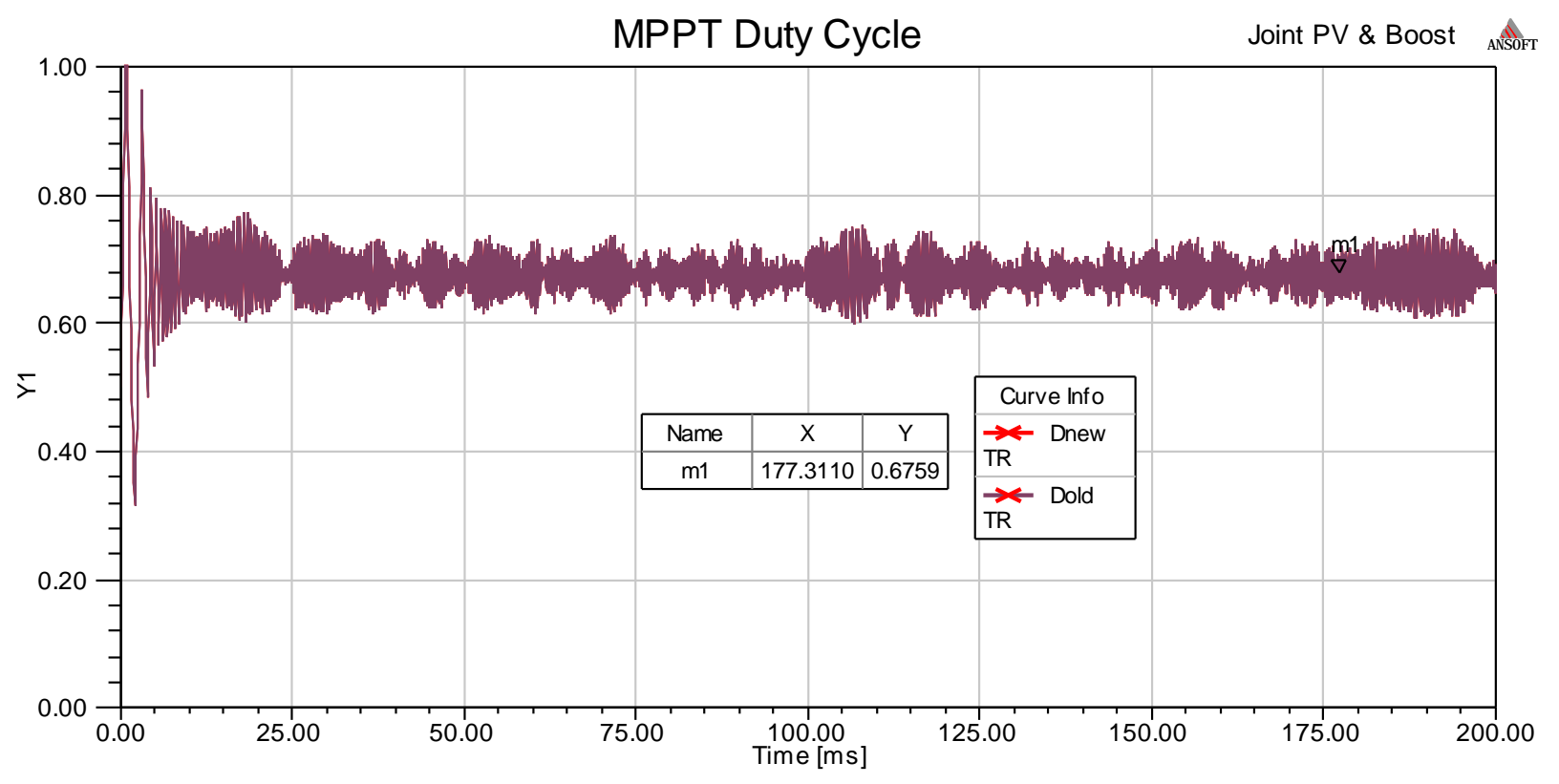

Figure 33. Boost Converter MPPT Duty Cycle

\subsection{BUCK-BOOST REGULATOR DESIGN}

The boost converter and the MPPT algorithm regulate the operation of the PV array, however, it does not take into account the regulation of its output voltage, which varies widely based on the solar irradiance. Therefore, an additional buck-boost regulator is added to the output of the boost converter in order to achieve a consistent and optimal output voltage of $95 \mathrm{~V}$ for the seamless connection to one of the TMMC modules. Similar to the boost converter, the buck-boost regulator was designed to operate in CCM with circuit parameters displayed in Table 10. 
Table 10. Buck-Boost Regulator Parameters

\begin{tabular}{cc}
\hline Parameter & Value \\
\hline $\mathbf{L}$ & $0.01 \mathrm{H}$ \\
$\mathbf{C}$ & $0.0002 \mathrm{~F}$ \\
$\mathbf{f}_{\mathbf{s}}$ & $50 \mathrm{kHz}$ \\
$\mathbf{R}$ & 5.166 \\
\cline { 2 - 2 } & $\frac{1.908 * \text { Irradiance }-169.51}{1747}$ \\
\hline
\end{tabular}

With a tightly regulated output voltage on the buck-boost regulator, it was necessary to vary the resistance on the output resistor relative to the irradiance level to achieve the desired output power levels. At full irradiance $\left(1000 \mathrm{~W} / \mathrm{m}^{2}\right)$, the output resistance was found (40).

$$
R_{\text {Load }}=\frac{V_{\text {out }}^{2}}{P_{\text {out }}}=\frac{95^{2}}{1747}=5.16599 \cong 5.166 \Omega
$$

Output power levels associated with irradiance values other than $1000 \mathrm{~W} / \mathrm{m}^{2}$ are attained by varying the output resistor value. The lower the irradiance value, the higher the output resistance. A plot of the irradiance and maximum power point data in Figure 27 was created as shown in Figure 34 in order to determine how best to adjust this load resistance. Based on this information, it was found that the relationship between irradiance and its respective maximum power point is almost entirely linear per (41) with an $\mathrm{R}^{2}$ value of 0.9995 .

$$
M P P=1.908 * \text { Irradiance }-169.51
$$




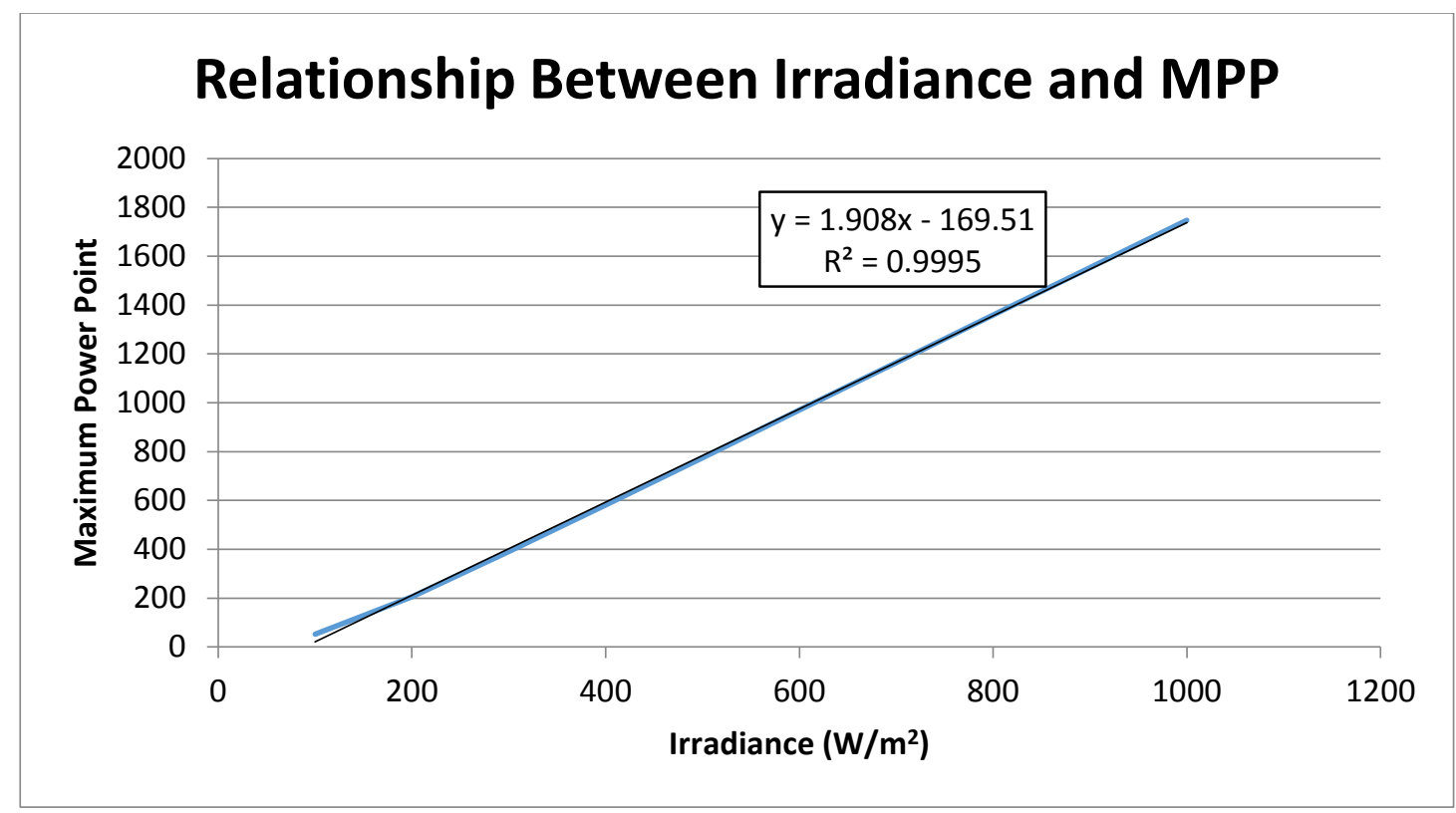

Figure 34. Plot of Irradiance and Maximum Power Points based on PV Curve

This linear relationship (41) is used as an adjustment factor for the output resistor relating the value (40) to the desired output power per operating irradiance levels. The equation for determining the new output resistor value is

$$
R_{\text {load, adjusted }}=\left(\frac{5.166}{\frac{1.908 * \text { Irradiance }-169.51}{1747}}\right)
$$

The actual voltage regulation function is performed using PI control. Since the modules of the TMMC are also buck-boost converters, the same process of determining PI gain values can be used for the regulator. The same settling time (25 ms), damping (0.707), settling time tolerance (2\%) is used for the regulator, keeping the math identical for the initial steps of gain calculation. 
Reusing the same natural frequency for the plant as the TMMC modules, $226.31 \mathrm{rad} / \mathrm{s}$ (15), the $\mathrm{P}$ and I gain terms for the regulator are calculated (43), (44). The duty cycle of the regulator varies anywhere from 0.3 to 0.7 , so an ideal value of 0.5 was selected for gain purposes.

$$
\begin{gathered}
K_{I, p v}=\frac{\omega_{0}^{2} C}{D^{\prime}}=\frac{(226.31)^{2}(0.0002)}{0.5}=\mathbf{2 0 . 4 8 6 5} \\
K_{p, p v}=\frac{2(0.707)(226.31)(0,0002)}{0.5}=\mathbf{0 . 0 6 4}
\end{gathered}
$$

It should be noted that several converters are used within the scope of this research effort. In order to avoid potential converter component resonance between converters with shared switching frequencies, each converter was given a unique switching frequency that was not a multiple or divisible by the others. The only shared switching frequency was between the ultracapacitor converters and the TMMC modules at $20 \mathrm{kHz}$. The full PV system including the PV array, the boost converter, and the buck-boost regulator is shown below in Figure 35. A couple small additions to this cascaded system were added including a DC-link capacitor in between the boost and buck-boost converters, and two additional switches in between the boost and buck-boost converters, to reduce start-up transients at the beginning of simulation. The DC-link capacitor is $0.2 \mathrm{~F}$ and helps to decouple the dynamics between the boost and buck-boost converters. The adjoining switch connects the two circuits at $1 \mathrm{~ms}$, which sufficiently eliminates initial spikes in voltage and current throughout the converter components.

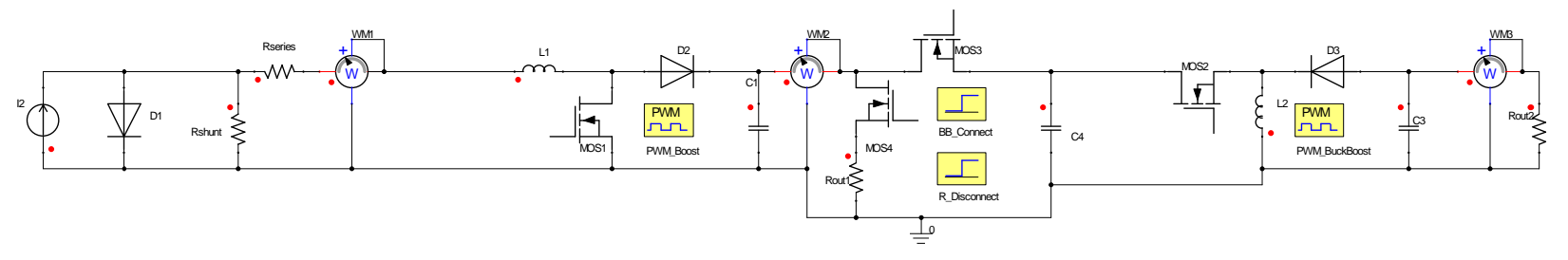

Figure 35. Simplorer PV Array System

Includes PV Array, Boost Converter (w/ MPPT), and Buck-Boost Regulator 


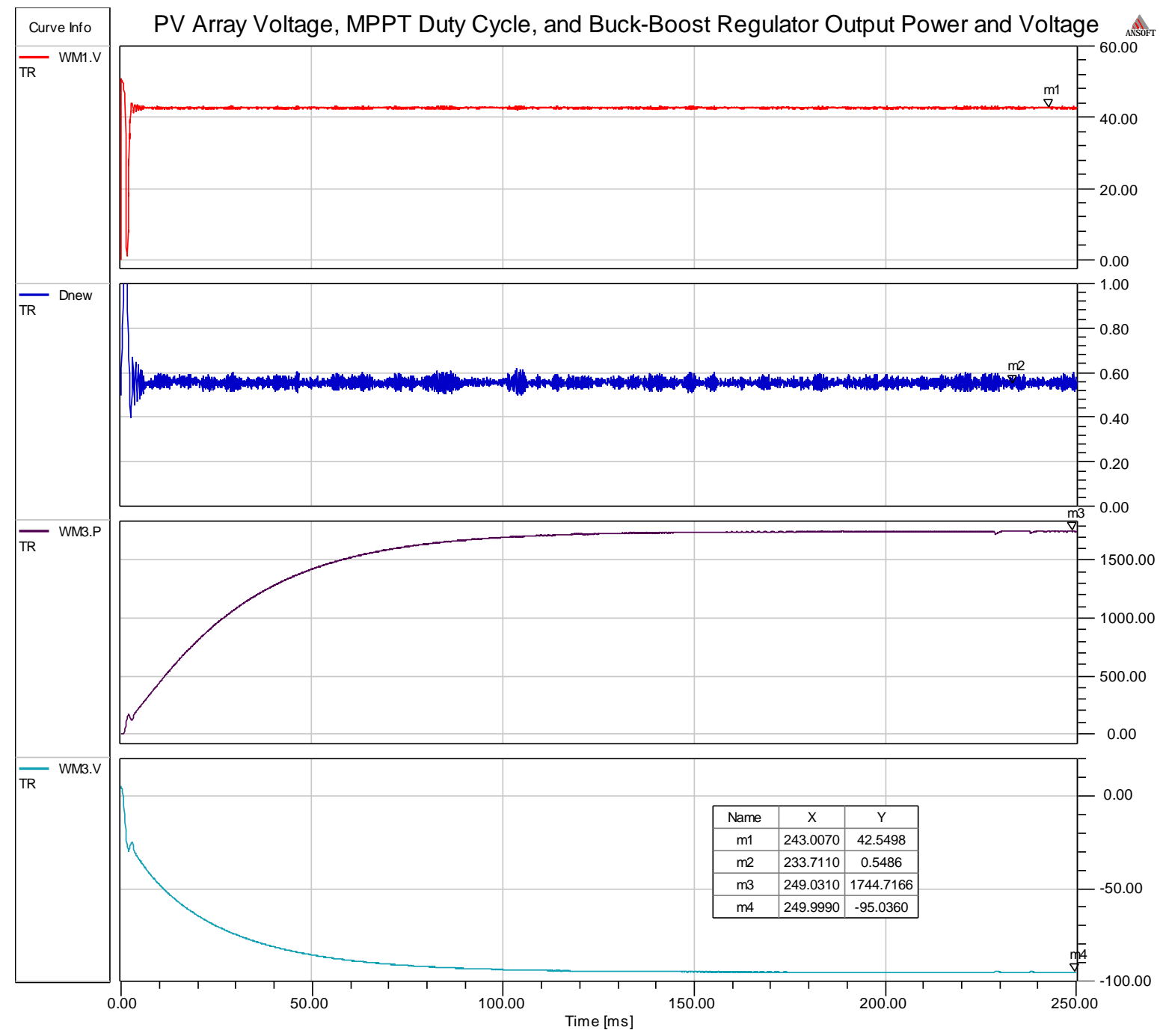

Figure 36. Demonstration of Stability for PV Array System

From Top to Bottom: PV Array Voltage, MPPT Duty Cycle, Regulator Output Power, and Regulator Output Voltage

The results of this joined circuit are shown above in Figure 36 including the PV array voltage, the boost converter duty cycle, output power across the buck-boost regulator load resistor, and voltage across the output terminals of the buck-boost regulator. The PV array voltage helps to verify proper maximum power point operation and is at a desirable $42.55 \mathrm{~V}$ as compared to the ideal maximum power point voltage of $42.94 \mathrm{~V}$. Similarly, the boost converter's duty cycle is also representative of the solid performance of the MPPT algorithm and hovers around 0.55 . With the 
MPPT algorithm functioning properly on the front end, the output power from the buck-boost regulator on the back end achieves $1744.7 \mathrm{~W}$ versus the ideal $1747 \mathrm{~W}$. Lastly, the output voltage of the buck-boost regulator is $-95.04 \mathrm{~V}$, which is very close to the desired $95 \mathrm{~V}$ for a connection to a TMMC module. This voltage magnitude is negative due to the inverting nature of buck-boost converters.

\subsection{INTEGRATION OF PV ARRAY SYSTEM TO TMMC}

Now that the full PV array system is operational achieving the desired power and voltage levels for the test bed, a method of integrating the PV into the TMMC must be developed. Due to some start up transients of the PV system, it initializes separately from the TMMC and ultracapacitors, and switch into the system. This dynamic can also be viewed as generation step change, helping to evaluate the performance of the TMMC and ultracapacitors in handling such a perturbation. Figure 37 shows the full PV system with interconnection switches and an LC filter for minimizing the switching ripple when adding the PV to the TMMC.

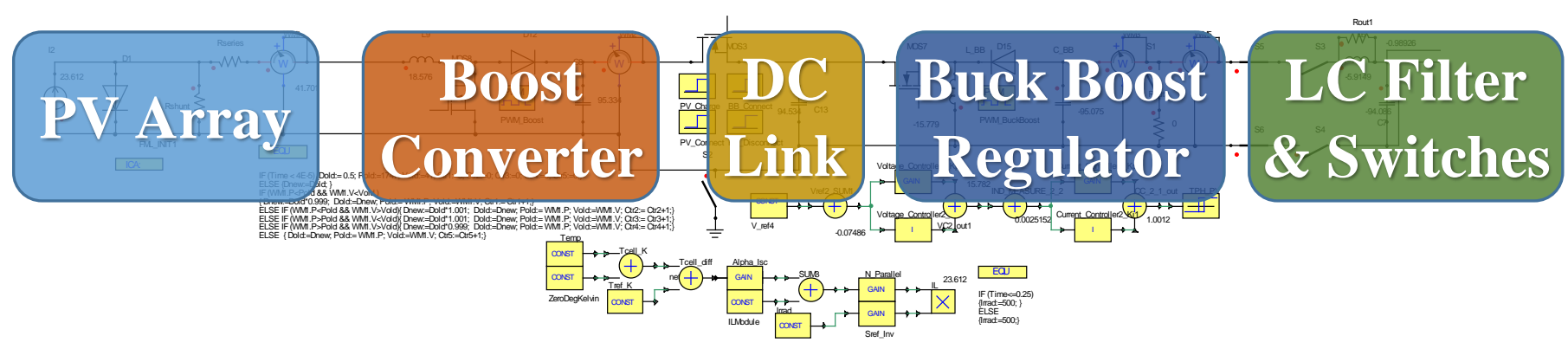

Figure 37. Full PV System with Interconnection Switches and LC filter for Integration into TMMC 
The PV system achieves steady state output levels around $150 \mathrm{~ms}$ at which point, the interconnection switches are turned ON -- connecting the PV system to the bottom-most left TMMC module’s capacitor. An additional set of switches exist to the right of the interconnection switches and exist to remove the PV from the system, simulating a large downward step change in PV output power. To account for the inverted voltage of the buck-boost converter, its positive and negative output leads connect to the negative and positive ports of the module, respectively. The LC low pass filter, blown up in Figure 38, was sized experimentally according to the following equations for cutoff frequency (45) and impedance (46) with parameters summarized in Table 11. An LC filter with inductor of $0.03 \mathrm{H}$ and capacitor of $0.002 \mathrm{~F}$ produced the greatest decrease of current ripple and power delivery.

$$
\begin{gathered}
f_{c}=\frac{1}{2 \pi \sqrt{L_{f} C_{f}}}=\frac{1}{2 \pi \sqrt{(0.03)(0.002)}}=20.547 \mathrm{~Hz} \\
Z=\sqrt{\frac{L_{f}}{C_{f}}}=\sqrt{\frac{0.03}{0.002}}=3.873 \Omega
\end{gathered}
$$

A damping resistor was placed in parallel to the inductor, as described in [37], to further reduce the ripple frequency superimposed on top of the signal buffered by the LC filter. The value of this resistor was also determined experimentally with a sweep of resistor values used with the most promising outcomes resulting from a value of $0.5 \Omega$. Ideally, (47) describes the transfer function related to the output current of the RLC filter.

$$
H_{R L C}(s)=\frac{s L_{f}+R_{d}}{s^{2} R_{d} L_{f} C_{f}+s L_{f}+R_{d}}
$$

where $L_{f}$ is the filter inductor, $C_{f}$ is the filter capacitor, and $R_{d}$ is the damping resistor. 


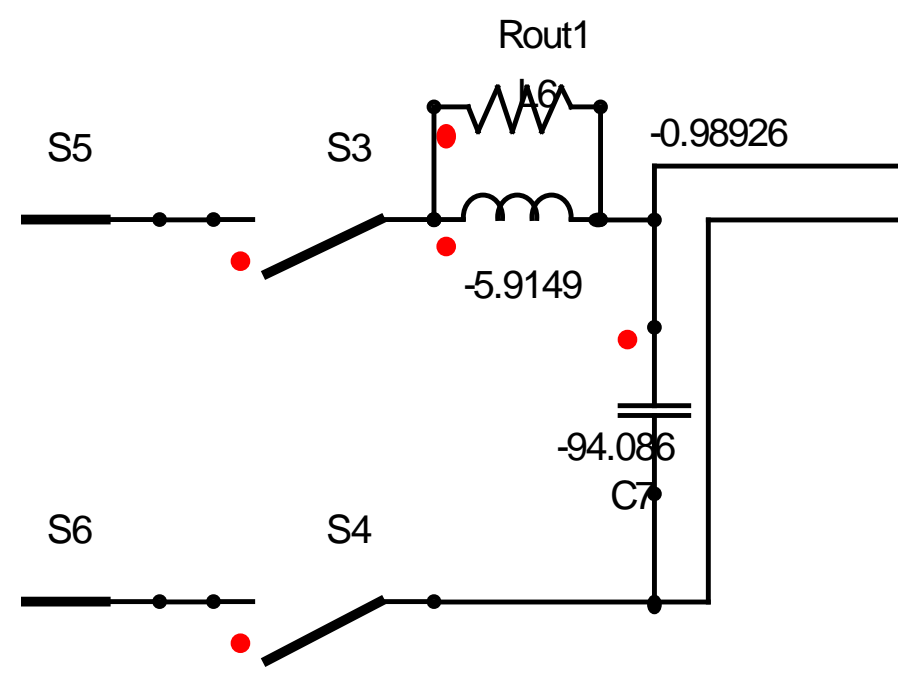

Figure 38. PV Interconnection Switches and LC Filter

Table 11. RLC Filter Parameters

\begin{tabular}{cc}
\hline Parameter & Value \\
\hline $\mathbf{L}_{\mathbf{f}}$ & $0.03 \mathrm{H}$ \\
$\mathbf{C}_{\mathbf{f}}$ & $0.002 \mathrm{~F}$ \\
$\mathbf{R}_{\mathbf{d}}$ & $0.5 \Omega$ \\
\hline
\end{tabular}




\subsection{RESULTS}

With all system parameters functional and interconnected, the performance of the ESS can now be validated in the presence of both load and generation step changes. In order to weaken the connection to the strong "grid" voltage source, an inductor, $0.5 \mathrm{H}$, was placed in between this source and the top row of the TMMC modules. This value was determined experimentally by running a simulation sweep of the three-row step-down TMMC through several values of inductors ranging from $0.0005 \mathrm{H}$ to $0.5 \mathrm{H}$. The inductor value that provided the most critically damped voltage with the least amount of signal ripple across the module capacitor voltages was $0.5 \mathrm{H}$ and therefore it was selected to weaken the grid connection. By weakening the grid connection, larger transients from load and generation step changes can be seen across the converter, allowing for the greatest opportunity to notice potential improvements from the ESS.

Three main test scenarios were simulated in Simplorer, comparing the TMMC output voltage, TMMC module voltages, TMMC output power, grid connection supplied current, and output power from the PV system. Three test cases evaluate the performance of the ESS by stressing the system with a combination of positive and negative step changes for both the PV generation and the output load demand. Each of the three tests on the system is run both without the ESS and with the ESS to determine how it affects the performance of the TMMC. Test systems comprise the TMMC, the PV system, and the ESS (switched in and out for comparison). The three test cases include: 
1. Test One: The irradiance of the PV system is set to $1000 \mathrm{~W} / \mathrm{m}^{2}$ and is switched into the converter at $150 \mathrm{~ms}$. An output load step at $250 \mathrm{~ms}$ doubles the load power demand by halving the resistance from $2.12 \Omega$ to $1.06 \Omega$.

2. Test Two: The irradiance of the PV system stays at $1000 \mathrm{~W} / \mathrm{m}^{2}$ and is still switched into the converter at $150 \mathrm{~ms}$. The output load step at $250 \mathrm{~ms}$ now halves the load power demand by doubling the resistance from $2.12 \Omega$ to $4.24 \Omega$.

3. Test Three: The irradiance of the PV system remains at $1000 \mathrm{~W} / \mathrm{m}^{2}$ initially, and is still switched into the converter at $150 \mathrm{~ms}$. The output load step is not altered for this test. However, the PV irradiance is dropped to $1 \mathrm{~W} / \mathrm{m}^{2}$ and switched out of the system at 250 ms, simulating a drop in power due to a loss in irradiance.

For each of these tests, the simulation runs for $350 \mathrm{~ms}$ with a time step of $1 \mu \mathrm{s}$. This time step is selected to accommodate the range of switching frequencies present throughout the system and to satisfy proper Nyquist Sampling Theorem. Nyquist dictates that the sampling frequency of a sampled system must be twice that of the highest frequency contained in the signal. Therefore, the largest frequency in the system, $70 \mathrm{kHz}$, is used to determine the threshold of a proper sampling frequency, and sampling time step in (48), (49), and (50).

$$
f_{s} \geq 2 f c
$$

where $f_{s}$ is the sampling frequency and $f_{c}$ is the highest frequency value within the system.

$$
\begin{gathered}
f_{s} \geq 2(70,000)=140 \mathrm{kHz} \\
T_{s, \text { max }}=\frac{1}{140000}=7.14 * 10^{-6}=7.14 \mu \mathrm{s}
\end{gathered}
$$


In order to improve the fidelity of the simulation and move away from this threshold time step, a time step for the modeling of $1 \mu s$ was chosen. Table 12 in Appendix A details all of the system parameters. The entire Simplorer model can also be found in Appendix A with Figure 54 and Figure 55.

\subsection{TEST ONE RESULTS - PV AND LOAD STEP UP}

The first test involves the connection of the PV array at full irradiance as well as the increased load (decreased output resistance) by a factor of two. These events should lead to a momentary spike in the TMMC output voltage and power when the PV is added to the system due to additional generation being added to the mix. Also, the increased load should incur a subsequent temporary dip in the output voltage while the system's generation portfolio can supply the load with adequate levels of power, while the output power should see a surge followed by an increased steady state operating point of output power (from around $4 \mathrm{~kW}$ to $8 \mathrm{~kW}$ ) to feed the larger load demand. With regards to the "grid" current, the addition of the PV generation should reduce the amount of current supplied by the grid (proportional to the ratio of PV power to total load power) since the "grid" no longer needs to supply the entirety of the load demand. However, the increased load should bring about a large increase in grid supplied current, proportional to the total in output power minus PV power. The PV power portfolio is a little more sporadic with added dynamics from the multiple converters associated with the PV system. Although, it is expected to steadily charge and be switched into the TMMC at its peak power output level. After being added to the system, its power drops somewhat due to the RLC filter added to the end of the PV system, but it should hold steady and have its power output react similarly to the "grid" current and output load power. 


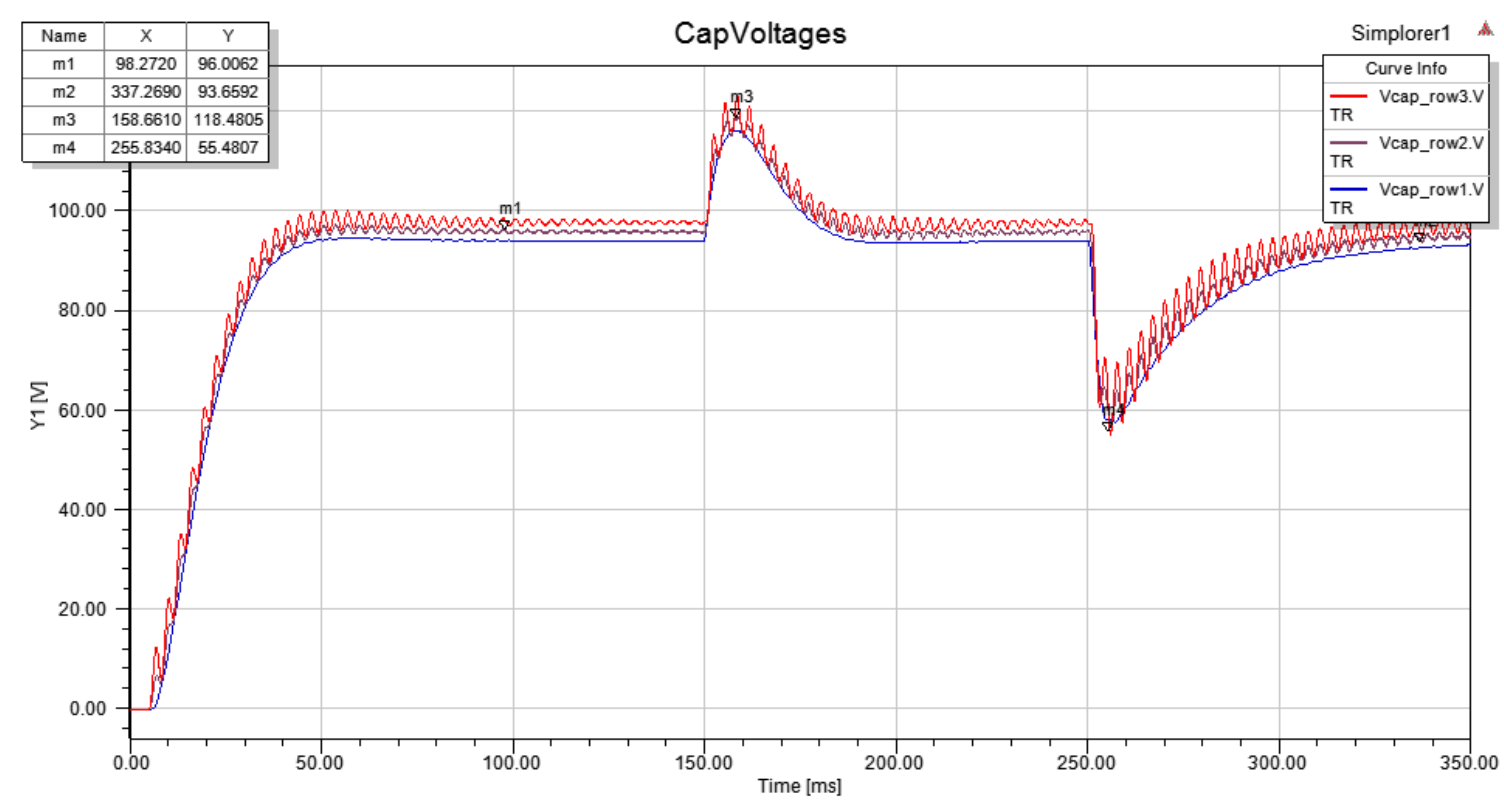

Figure 39. Test One - TMMC Capacitor Voltages - No ESS

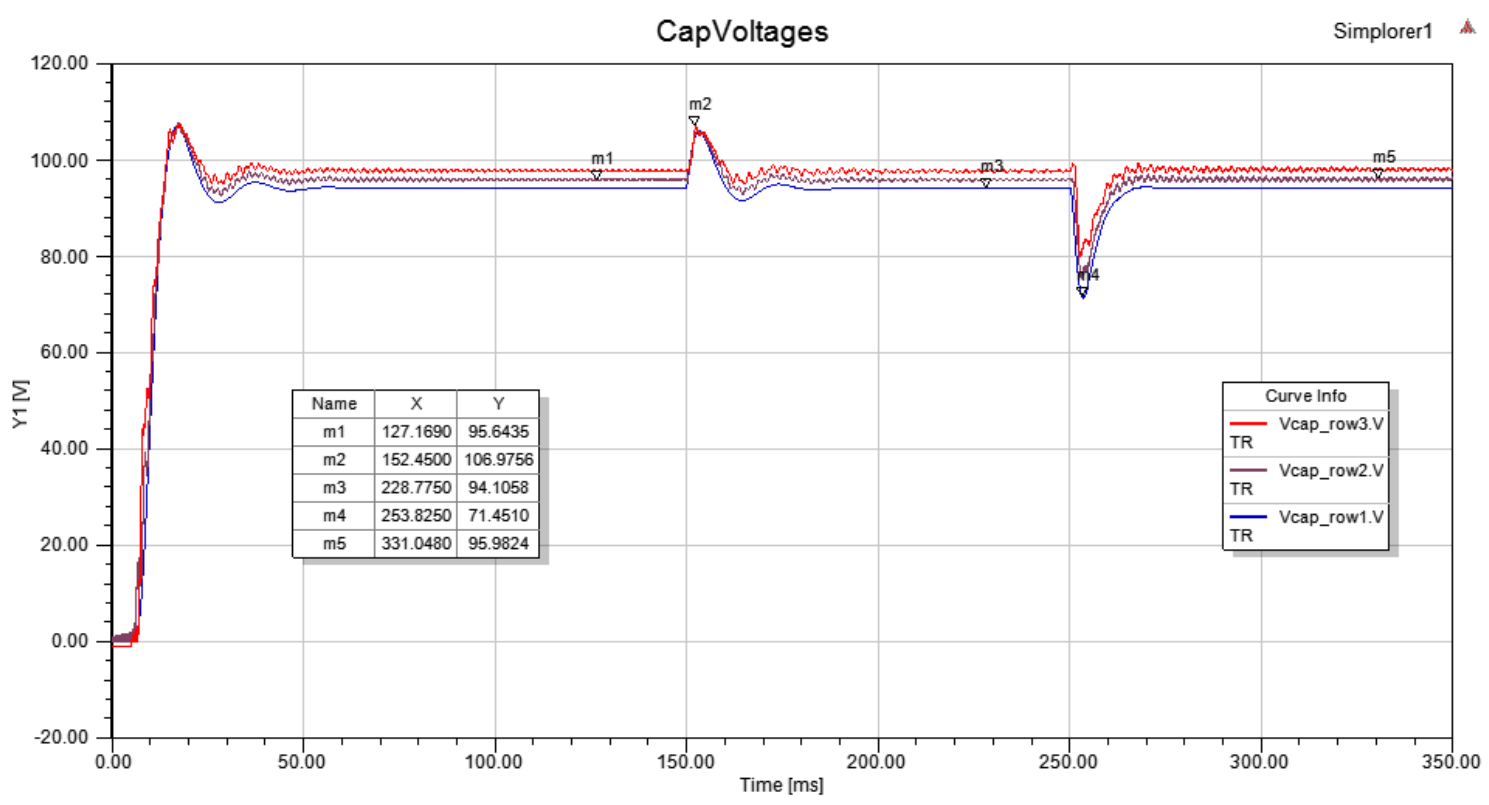

Figure 40. Test One - TMMC Capacitor Voltages - with ESS

Figure 39 and Figure 40 show TMMC capacitor voltages, and the main points of interest are the extreme points of each spike related to the PV connection and load change, respectively. Without the ESS, steady state voltage is around $95 \mathrm{~V}$ averaged between all rows, and the two 
spikes are $118.48 \mathrm{~V}$ and $55.48 \mathrm{~V}$; meanwhile, with the addition of ESS, the spikes are $106.97 \mathrm{~V}$ and $71.45 \mathrm{~V}$. These transient values are reduced by $11.51 \mathrm{~V}(\sim 12 \%$ of steady state voltage) and $15.97 \mathrm{~V}(\sim 17 \%$ of steady state voltage), and reduce the time it takes for the signals to return to their nominal values.

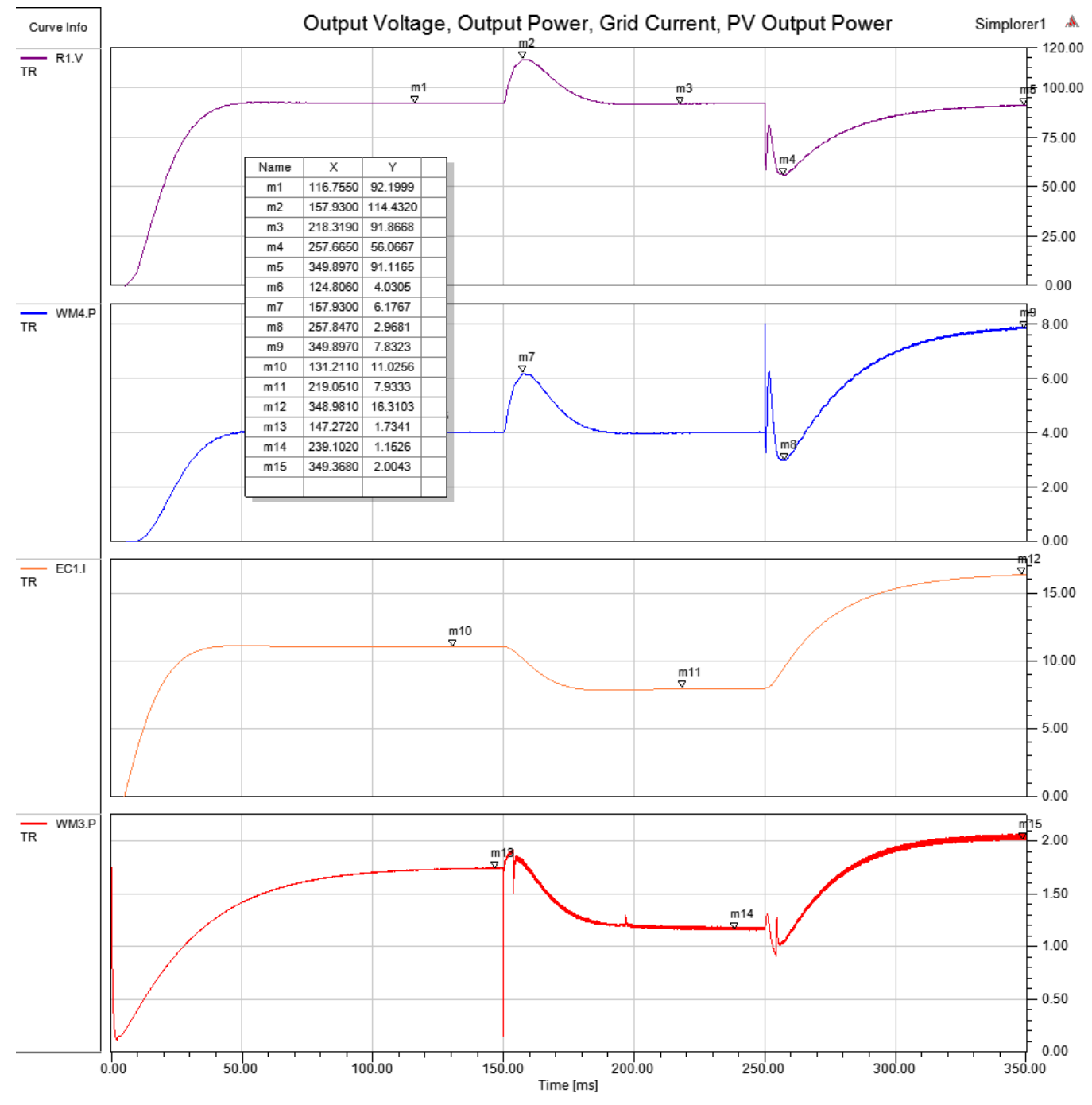

Figure 41. Test One - TMMC Output Voltage and Power, Grid Current, PV Output Power No ESS 


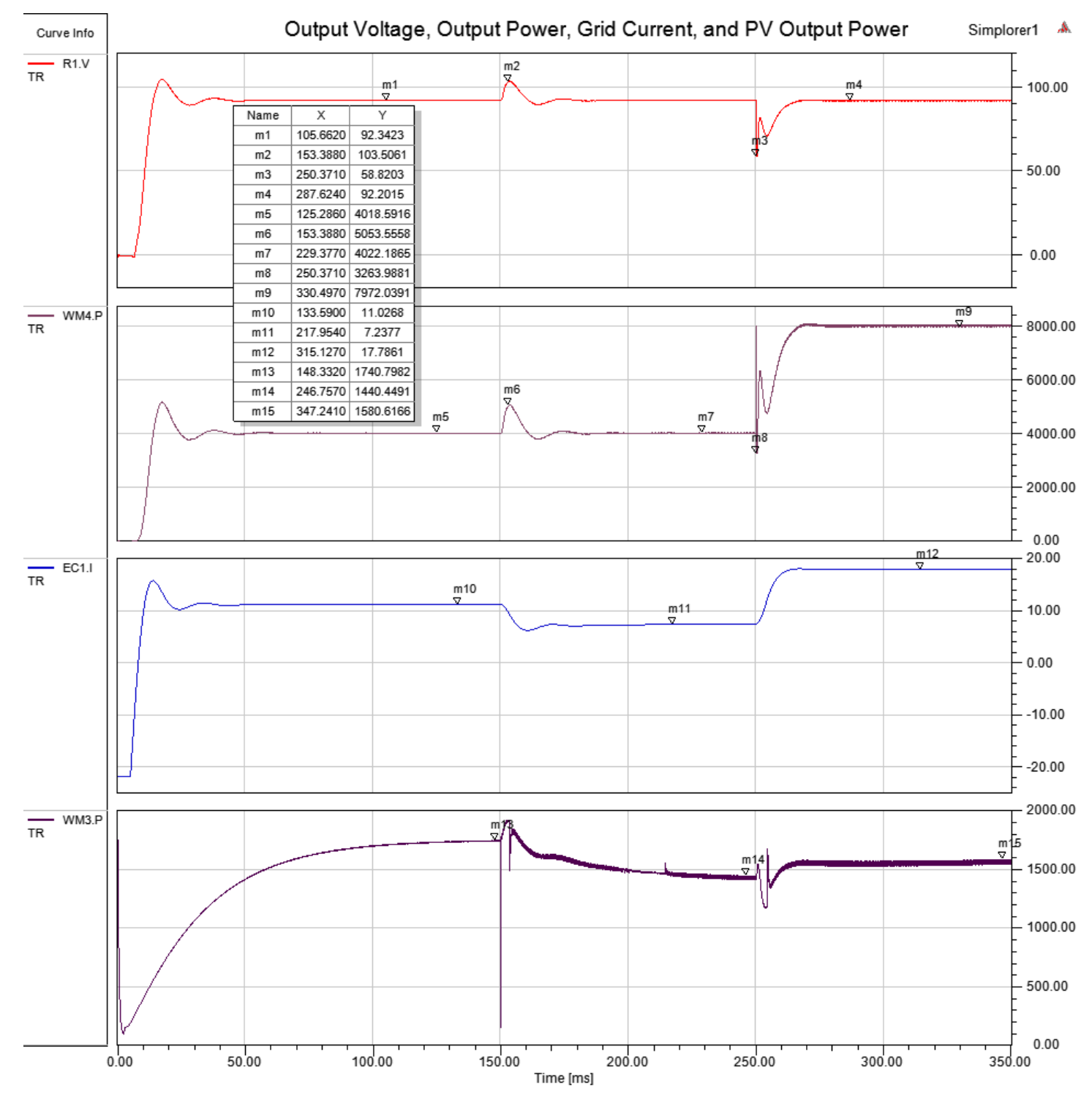

Figure 42. Test One - TMMC Output Voltage and Power, Grid Current, PV Output Power With ESS

The same trends from the capacitor voltages are extended to the output voltage, output power, grid current, and PV power in Figure 41 and Figure 42- transient spikes are less severe with the ESS and recovery times are increased greatly. The biggest recovery time improvement is noticeable after the load change. The ESS system is able to recover within 25 ms, while the nonESS system continues to settle towards steady state after 100ms. Interestingly, the PV power 
without ESS is extended past its designed operating range in terms of maximum power, while the PV with ESS operates within its feasible capabilities. Per load predictions, the output power approximately doubles from $4022 \mathrm{~W}(4030 \mathrm{~W})$ to $7972 \mathrm{~W}$ (7832 W).

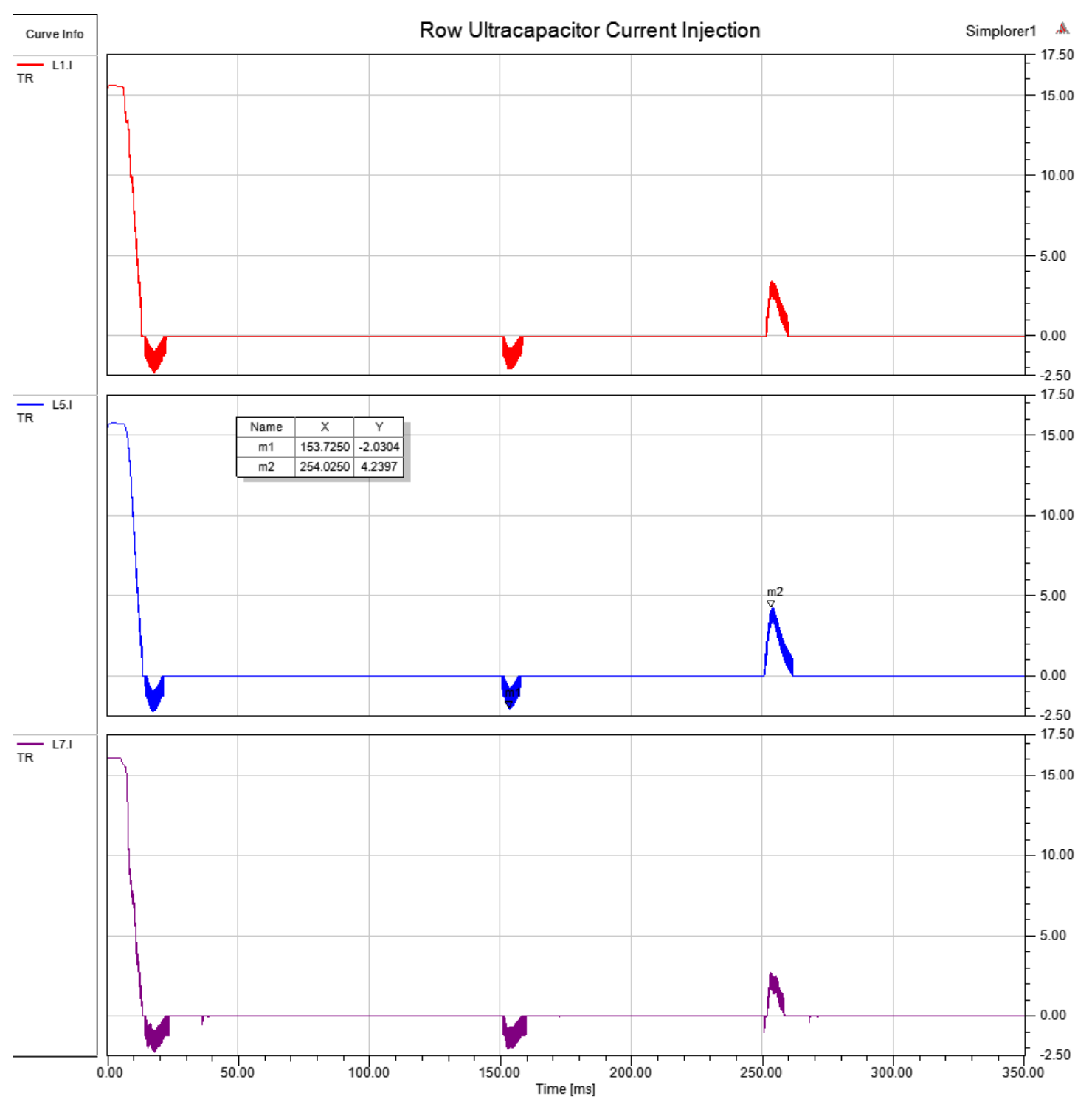

Figure 43. Test One - ESS Row Ultracapacitor Current Injection 
Figure 43 displays the ESS ultracapacitor current injection for each TMMC row designed to mitigate transient events within the converter's operation. Each of the upward and downward current flows demonstrate the ESS respectively either discharging and raising the capacitor voltages, or charging and lowering the voltages. Each of these current flows, directly match up with a transient event in Figure 42.

\subsection{TEST TWO RESULTS - PV AND LOAD STEP DOWN}

Test two similarly has the PV system switched into the system at full irradiance; however, the load is now stepped down by half (output resistance doubled). This load change requires the output load to change power demands from $4 \mathrm{~kW}$ down to $2 \mathrm{~kW}$. This step change causes a spike in voltage across the capacitors and output resistor due to an excess of power flowing into the system as the load demands are decreasing. Moreover, a decrease in power demands from the load requires less

power from both the "grid" connection as well as the PV system, which should both see a downward trend in generation.

Comparing the results from the capacitor voltages in Figure 44 and Figure 45, the same trend of reduced transient spikes in seen in test two. The spike from decreasing the load requirement by half creates a very large spike about $131.80 \mathrm{~V}$ or $136 \%$ of the nominal value. Although with the addition of ESS, the peak reduces to $108.17 \mathrm{~V}$, reducing the transient voltage stress on the system by $23.63 \mathrm{~V}$ or $24.87 \%$ of steady state voltage. The initial spike changes are the same as those recorded in test one. 


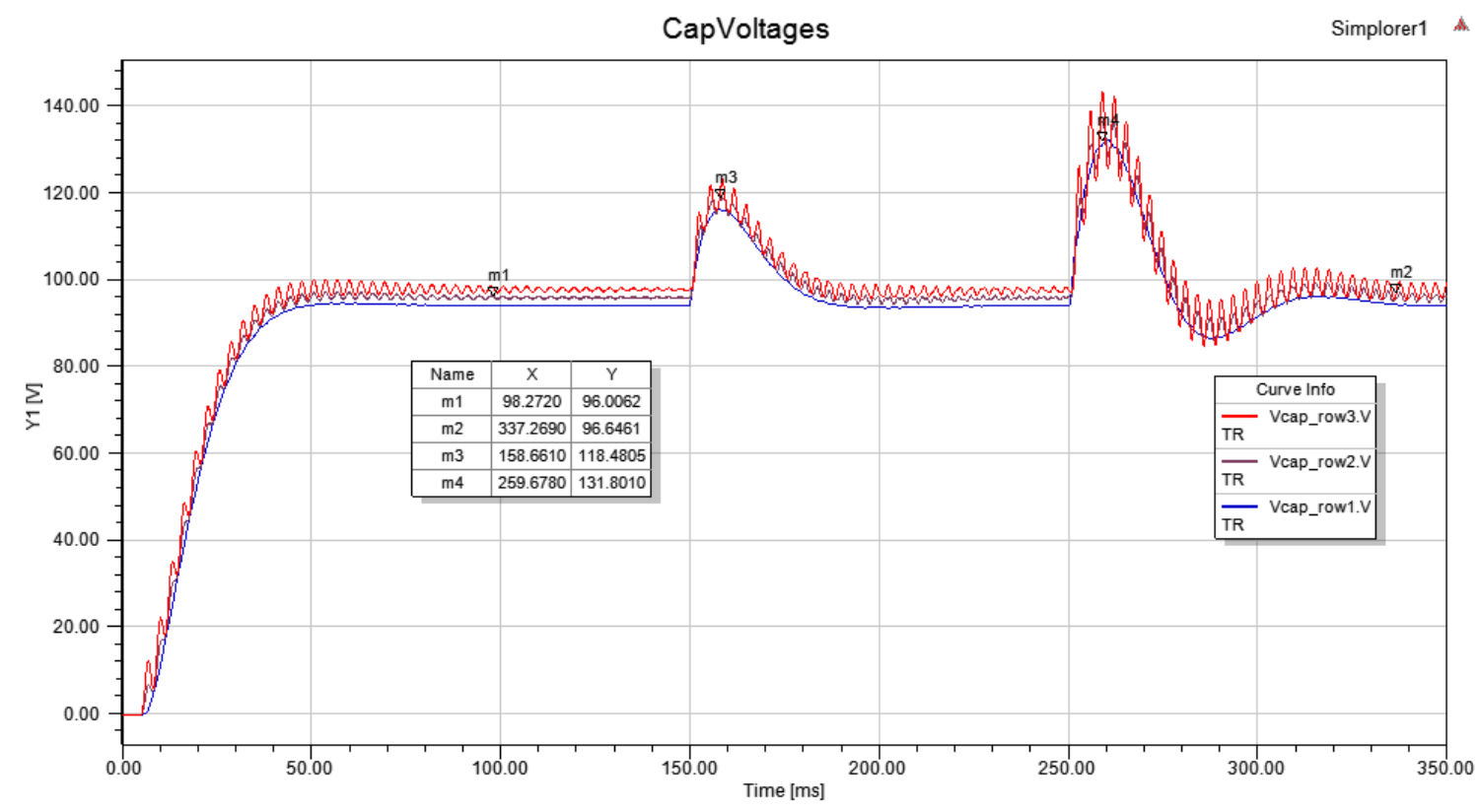

Figure 44. Test Two - TMMC Capacitor Voltages - No ESS

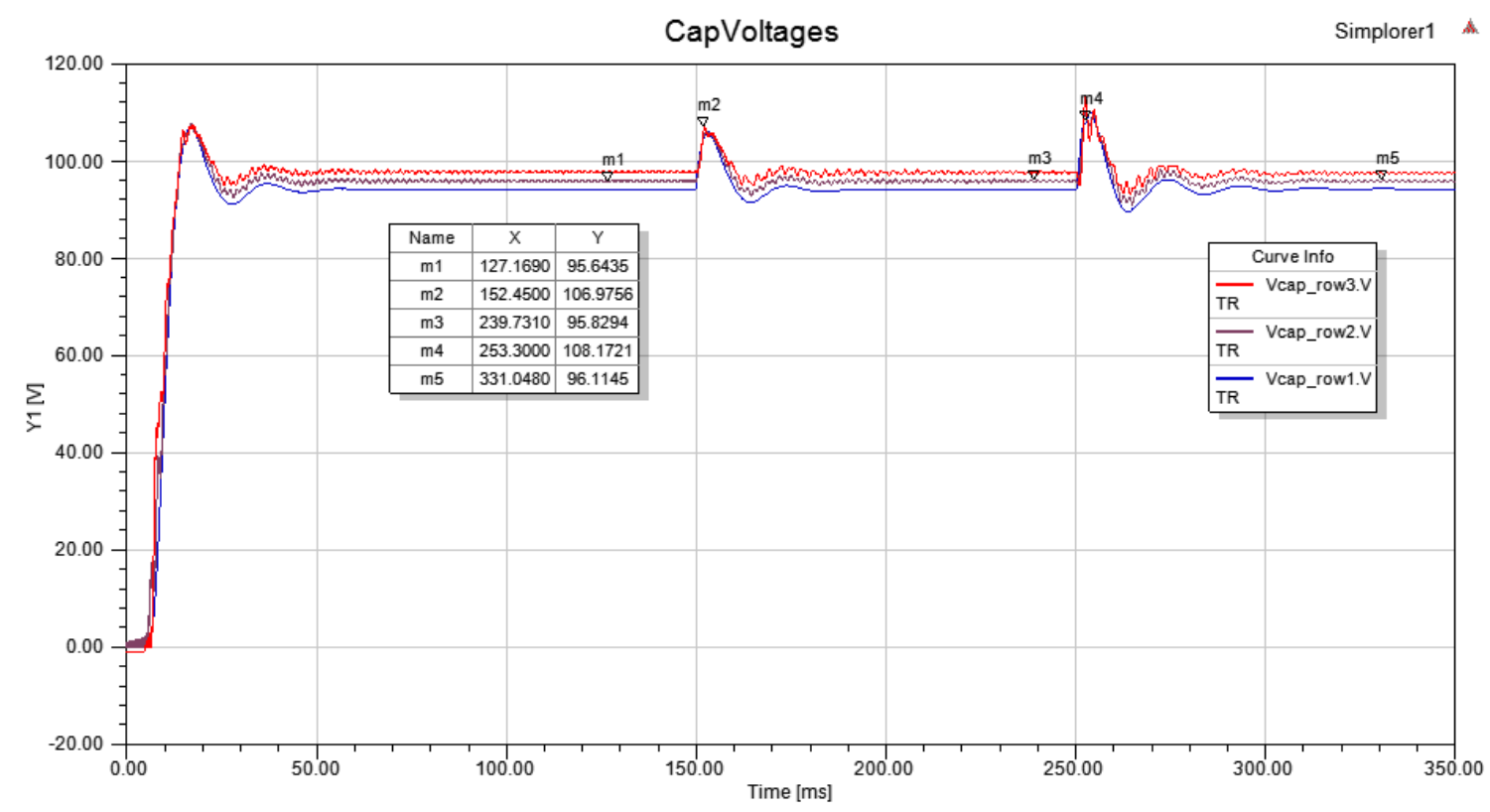

Figure 45. Test Two - TMMC Capacitor Voltages - With ESS 


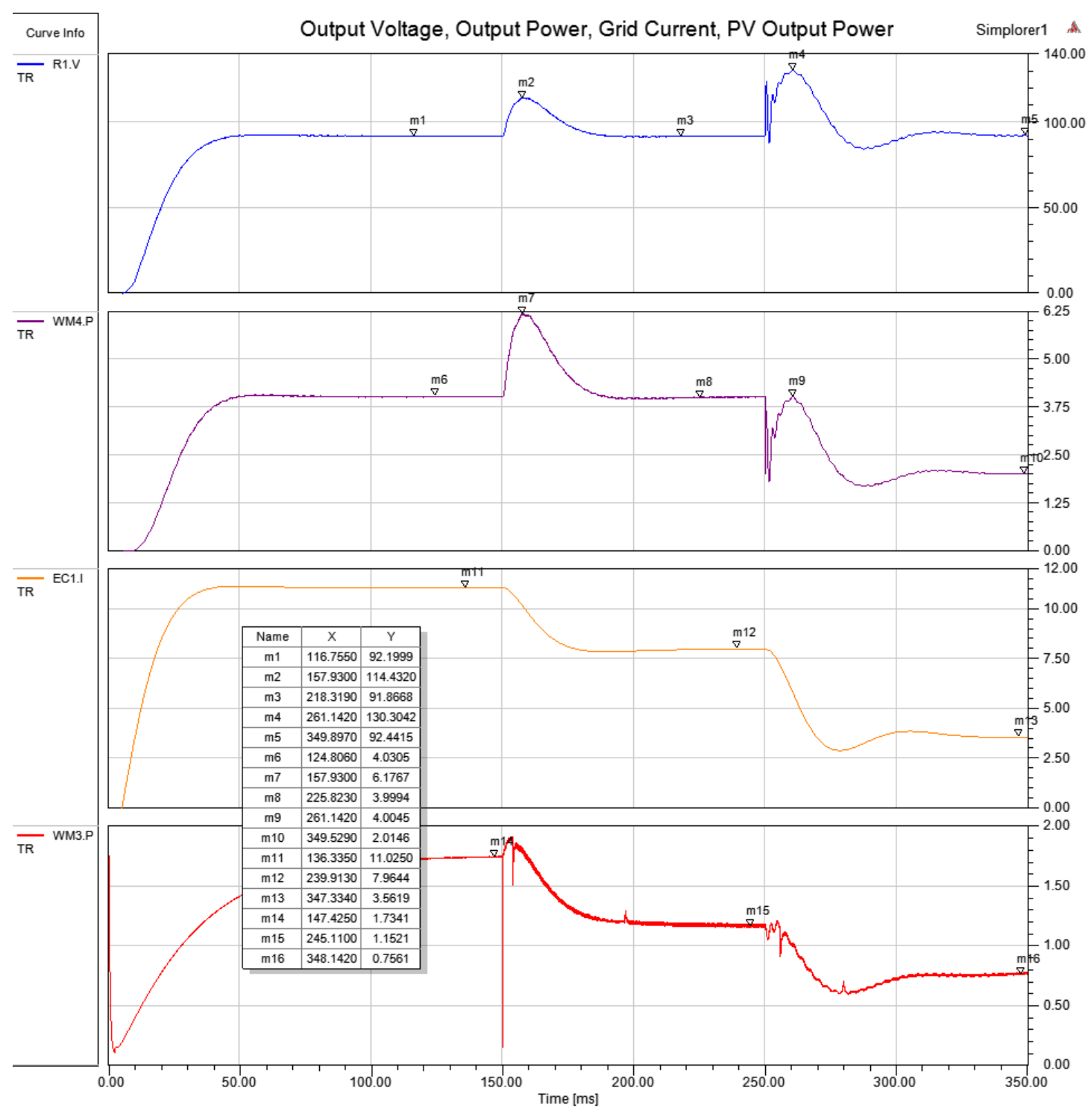

Figure 46. Test Two - TMMC Output Voltage and Power, Grid Current, PV Output Power No ESS

These trends continue when looking at Figure 46 and Figure 47. Voltage and power spikes decrease in magnitude with faster recovery times to new steady state values. As designed, the output power decreases by roughly half from $4028 \mathrm{~W}$ (3999 W) to $2023 \mathrm{~W}$ (2015 W) after the 
output resistance is doubled. Transient recovery times for the non-ESS system is about $100 \mathrm{~ms}$, and fall to around 25 ms when introducing the ultracapacitors.

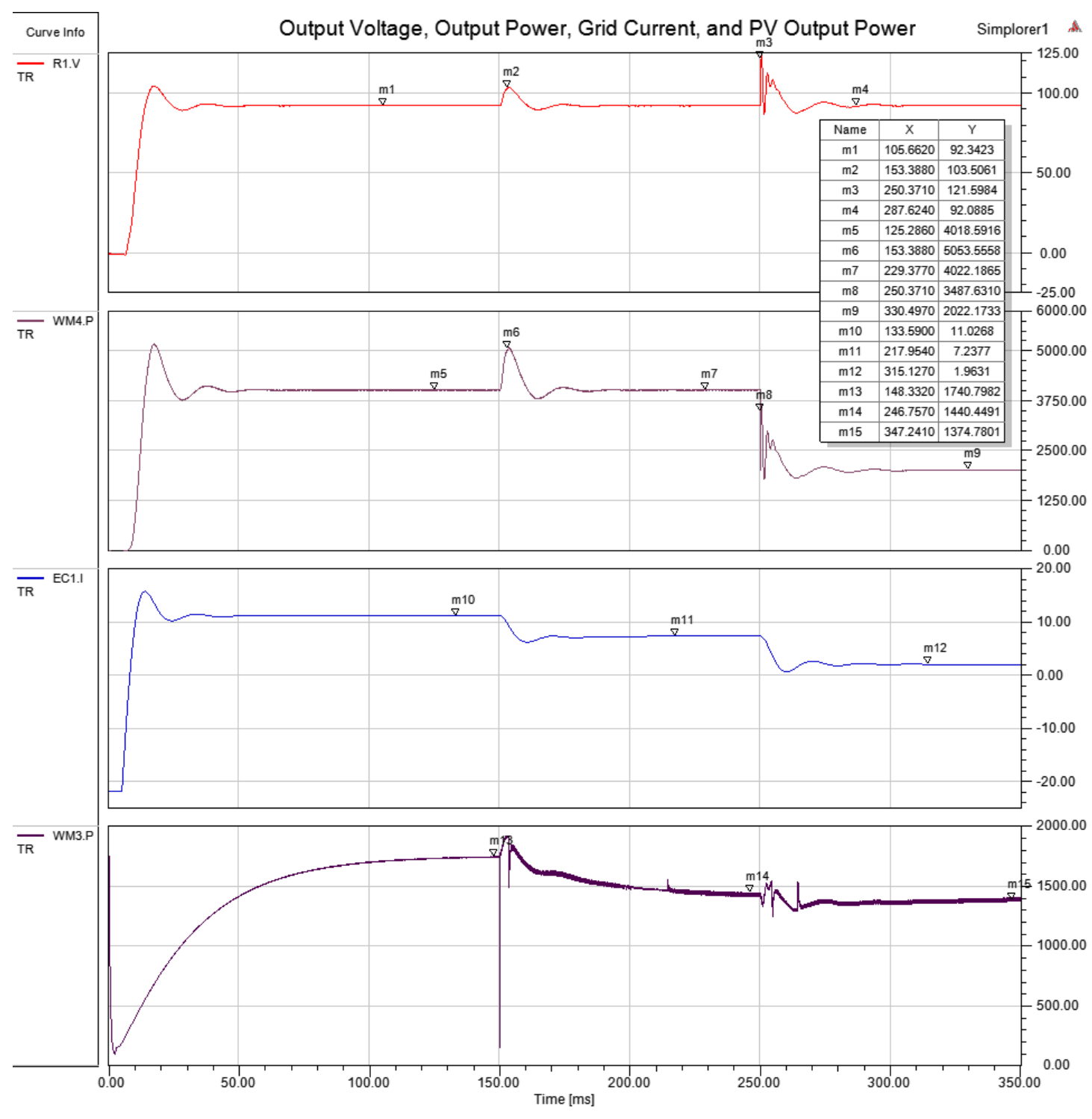

Figure 47. Test Two - TMMC Output Voltage and Power, Grid Current, PV Output Power With ESS 


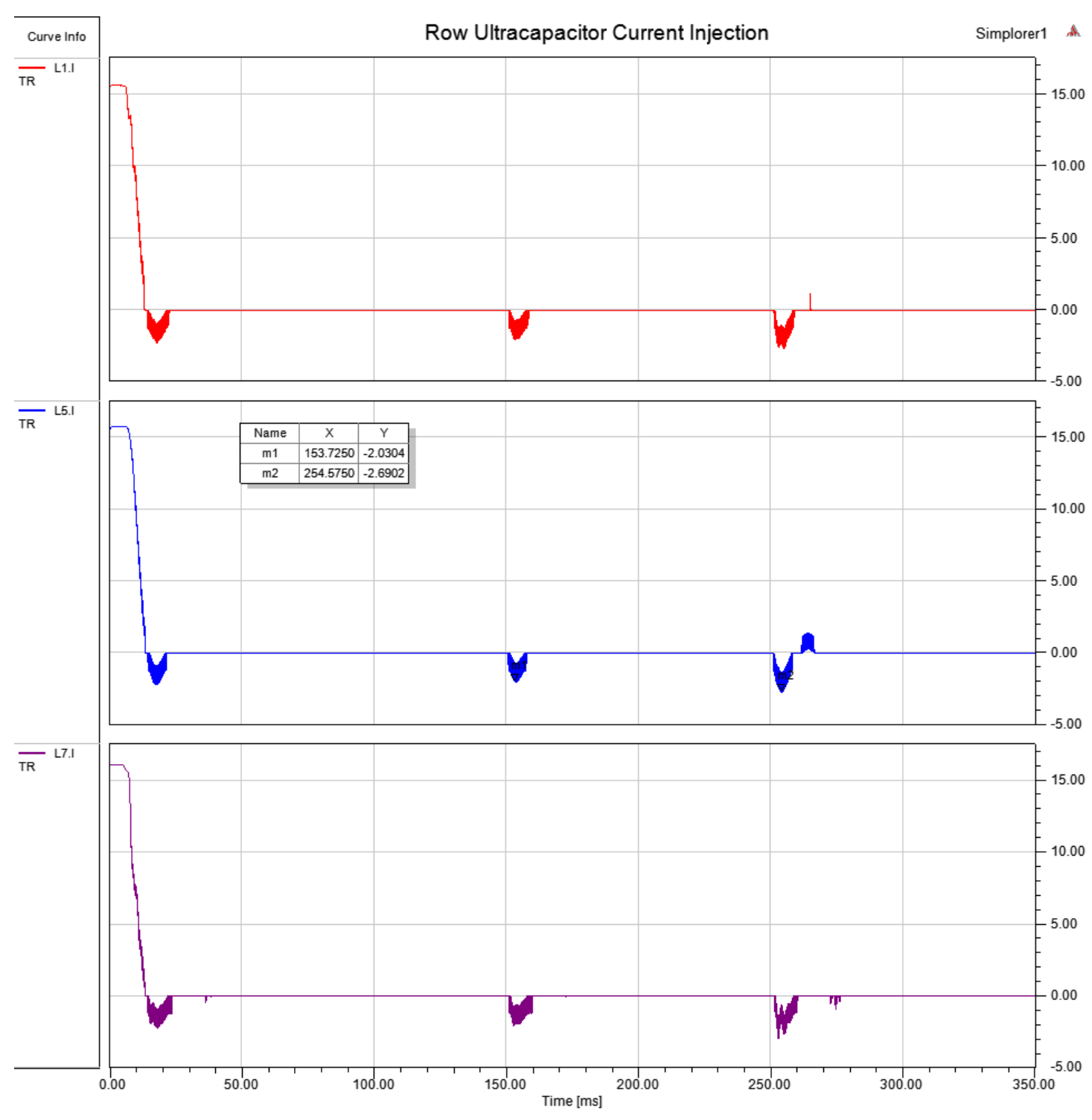

Figure 48. Test Two - ESS Row Ultracapacitor Current Injection 


\subsection{TEST THREE RESULTS - PV STEP UP AND DOWN}

The third and last test focuses mainly on the impact of large PV step changes on the system with the PV first connected at maximum irradiance, and then later disconnected promptly creating a large deficit in generation. The output load stays constant throughout the whole simulation, so there is no main change in system power demands. The capacitor and output voltages are also expected to spike upwards when the PV is connected and subsequently take a large dip when the PV is disconnected entirely. The "grid" current dips proportionally to the amount of power offset from the grid to the PV system upon connection, and then return to initial values when the PV is no longer connected to the TMMC. The PV system itself responds as before when it interconnects with the TMMC; however, it output power drops quickly down to zero output, as soon as it disconnects from the system.

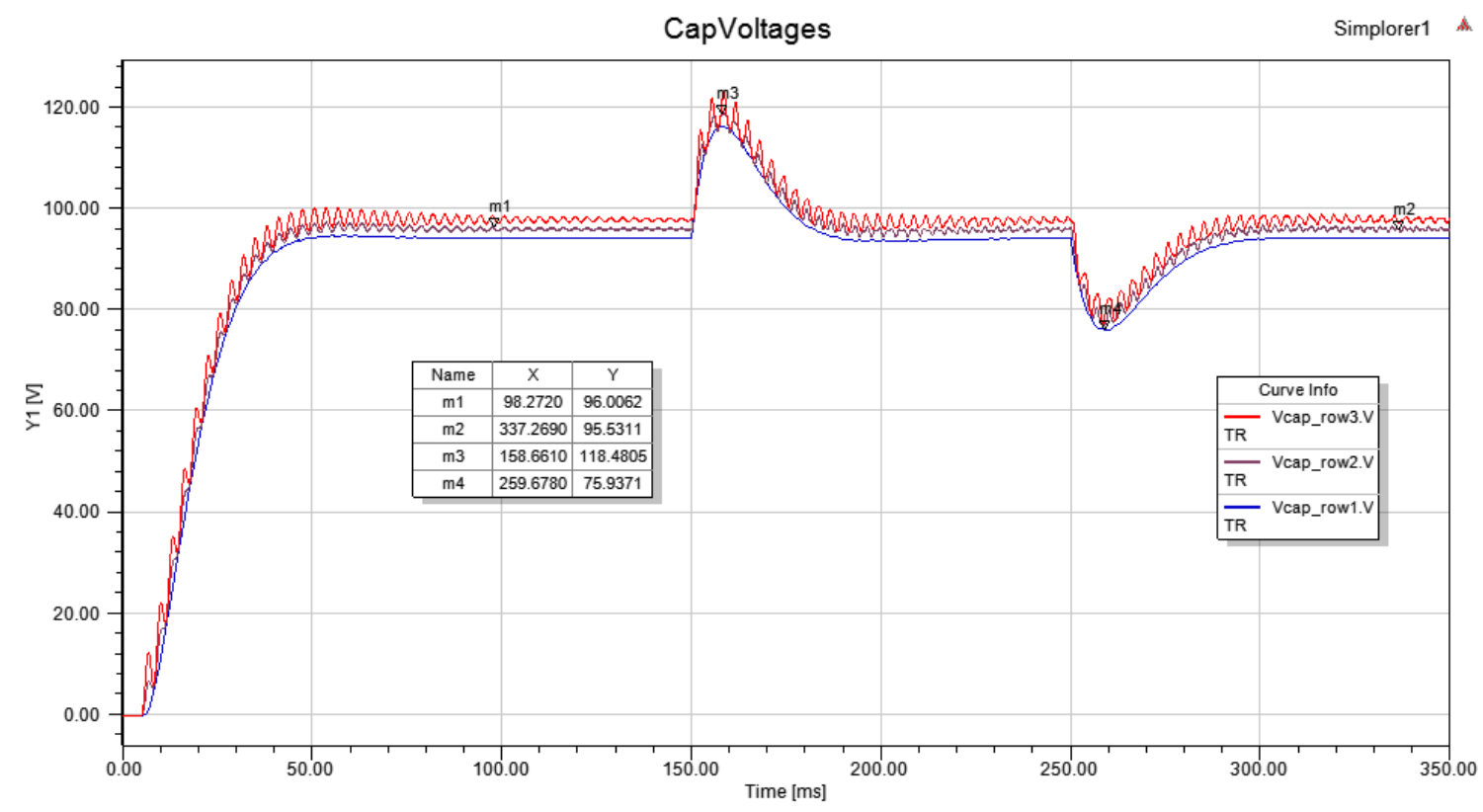

Figure 49. Test Three - TMMC Capacitor Voltages - No ESS 


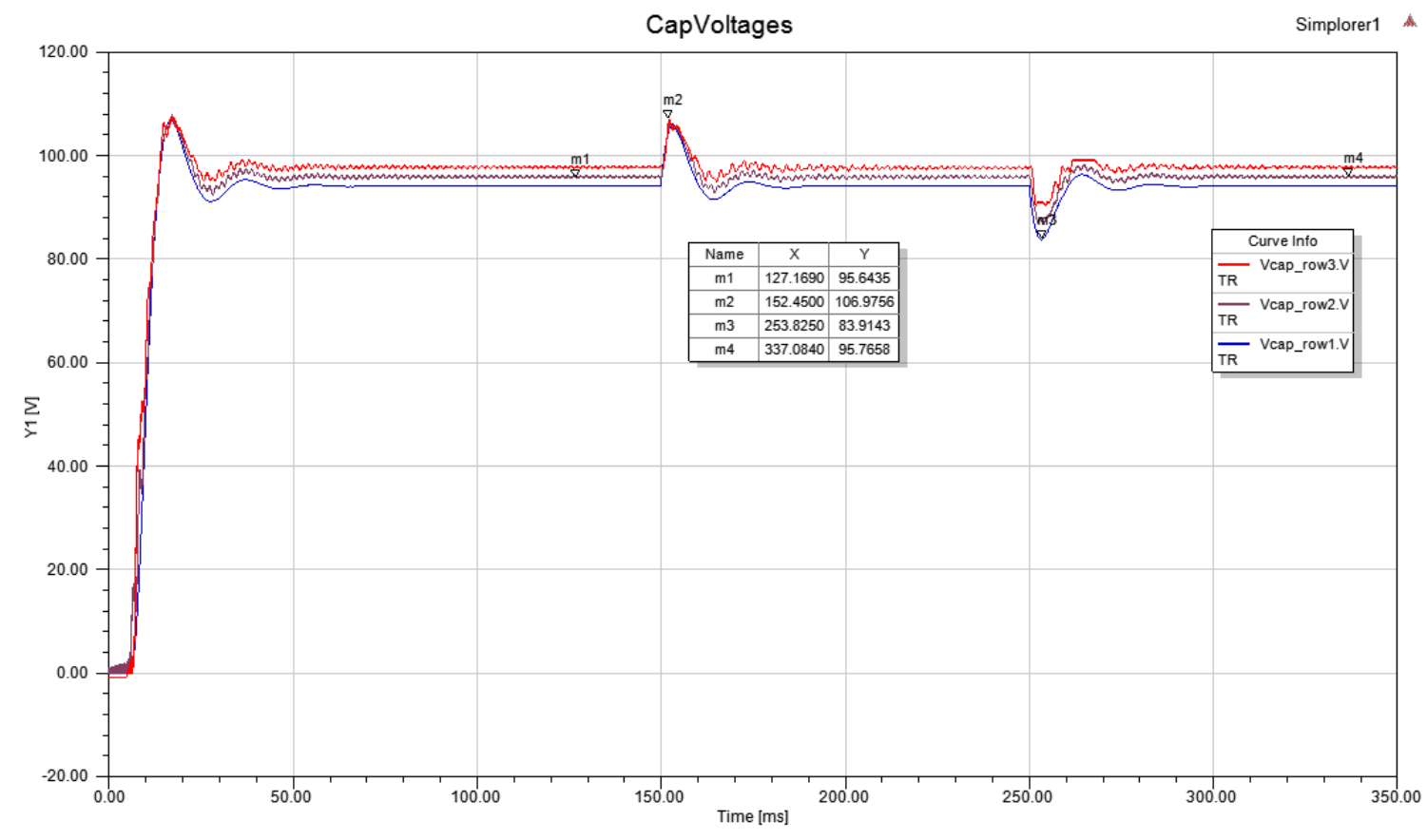

Figure 50. Test Three - TMMC Capacitor Voltages - With ESS

A sizable difference in spikes between ESS and non-ESS systems is present once more in Figure 49 and Figure 50. The second spike dipping downward due to the disconnected PV hits a trough value of $75.94 \mathrm{~V}$ for the traditional TMMC as compared to $83.83 \mathrm{~V}$ for the ESS-enhanced model. This reduction of $7.89 \mathrm{~V}$ or $8.3 \%$ of steady state voltage is less dramatic than the other tests, but a noticeable improvement nonetheless. The initial spike changes are the same as those recorded in test one. 


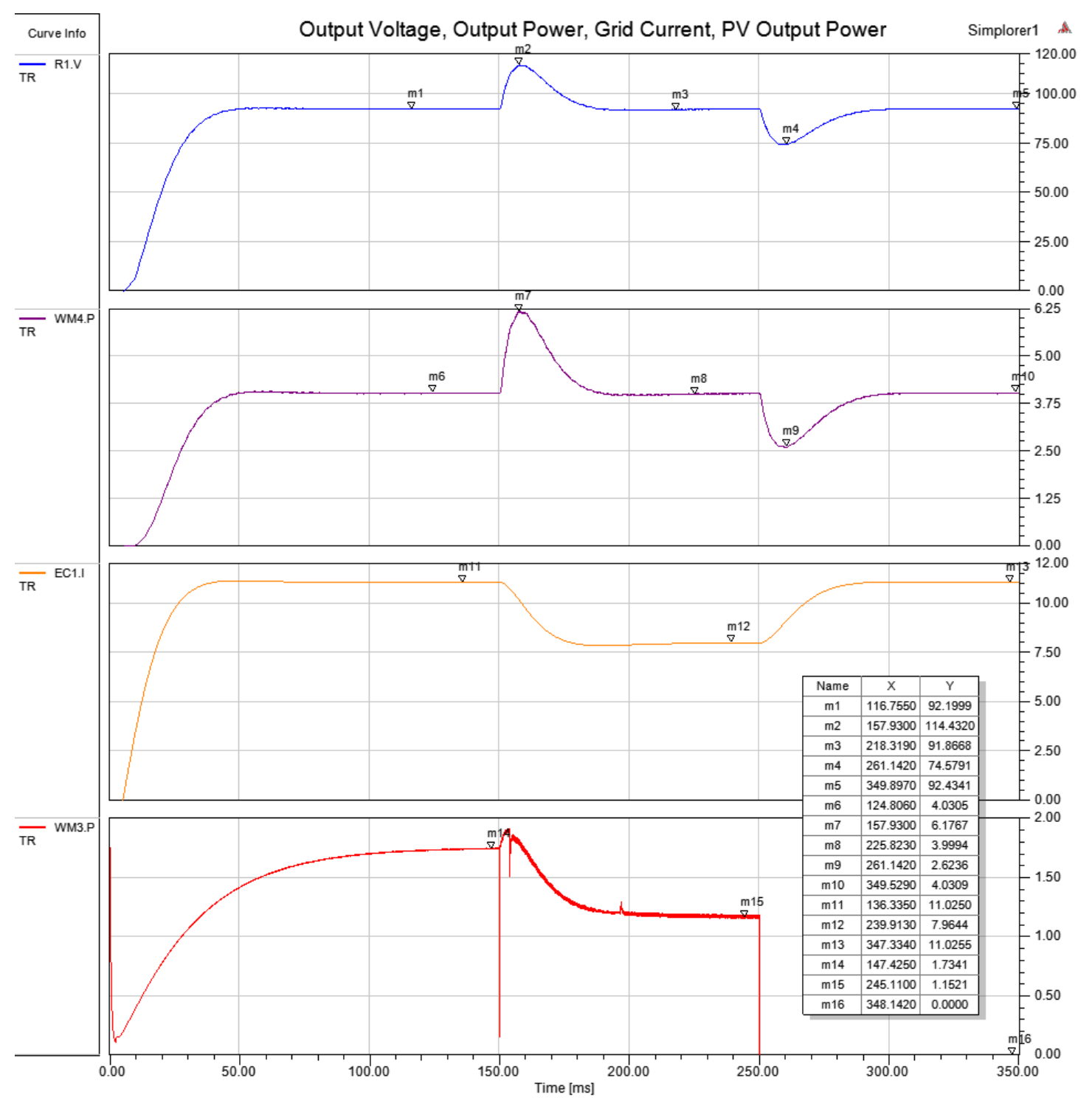

Figure 51. Test Three - TMMC Output Voltage and Power, Grid Current, PV Output Power No ESS

The connection and disconnection of the PV has a somewhat mirrored impact upon the output voltage, output power, and "grid” current. The transient recovery for the non-ESS system from the PV step changes is decent with about $50 \mathrm{~ms}$ of recovery time. This recovery is about cut in half when introducing the ESS however. The current injections in Figure 53 once again line up well with the transient events present in Figure 52. 


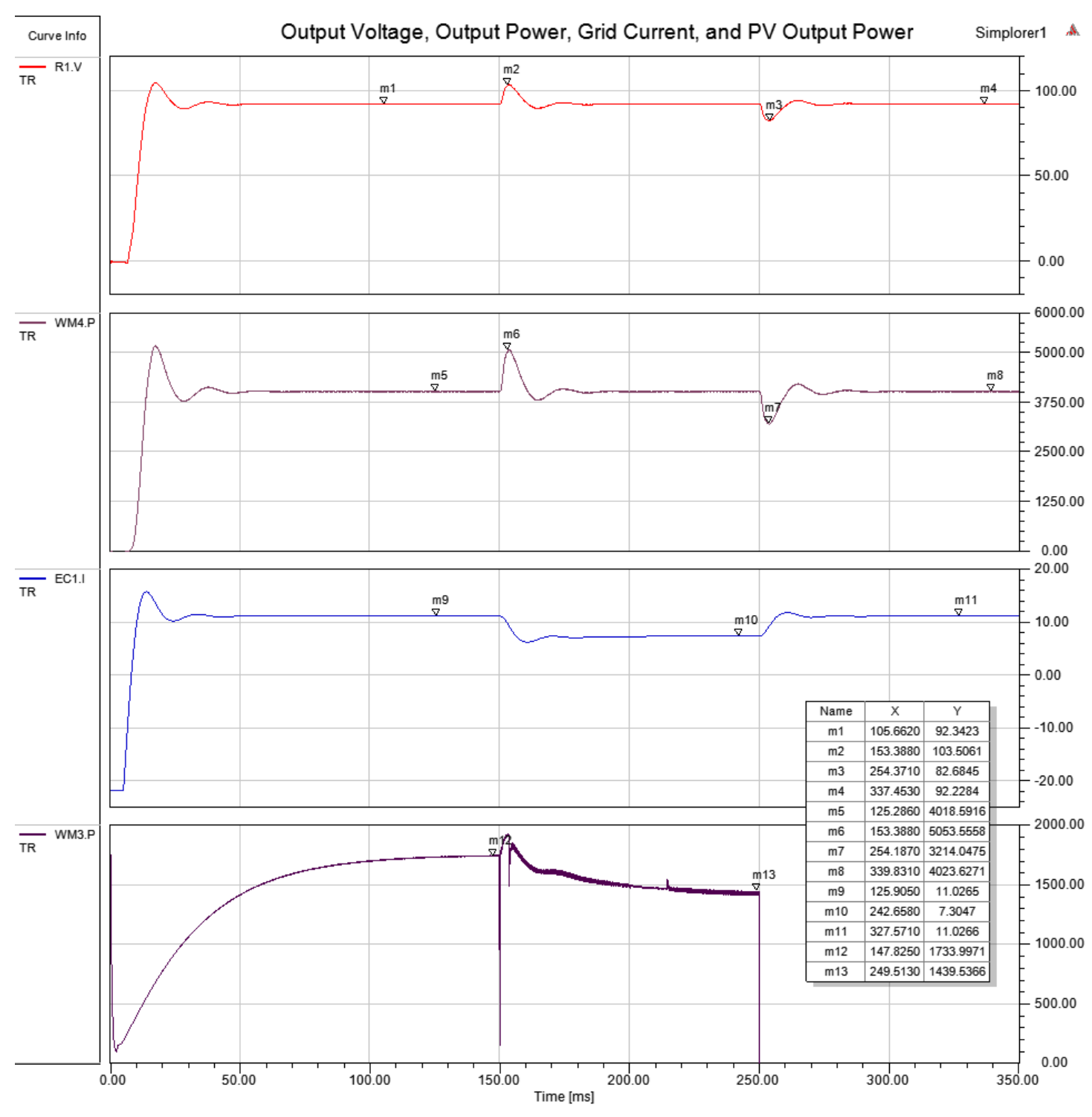

Figure 52. Test Three - TMMC Output Voltage and Power, Grid Current, PV Output Power With ESS 


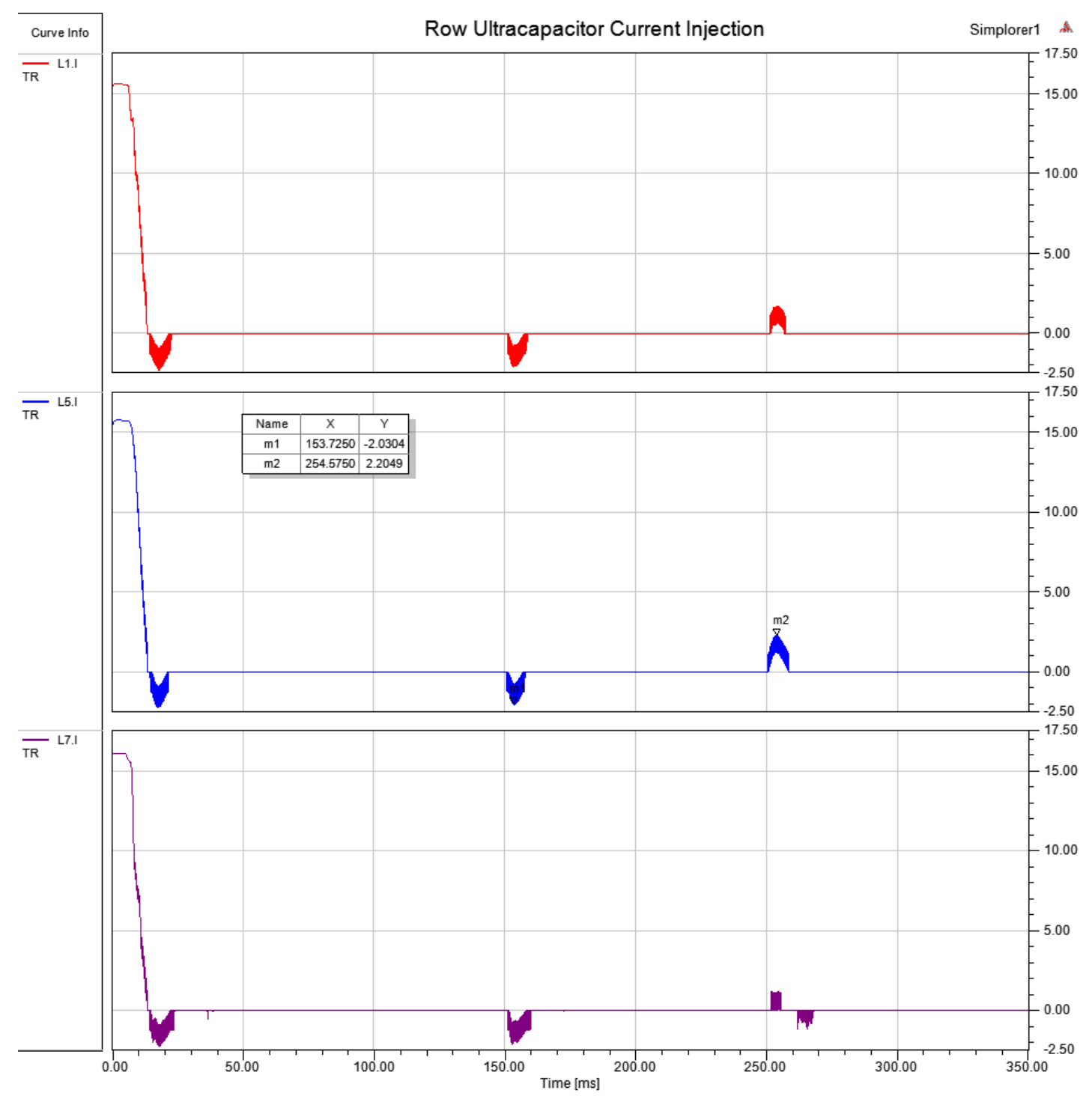

Figure 53. Test Three - ESS Row Ultracapacitor Current Injection 


\subsection{CONCLUSION}

As the "modern" power grid continues to evolve in order to meet the growing and diversifying generation and load landscape, interfacing converters will likely play an important role in regulating system-level power flow and power quality throughout distribution grid structures such as microgrids. Renewable sources of generation supplement the growing development in meeting the growing electricity demands; however, they also provide additional challenges with managing their intermittent supply profile. However, a grid system that utilizes modular converters enhanced with energy storage that connect an arrangement of sources and loads, could allow for a greater penetration of renewable sources. The triangular modular multilevel converter utilizing ultracapacitors affixed to each of its modules has been proven a solid candidate for interfacing loads with intermittent generation sources. It is capable of mitigating the transient spikes associated with large step changes both in load as well as PV generation, as well as reducing the recovery time necessary to return to nominal steady state voltage and power levels. Both of these qualities are valuable as the focus on converter research continues to shift towards the development of power routing and power buffering interfacing converters. 


\subsection{FUTURE WORK}

Future iterations of this work would rework several portions of the overall system in order to optimize overall performance. For starters, the control system of the TMMC needs to be overhauled in order to achieve true voltage and current sharing between rows. The power-sharing mechanic of the TMMC was maintained throughout the system, but a gradient of module voltages

from the top to bottom row appeared as the number of rows expanded and the power demands of the topology were increased. Additionally, the ultracapacitor selection for the ESS could be more optimally chosen in order to precisely choose the proper amount of energy for the converter system based off load and generation requirements. The PV array system could also benefit from a more streamlined integration into the converter versus the brute forced switching that was implemented.

Next immediate steps for this converter topology include the realization of the design using a hardware-in-the-loop platform, as well as the expansion of the model to pursue the development of an APDN design with multiple inputs and multiple outputs still utilizing an ESS to power buffer the flow the power from source to load. 


\section{APPENDIX}

\section{SYSTEM PARAMETERS AND DIAGRAMS}

Table 12. Complete System Parameters

\begin{tabular}{|c|c|c|c|}
\hline \multicolumn{2}{|c|}{ Name } & $\begin{array}{c}\text { Evaluated } \\
\text { Value }\end{array}$ & \multicolumn{2}{c|}{ Name } & $\begin{array}{c}\text { Evaluated } \\
\text { Value }\end{array}$ \\
\hline C & $6 \mathrm{e}-005 \mathrm{~F}$ & Vref_UC_Ctrl & $55 \mathrm{~V}$ \\
L & $0.00056 \mathrm{H}$ & nI & 0.97 \\
Vin & $380 \mathrm{~V}$ & Nparallel & 5 \\
TPHmax & 60 & Nseries & 1 \\
TPHmin & -60 & Rsh & $47.9694 \Omega$ \\
Vo & $48 \mathrm{~V}$ & Rs & $0.22828 \Omega$ \\
Kp & 0.0384 & UC_UpperThreshold & $99 \mathrm{~V}$ \\
Ki & 6.14 & UC_LowerThreshold & $91 \mathrm{~V}$ \\
SC & $83 \mathrm{~F}$ & UC_initval & $48 \mathrm{~V}$ \\
Lf & $0.001 \mathrm{H}$ & Dnew & 0.5 \\
Rf & $2990 \mathrm{~m} \Omega$ & Ki_pv & 20.4865 \\
UC_ESR & $10 \mathrm{~m} \Omega$ & Kp_pv & 0.064 \\
Kpuc & 1.777 & Irrad & $1000 \mathrm{~W} / \mathrm{m}^{2}$ \\
Kiuc & 1579 & Rload & $2.12 \Omega$ \\
Ts & $5 \mathrm{e}-005 \mathrm{~s}$ & & \\
\hline
\end{tabular}




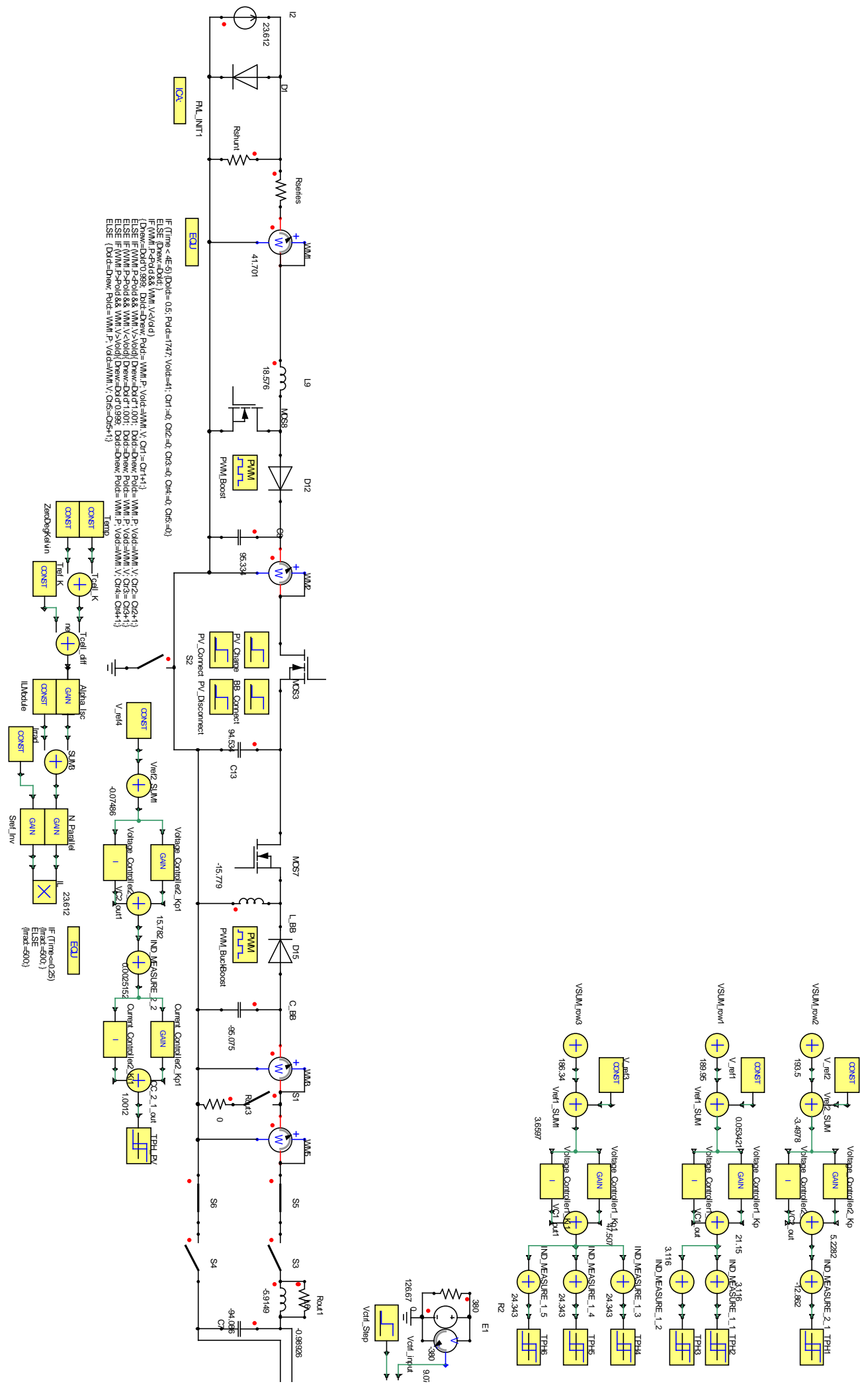

Figure 54. Left Side of Model. Includes PV System, PV Filter, TMMC Controller, and Grid Connection 


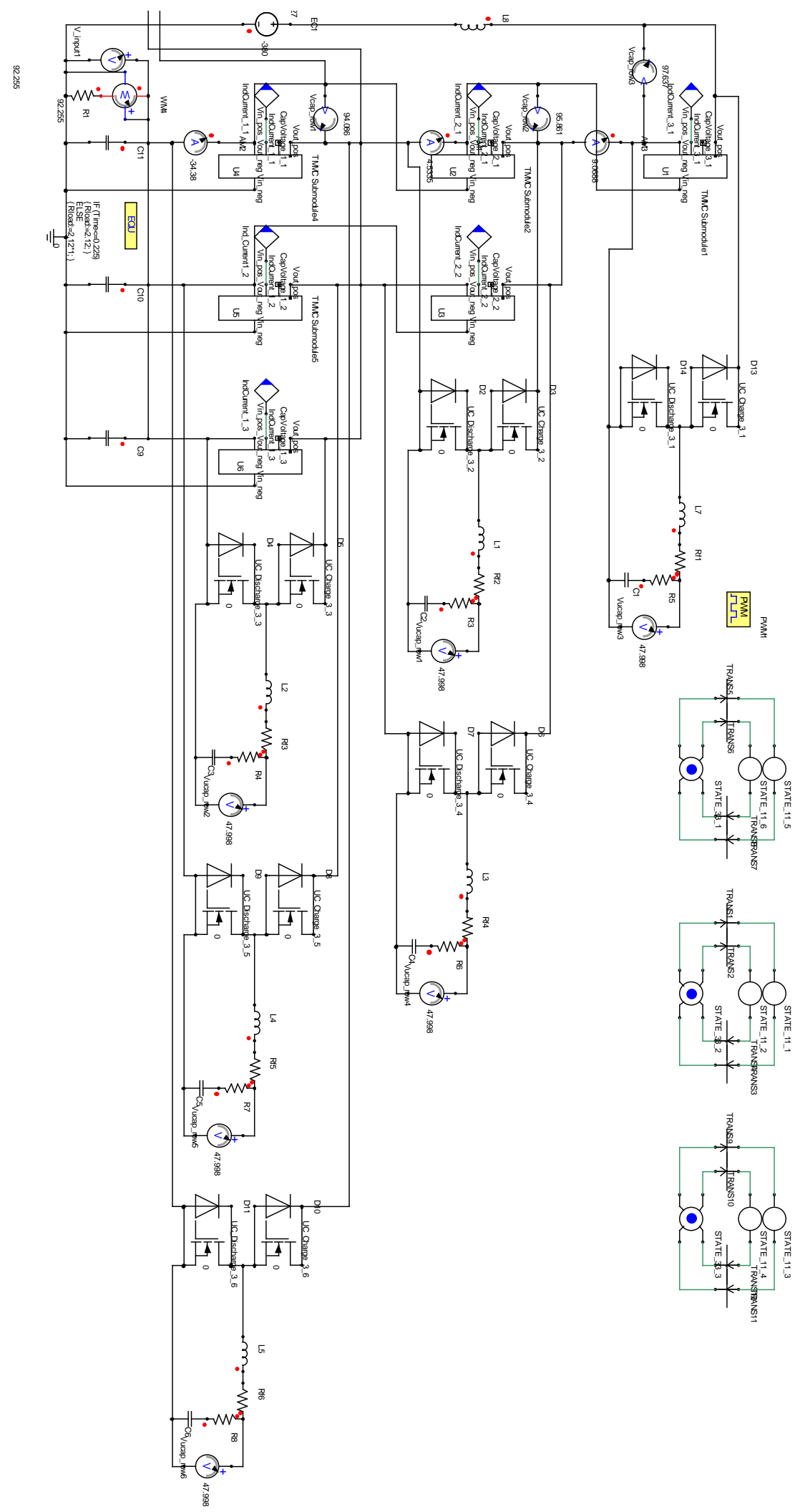

Figure 55. Right Side of Model. Includes TMMC, Ultracapacitor ESS, and ESS Controllers 


\section{BIBLIOGRAPHY}

[1] J. Conti, “International Energy Outlook 2013,” International Energy Outlook, 2013. [Online]. Available: http://www.eia.gov/forecasts/ieo/pdf/0484(2013).pdf. [Accessed: 01-Apr-2015].

[2] A. Kwasinski, "Advanced power electronics enabled distribution architectures: Design, operation, and control," in 8th International Conference on Power Electronics - ECCE Asia, 2011, pp. 1484-1491.

[3] H. Kakigano, Y. Miura, and T. Ise, “Low-Voltage Bipolar-Type DC Microgrid for Super High Quality Distribution,” IEEE Trans. Power Electron., vol. 25, no. 12, pp. 30663075, Dec. 2010.

[4] L. Che, M. Shahidehpour, A. Alabdulwahab, and Y. Al-Turki, "Hierarchical Coordination of a Community Microgrid With AC and DC Microgrids," IEEE Trans. Smart Grid, pp. 1-1, 2015.

[5] Xiong Liu, Peng Wang, and Poh Chiang Loh, "A Hybrid AC/DC Microgrid and Its Coordination Control,” IEEE Trans. Smart Grid, vol. 2, no. 2, pp. 278-286, Jun. 2011.

[6] D. Gunasekaran and L. Umanand, "Integrated magnetics based multi-port bidirectional DC-DC converter topology for discontinuous-mode operation,” IET Power Electron., vol. 5, no. 7, pp. 935-944, Aug. 2012.

[7] H. Nikkhajoei and R. H. Lasseter, "Distributed Generation Interface to the CERTS Microgrid,” IEEE Trans. Power Deliv., vol. 24, no. 3, pp. 1598-1608, Jul. 2009.

[8] A. Kwasinski and C. N. Onwuchekwa, "Dynamic Behavior and Stabilization of DC Microgrids With Instantaneous Constant-Power Loads,” IEEE Trans. Power Electron., vol. 26, no. 3, pp. 822-834, Mar. 2011.

[9] A. Kwasinski and P. T. Krein, "Multiple-input dc-dc converters to enhance local availability in grids using distributed generation resources," in APEC 07 - TwentySecond Annual IEEE Applied Power Electronics Conference and Exposition, 2007, pp. 1657-1663.

[10] A. Kwasinski, "Identification of Feasible Topologies for Multiple-Input DC-DC Converters,” IEEE Trans. Power Electron., vol. 24, no. 3, pp. 856-861, Mar. 2009. 
[11] C. N. Onwuchekwa and A. Kwasinski, "A Modified-Time-Sharing Switching Technique for Multiple-Input DC-DC Converters,” IEEE Trans. Power Electron., vol. 27, no. 11, pp. 4492-4502, Nov. 2012.

[12] L. Solero, F. Caricchi, F. Crescimbini, O. Honorati, and F. Mezzetti, "Performance of a 10 $\mathrm{kW}$ power electronic interface for combined wind/PV isolated generating systems," in PESC Record. 27th Annual IEEE Power Electronics Specialists Conference, 1996, vol. 2, pp. 1027-1032.

[13] Y.-M. Chen, Y.-C. Liu, and F.-Y. Wu, "Multiinput Converter With Power Factor Correction, Maximum Power Point Tracking, and Ripple-Free Input Currents," IEEE Trans. Power Electron., vol. 19, no. 3, pp. 631-639, May 2004.

[14] R. Zhao and A. Kwasinski, "Efficiency improvement of a low-power multiple-input converter with forward-conducting-bidirectional-blocking switches," in 2013 IEEE Energy Conversion Congress and Exposition, 2013, pp. 5566-5573.

[15] R. Zhao, S.-Y. Yu, and A. Kwasinski, "Modeling of multiple-input DC-DC converters considering input-coupling effects," in 2011 IEEE Energy Conversion Congress and Exposition, 2011, pp. 698-705.

[16] Y. Li, X. Ruan, D. Yang, F. Liu, and C. K. Tse, "Synthesis of Multiple-Input DC/DC Converters,” IEEE Trans. Power Electron., vol. 25, no. 9, pp. 2372-2385, Sep. 2010.

[17] Dongsheng Ma, Wing-Hung Ki, and Chi-ying Tsui, "A pseudo-CCM/DCM SIMO switching converter with freewheel switching,” IEEE J. Solid-State Circuits, vol. 38, no. 6, pp. 1007-1014, Jun. 2003.

[18] W. M. dos Santos, T. A. Pereira, C. Knaesel, H. R. Mamede, and D. C. Martins, "Modeling and control of the new DC-DC step-up converter to bipolar DC microgrid," in 2014 IEEE 36th International Telecommunications Energy Conference (INTELEC), 2014, pp. $1-8$.

[19] A. Nami, F. Zare, A. Ghosh, and F. Blaabjerg, "Multi-output DC-DC converters based on diode-clamped converters configuration: topology and control strategy," IET Power Electron., vol. 3, no. 2, p. 197, 2010.

[20] D. Trevisan, P. Mattavelli, and P. Tenti, "Digital Control of Single-Inductor MultipleOutput Step-Down DC-DC Converters in CCM,” IEEE Trans. Ind. Electron., vol. 55, no. 9, pp. 3476-3483, Sep. 2008.

[21] H. Behjati and A. Davoudi, “A Multiple-Input Multiple-Output DC-DC Converter,” IEEE Trans. Ind. Appl., vol. 49, no. 3, pp. 1464-1479, May 2013.

[22] S. Saggini and P. Mattavelli, "Power management in multi-source multi-load energy harvesting systems.” pp. 1-10, 2009. 
[23] M. Kim and A. Kwasinski, "Decentralized Hierarchical Control of Active Power Distribution Nodes,” IEEE Trans. Energy Convers., vol. 29, no. 4, pp. 934-943, Dec. 2014.

[24] M. Kim and A. Kwasinski, "Distribution interface for microgrid operation and expansion with local energy management," in 2014 IEEE 5th International Symposium on Power Electronics for Distributed Generation Systems (PEDG), 2014, pp. 1-8.

[25] K. Filsoof and P. W. Lehn, "A Bidirectional Modular Multilevel DC-DC Converter of Triangular Structure,” IEEE Trans. Power Electron., vol. 30, no. 1, pp. 54-64, Jan. 2015.

[26] A. Kwasinski and P. T. Krein, "A Microgrid-based Telecom Power System using Modular Multiple-Input DC-DC Converters," in INTELEC 05 - Twenty-Seventh International Telecommunications Conference, 2005, pp. 515-520.

[27] L. Solero, A. Lidozzi, and J. A. Pomilio, "Design of Multiple-Input Power Converter for Hybrid Vehicles," IEEE Trans. Power Electron., vol. 20, no. 5, pp. 1007-1016, Sep. 2005.

[28] J. M. Carrasco, L. G. Franquelo, J. T. Bialasiewicz, E. Galvan, R. C. PortilloGuisado, M. A. M. Prats, J. I. Leon, and N. Moreno-Alfonso, "Power-Electronic Systems for the Grid Integration of Renewable Energy Sources: A Survey,” IEEE Trans. Ind. Electron., vol. 53, no. 4, pp. 1002-1016, Jun. 2006.

[29] M. Vasiladiotis and A. Rufer, "Analysis and Control of Modular Multilevel Converters With Integrated Battery Energy Storage,” IEEE Trans. Power Electron., vol. 30, no. 1, pp. 163-175, Jan. 2015.

[30] I. Trintis, S. Munk-Nielsen, and R. Teodorescu, "A new modular multilevel converter with integrated energy storage," in IECON 2011 - 37th Annual Conference of the IEEE Industrial Electronics Society, 2011, pp. 1075-1080.

[31] Y. Yang, F. Blaabjerg, and H. Wang, "Constant power generation of photovoltaic systems considering the distributed grid capacity," in 2014 IEEE Applied Power Electronics Conference and Exposition - APEC 2014, 2014, pp. 379-385.

[32] S. R. Holm, H. Polinder, J. A. Ferreira, P. Van Gelder, and R. Dill, “A Comparison of Energy Storage Technologies as Energy Buffer in Renewable Energy Sources with respect to Power Capability.” 2002.

[33] Tecate Group, "Ultracapacitor and Supercapacitor Frequently Asked Questions.” [Online]. Available:

https://www.tecategroup.com/ultracapacitorssupercapacitors/ultracapacitor-FAQ.php.

[34] M. Kale and E. Ozdemir, "A novel adaptive hysteresis band current controller for shunt active power filter," in Proceedings of 2003 IEEE Conference on Control Applications, 2003. CCA 2003., 2003, vol. 2, pp. 1118-1123. 
[35] B. J. Arnet and L. P. Haines, "High power DC-to-DC converter for supercapacitors," in IEMDC 2001. IEEE International Electric Machines and Drives Conference (Cat. No.01EX485), 2001, pp. 985-990.

[36] T. Esram and P. L. Chapman, "Comparison of Photovoltaic Array Maximum Power Point Tracking Techniques,” IEEE Trans. Energy Convers., vol. 22, no. 2, pp. 439-449, Jun. 2007.

[37] X. Wang, H. Lin, B. Feng, and Y. Lyu, "Damping of input LC filter resonance based on virtual resistor for matrix converter," in 2012 IEEE Energy Conversion Congress and Exposition (ECCE), 2012, pp. 3910-3916. 